\title{
Medicines Regulatory Systems and Scope for Regulatory Harmonization in Southeast Asia
}




\section{Table of Contents}

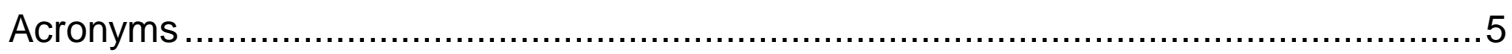

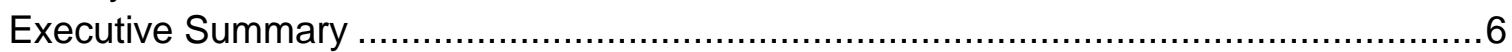

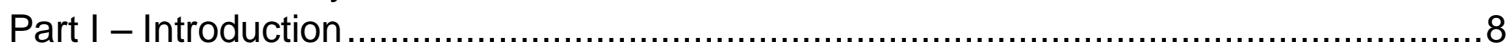

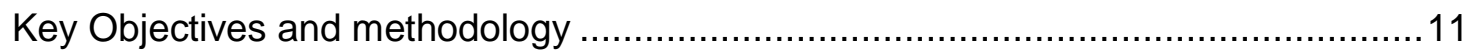

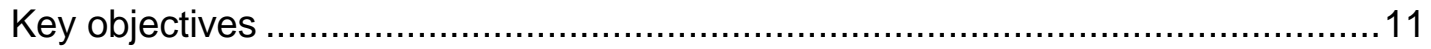

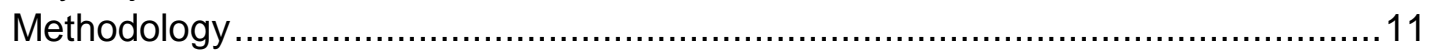

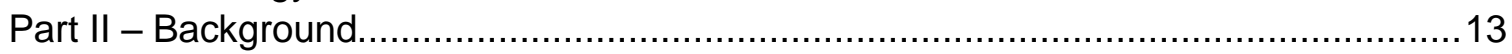

Southeast Asia region: Socioeconomic context ................................................13

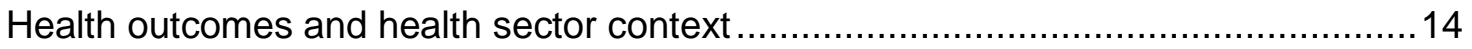

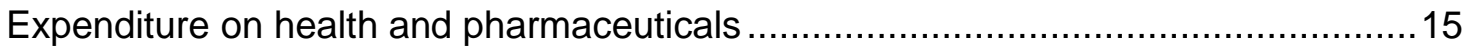

Access, affordability, and quality of medicines...................................................16

Part III - ASEAN pharmaceutical markets........................................................18

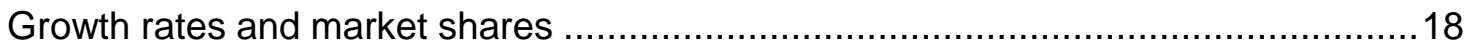

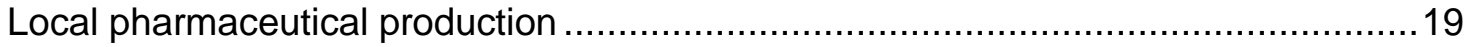

Trade in pharmaceutical products ...............................................................19

Trends in imports and exports ...................................................................19

Impact of regional trade developments on access to medicines and regulatory

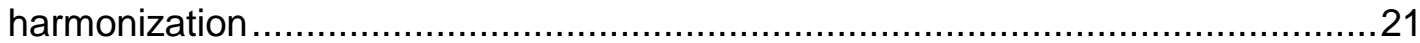

National pharmaceutical sector policies..........................................................22

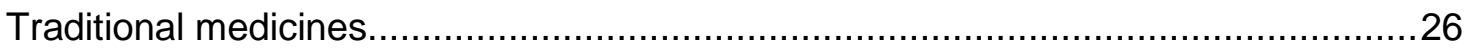

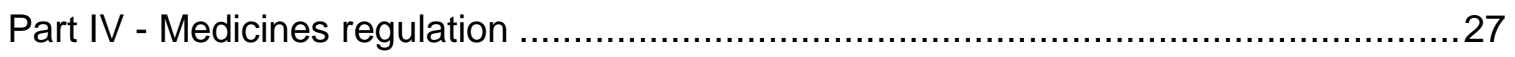

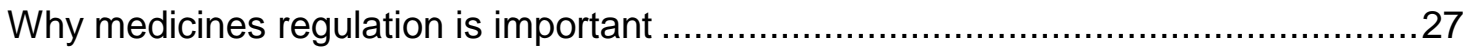

Part V - Review of selected National Medicines Regulatory Authorities in ASEAN ........30

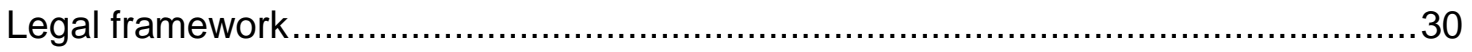

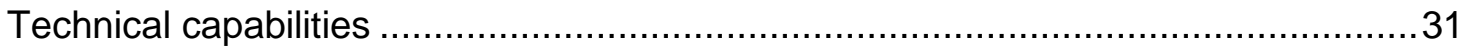

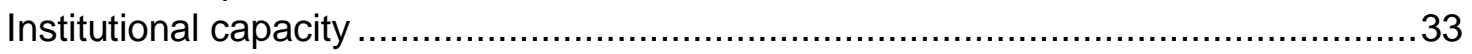

Key capacity development needs for regulators and pharmaceutical industry ...........34

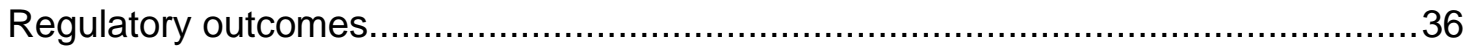

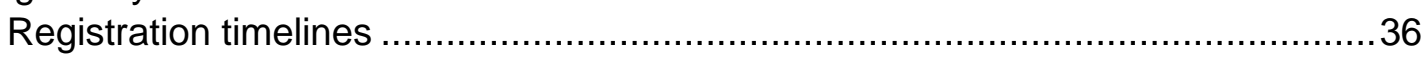

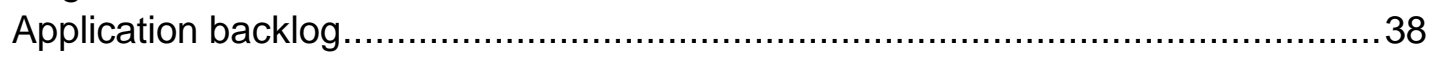

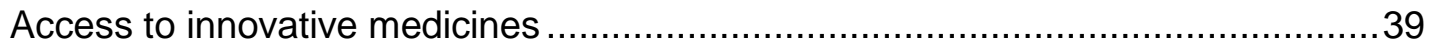

Part VI - Framework for medicines regulatory harmonization ..................................42

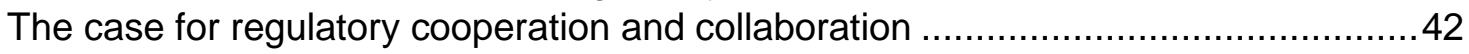

Frameworks for collaboration and harmonization efforts.........................................4

Part VII - Medicines regulatory harmonization initiatives and status of harmonization in

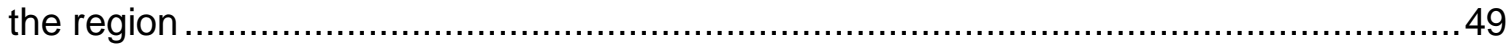

Achievements and milestones ...................................................................... 49

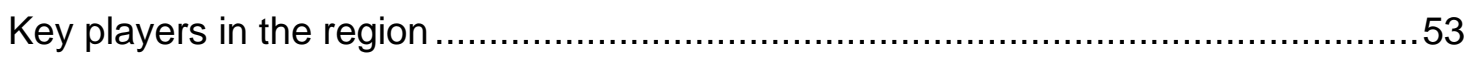

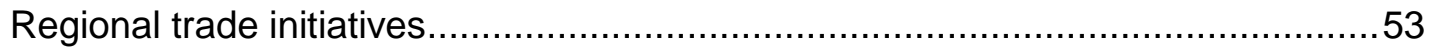

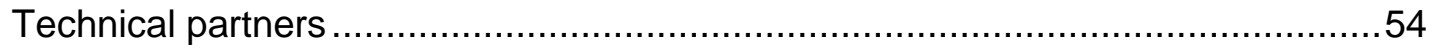

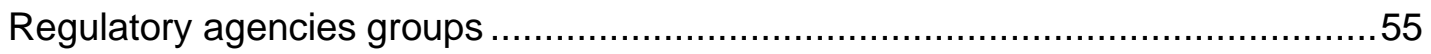

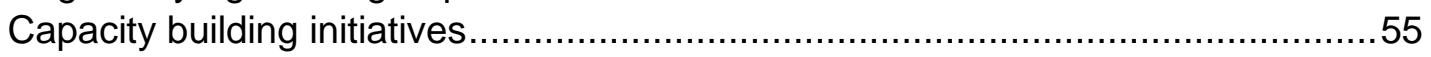

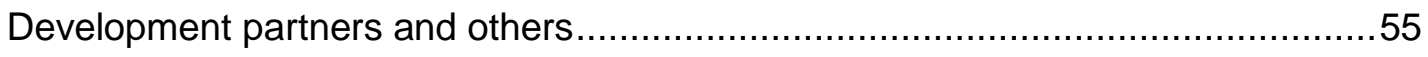


Status and characteristics of medicines regulatory harmonization in ASEAN ...........56

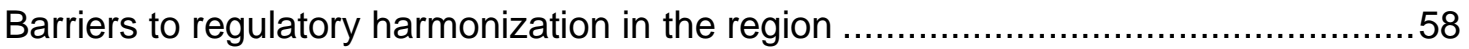

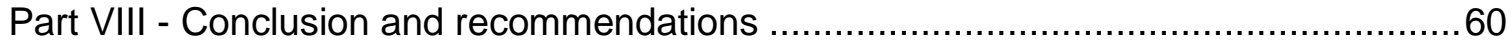

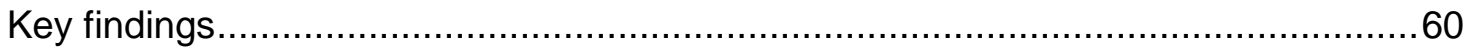

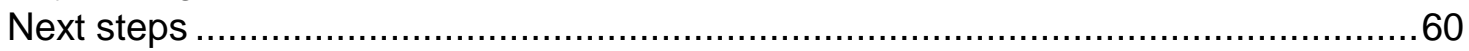

Country-specific recommendations: .......................................................... 61

Improve institutional and technical capacity development of NMRAs and industry.61

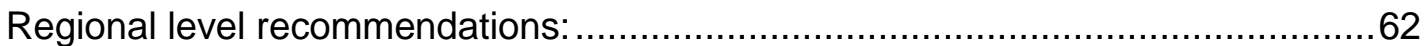

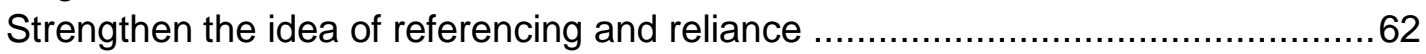

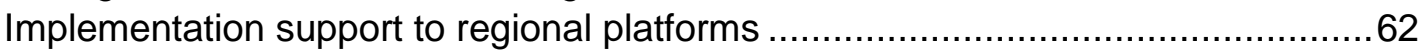

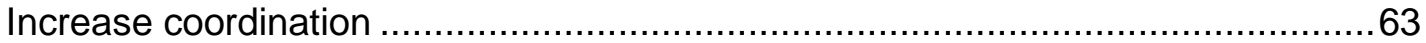

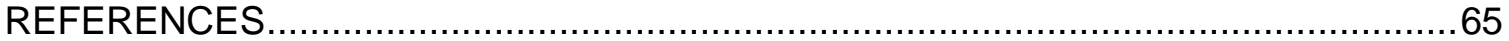

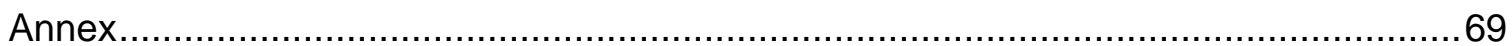

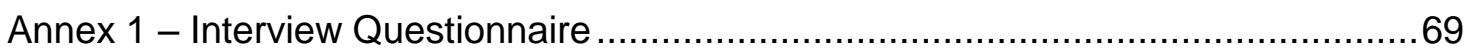

Annex 2 - List of Interview Partners by Country .................................................. 76

\section{List of Tables, Figures, and Boxes}

Table 1: Rising burden of non-communicable diseases in ASEAN, 1990 vs. $2013 \ldots \ldots . .15$

Table 2: Key macroeconomic and health expenditure information in selected countries,

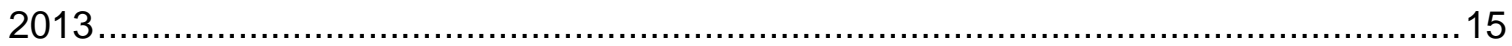

Table 3: Pharmaceutical expenditure in selected ASEAN countries, $2010 \ldots \ldots \ldots \ldots \ldots \ldots . . .16$

Table 4: Median price ratio of medicines in Indonesia, Malaysia, Philippines and

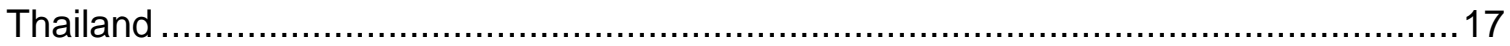

Table 5: Examples of governmental initiatives to support local pharmaceutical production

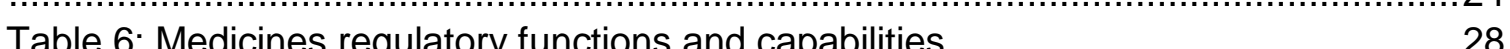

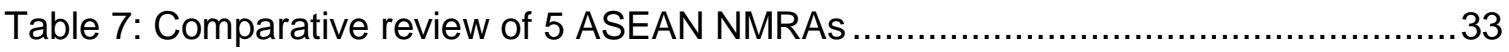

Figure 1: Access to medicines in the context of UHC and the pharmaceutical sector ......9

Figure 2: ASEAN population, 2015 ............................................................... 13

Figure 3: Burden of Disease in East Asia and Pacific by cause of DALYs, 1990-2013 ..14

Figure 4: Medicines consumption from domestic medicines (value wise), 2015 ...........19

Figure 5: ASEAN exports and imports of pharmaceutical products (1993-2013) ..........20

Figure 6: Key objectives of medicines regulation................................................. 27

Figure 7: Framework with key component of medicines regulation.............................29

Figure 8: Key capacity development needs for regulators and industry in the region.....35

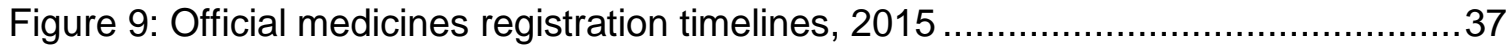

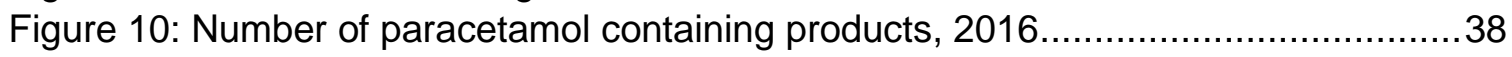

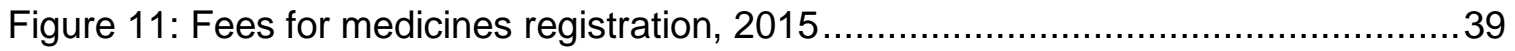

Figure 12: Average lag in introduction of innovative medicines onto ASEAN markets ...40

Figure 13: Challenges for medicines regulators..................................................... 42

Figure 14: Benefits of medicines regulatory harmonization.......................................44 
Figure 15: Medicines registration procedures in the European Medicines Agency and the

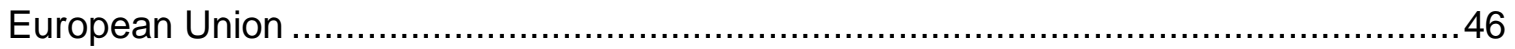

Figure 16: Four step theoretical framework for regulatory convergence .....................48

Figure 17: ASEAN harmonization milestones and pharmaceutical product cycle ..........49

Figure 18: ASEAN medicines regulatory harmonization mechanisms .......................57

Box 1: Pharmaceutical Inspection Convention and Pharmaceutical Inspection Co-

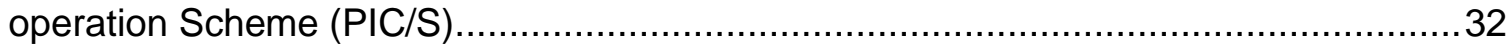

Box 2: Complexity of biopharmaceuticals requires skilled experts in industry and

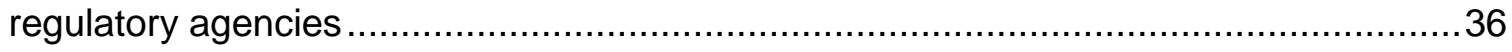

Box 3: Examples of international and regional harmonization efforts ..........................47

Box 4: The ASEAN Reference Substances (ARS) Project ......................................51

Box 5: Country-Level Harmonization Initiatives .................................................. 52 


\section{ACRONYMS}

$\begin{array}{ll}\text { AMRH } & \text { African Medicines Regulatory Harmonization } \\ \text { APEC } & \text { Asia-Pacific Economic Cooperation } \\ \text { API } & \text { Active Pharmaceutical Ingredient } \\ \text { ASEAN } & \text { Association of Southeast Asian Nations } \\ \text { BA } & \text { Bioavailability } \\ \text { BE } & \text { Bioequivalence } \\ \text { CTD } & \text { Common Technical Document } \\ \text { DAV } & \text { Drug Administration of Vietnam } \\ \text { EAP } & \text { East Asia and Pacific } \\ \text { EMA } & \text { European Medicines Agency } \\ \text { FDA } & \text { Food and Drug Administration } \\ \text { FPP } & \text { Finished Pharmaceutical Product } \\ \text { GCP } & \text { Good Clinical Practice } \\ \text { GDP } & \text { Good Distribution Practice } \\ \text { GIZ } & \text { Gesellschaft fuer Internationale Zusammenarbeit GmbH } \\ \text { GLP } & \text { Good Laboratory Practice } \\ \text { GMP } & \text { Good Manufacturing Practice } \\ \text { ICH } & \text { International Council for Harmonisation of Technical Requirements } \\ & \text { for Pharmaceuticals for Human Use } \\ \text { IMP } & \text { Investigational medicinal product } \\ \text { IRP } & \text { International Reference Price } \\ \text { ISO } & \text { International Organization for Standardization } \\ \text { MA } & \text { Marketing Authorization } \\ \text { MOH } & \text { Ministry of Health } \\ \text { NCD } & \text { Non communicable diseases } \\ \text { NIDQC } & \text { National Institute of Drug Quality Control (Vietnam) } \\ \text { NMRA } & \text { National Medicines Regulatory Authority } \\ \text { PIC/S } & \text { Pharmaceutical Inspection Convention and Pharmaceutical Inspection } \\ \text { PMS } & \text { Co-operation Scheme } \\ \text { QMS } & \text { Post-marketing Surveillance } \\ \text { RQCL } & \text { Quality Management System } \\ \text { SRA } & \text { Regulatory quality control laboratory } \\ \text { WHO } & \text { Stringent Regulatory Authority } \\ & \text { World Health Organisation } \\ & \end{array}$




\section{EXECUTIVE SUMMARY}

Ensuring access to essential medicines is a key objective of all health systems, and is an integral component of the progress towards universal health coverage (UHC). Despite global and national efforts to improve access and affordability of medicines, millions of people - particularly in low- and middle-income countries - still remain without access to quality-assured and affordable medicines.

Medicines regulation is important to ensure the availability of high quality medicines. Medicines of uncertain quality, safety, and efficacy can be worse than no treatment at all; regulators worldwide are therefore obliged to protect public health. Effective medicines regulation involves a range of processes including licensing of production and distribution of medicines, registration of products, inspection, quality control, and surveillance. Sufficient capacity and capability of National Medicines Regulatory Authorities (NMRAs) is necessary for effective regulation of medicines. Many NMRAs, however, often fall short of the necessary resources and expertise to carry out all their regulatory tasks.

Regulatory cooperation and harmonization is a viable way to improve regulatory oversight by NMRAs. Medicines regulatory harmonization aims to improve and streamline regulatory requirements by shifting from a country-focused approach to a collaborative, cross-country approach. Medicines regulatory harmonization initiatives vary in scope, institutional arrangements, and degree, and the approaches towards this area of work vary across countries and regions. Regulatory harmonization is increasingly important given the globalized nature of pharmaceutical production and trade, and the growing complexity of medicinal products. Complex supply chains extend the responsibilities of regulators: they need to review large amounts of information and monitor various processes that take place outside their national borders, and may be beyond their capacities. Today, no regulator can function effectively in isolation - without regulatory cooperation, national regulation may become a barrier to access.

This study aims to contribute to existing knowledge on regulatory systems and harmonization efforts in Southeast Asia. Focusing on five member states of the Association of Southeast Asian Nations (ASEAN) - Indonesia, Malaysia, the Philippines, Thailand, an Vietnam - this study gives an overview of pharmaceutical markets and key pharmaceutical policies in the region, provides a cross-country comparison of medicines regulatory systems, and details harmonization efforts, opportunities, and challenges.

Key findings from the study show that while ASEAN pharmaceutical markets are growing rapidly, there is still a high dependency on imported pharmaceutical products, especially innovative medicines. National pharmaceutical policies increasingly encourage domestic production and more innovation, with the objective of becoming increasingly selfsufficient in pharmaceutical production. However, achieving this objective would need substantial improvements in technical expertise, both for industry players as well as regulatory authorities. Exports by domestic ASEAN pharmaceutical manufacturers have been increasing over the past decade, and there is ambition by many countries to develop the ability to increase the export of medicines. From the trade perspective, more cooperation and harmonization would reduce regulatory barriers and broaden export markets. 
A review of five regulators in the region finds that NMRAs face constraints in both technical capability and institutional capacity. Focusing on two regulatory functions marketing authorization and inspections for Good Manufacturing Practice (GMP) - we find that there is substantial scope for raising the capabilities of regulators. On marketing authorization, for example, there are proper and clear technical guidelines for the registration of medicines, and ASEAN regulators have adopted the ASEAN Common Technical Document (ACTD) for the submission of dossiers to apply for medicines registration. Nonetheless, regulators face challenges in the evaluation of dossiers and issuance of marketing authorization. Key constraints include inadequate expertise of personnel in evaluating dossiers and insufficient experience in specialized areas such as evaluating innovative medicines. There are also critical institutional constraints, such as a problem of understaffing. Due to a lack of in-house capacity, NMRAs often use external contract staff for regulatory functions, which limits the ability of the NMRA to build up its expertise in the longer term. Regulators face an immense workload, and there is often a backlog of applications. In turn, this leads to a lag in introduction of new medicines onto ASEAN markets.

ASEAN has made substantial progress in its efforts on medicines regulatory harmonization over the last 20 years. To date, the most important and effective forum for convening ASEAN NMRAs is the Pharmaceutical Product Working Group (PPWG). Significant milestones of the PPWG include the introduction of the ACTD and a Mutual Recognition Agreement on GMP, among others. Yet, implementation has been challenging due to differences in interpretation and implementation of guidelines, limited capacity among NMRAs for implementation of harmonization activities, and insufficient supervision, monitoring, and evaluation of work plans and their progress. The uneven implementation of harmonization initiatives has resulted in an approach termed "ASEAN minus X" - denoting the way in which ASEAN member states with more advanced regulatory agencies often take the lead in developing and implementing harmonized standards, while others may adopt the standards later on when they become technically, institutionally and financially ready to do so. In addition to NMRAs who undertake regulatory harmonization activities, there is also a range of institutions supporting this agenda in the region. These include technical partners, multilateral development partners, and academic institutions and training centres. Better alignment of efforts across partners would help to prevent duplication of efforts, and thus better support the harmonization agenda.

Based on these findings, we suggest four areas for further work, which would help to consolidate and improve efforts on the medicines regulatory harmonization agenda in ASEAN. First, as an underlying requirement for harmonization, is to provide adequate institutional and technical capacity development of NMRAs and industry. This will help to "level up" the expertise of personnel in these organizations, and improve their comfort with and willingness to engage in regulatory harmonization activities. Second, strengthen the idea of referencing and reliance, so that regulators can capitalize on and benefit from data and decisions from Stringent Regulatory Authorities, instead of working in isolation. Third, provide operational support to PPWG, in order to improve implementation of PPWG work and decisions at the country level. Finally, increase coordination across regulators and the range of partners working in this space, so as to benefit from the breadth of experience across the region and provide holistic support to the medicines regulatory harmonization agenda. 


\section{PART I - INTRODUCTION}

1. Ensuring access to essential medicines is a key objective of all health systems, and is an integral component of the progress towards universal health coverage (UHC). The goal of UHC is to ensure that all people obtain the health services they need without suffering financial hardship when paying for them. Medicines are indispensable for delivering key aspects of UHC - including coverage, service provision, and risk protection - because they are a requirement for high quality care, contribute significantly to household health expenditures, and are one of the major causes of health system inefficiency. ${ }^{1}$ Medicines are a critical input in health service delivery, without which many people across the world are denied proper care. Medicines provide important life-saving measures, provide crucial preventive therapies for diseases, provide much needed relief for chronic illnesses, prolonging life-span and improving quality of life for patients. Thus, equitable access to safe and affordable medicines is necessary for the attainment of the highest possible standard of health ${ }^{2}$. Indeed, the Sustainable Development Goals call for access to quality essential healthcare services and access to safe, effective, quality and affordable essential medicines and vaccines for all, as part of achieving UHC.

2. Globally, medicines contribute to about 25 percent of total health expenditure. The expenditure on medicines as a share of total health expenditure can vary significantly across countries, from as low as 8 percent to as high as 68 percent $^{3}$. The cost of medicines is also borne differently across countries: by government, via third party payments such as health insurance, through out of pocket (OOP) expenses by individuals, or a combination of methods. Especially where pharmaceutical expenditure is high and where a large share of this expense is borne by individuals, a key concern is whether this level of expenditure is efficient, and if it is fiscally sustainable to the health system and affordable by patients.

3. Despite global and national efforts to improve access and affordability of medicines, millions of people - particularly in low- and middle-income countries still remain without access to quality-assured and affordable medicines. Even with the expansion of UHC across the world, many people have to pay for their medicines out-of-pocket but lack the necessary financial resources to do so. This can result in either non-treatment or catastrophic expenditure, especially where there is no generic competition to originator products that can push down the price of medicines for the consumer and government procurement agencies.

4. Ensuring access to medicines is a multidimensional issue involving multiple stakeholders and sectors, policy areas, and processes. On the one hand there is the supply side (production) of pharmaceutical products, including parameters such as product discovery (research and development), licensing of products and market participants, pricing, quality assurance, pharmacovigilance, marketing, and

\footnotetext{
${ }^{1}$ Maryam Bigdeli, David H. Peters, Anita K. Wagner eds, "Medicines in Health Systems: Advancing access, affordability and appropriate use", WHO, 2014

${ }^{2}$ WHO. 2009. Statement on Access to Medicines, 13 March 2009. http://www.who.int/mediacentre/news/statements/2009/access-medicines-20090313/en/ [March 2016]

${ }^{3}$ WHO. 2011. The World Medicines Situation 3rd Edition: Medicines Expenditures. Geneva: $\mathrm{WHO}$
} 
promotion. On the other hand, the demand side of the pharmaceutical market (consumption) is influenced by who pays for medicines, procurement systems, purchasing arrangements, and supply chain management. Overall, the structure of a country's pharmaceutical market is also influenced by national pharmaceutical policies, as well as events and reforms in other sectors, such as industrial policy and trade agreements. All these factors interact with each other - see Figure 1 - and have an impact on eventual access to medicines by patients. Among other factors, effective medicines (product) regulation is important in ensuring access to medicines. The impact of product regulation on access to medicines is the focus of this report.

Figure 1: Access to medicines in the context of UHC and the pharmaceutical sector

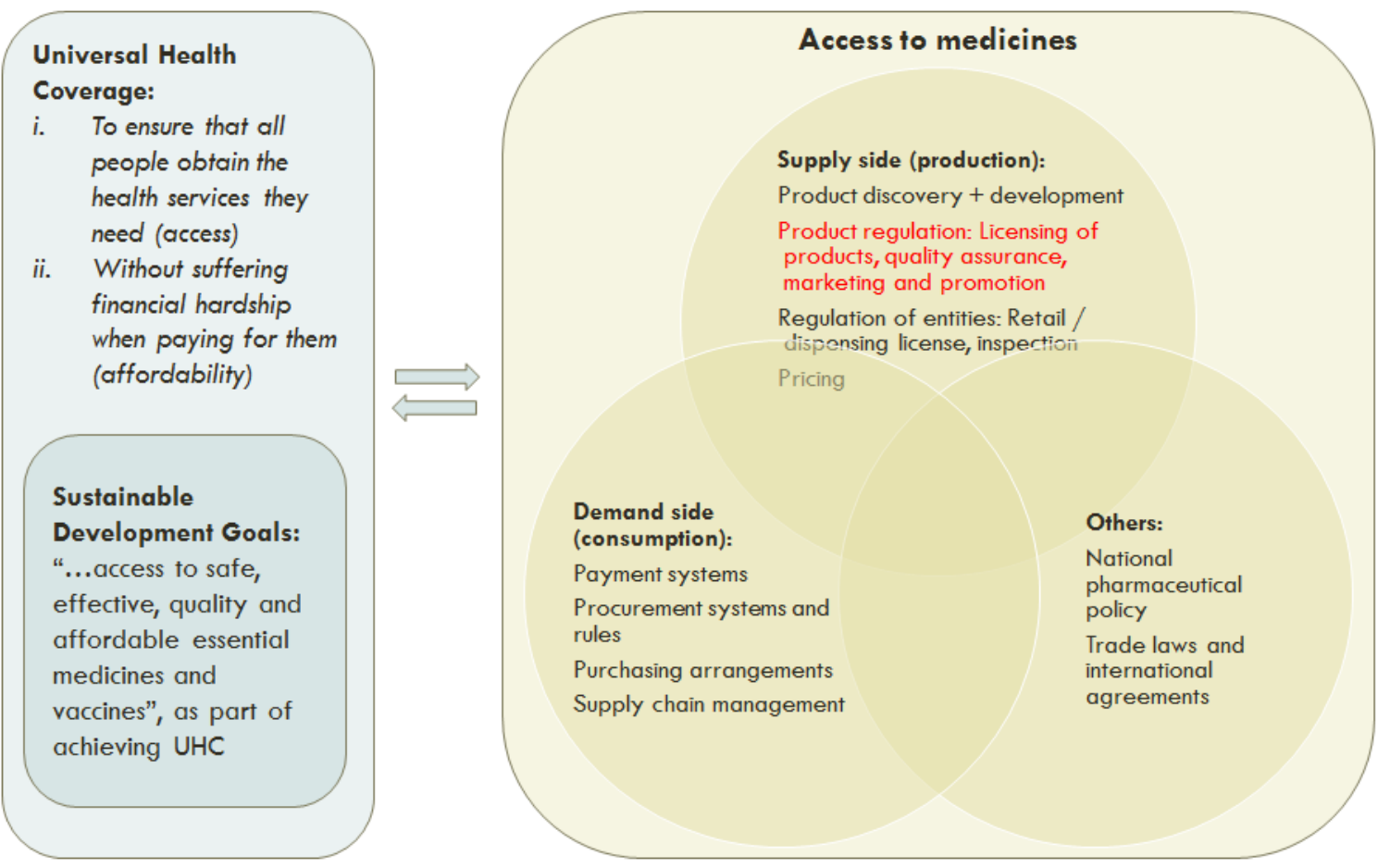

5. It is important that medicines in the market are safe, effective and qualityassured. As products containing active pharmaceutical ingredients, medicines elicit direct pharmacological responses in patients. When prescribed appropriately and taken rationally, these pharmacological responses are the exact reactions required to prevent, treat or maintain the patients' conditions. However, when medicines containing substandard, spurious, falsely labelled, falsified and counterfeit (SSFFC) ingredients are taken by patients, the products could produce unintended, potentially fatal, consequences. In addition, for certain medicines such as antibiotics, the presence of falsified, ineffective medicines in the market could result in widespread resistance, threatening public health. Therefore, it is important that medicines are regulated for its quality and safety.

6. Medicines regulation is important to ensure the availability of high quality medicines. Effective medicines regulation involves a range of processes including licensing of production and distribution of medicines, registration of products, inspection, and quality control and surveillance. The availability and affordability of quality-assured medicines is also dependent on the successful implementation of a number of related 
interventions, such as relevant national pharmaceutical policies and a robust drug development and manufacturing sector.

7. Medicines regulation is complex for all parties involved. With increasing globalization of pharmaceutical production and technological advancements, it is becoming increasingly challenging for National Medicines Regulatory Authorities (NMRAs) to effectively carry out their regulatory tasks. In many low- and middleincome countries, regulatory authorities and control laboratories are often short of funds, and lack the technical equipment, human resources, and expertise required to effectively police the market and test control samples and inspect companies. This can result in falsified or sub-standard medicines circulating in the market, with potentially harmful effects for the consumer. For this reason, stronger governance, regulations, and accountability of the pharmaceutical sector are required to facilitate access to essential drugs and to protect the quality of medicines.

8. Medicines regulatory harmonization initiatives aim to improve and streamline regulatory requirements by shifting from a country-focused approach to a collaborative, cross-country approach. Without trans-national regulatory harmonization, strengthened and increasingly sophisticated regulation may ironically lead to increased costs for meeting regulatory standards, with implications for market entry and access. Yet, enormous financial, expertise and infrastructure investments are required to ensure the medicines released to the market is safe and of good quality. Collaborative, regional initiatives enable the pooling of resources and expertise to address the challenges and complexities of regulatory systems, keeping in mind the ultimate goal of ensuring timely access to quality and affordable medicines.

9. In addition to public health concerns, there are also strong economic imperatives for improved regulation of pharmaceuticals and regulatory harmonization. From the trade perspective, streamlined and harmonized regional standards can facilitate entry of domestic pharmaceutical manufacturers into regional and global pharmaceutical markets by reducing the cost of review, while providing assurance of quality along internationally accepted standards. Conversely, non-tariff barriers can impede free trade of pharmaceutical products. Especially relevant to the pharmaceutical sector are non-tariff barriers such as intellectual property rights, specifications on the use of data, and national pharmaceutical policies which promote domestic industrial policy interests over the free movement of goods. An understanding of these policy tensions and competing interests is critical to assessing how pharmaceutical markets are shaped, and how medicines regulatory harmonization initiatives can help to improve access to medicines in a particular country or region. 


\section{Key objectives and methodology}

Key objectives

10. It is well recognized that effective medicines regulation is necessary to ensure access to quality-assured medicines. This requires strong regulatory capacity and capability of NMRAs. In the current regulatory landscape, effective coordination and collaboration across NMRAs to harmonize regulatory requirements is also important to help to reduce the regulatory burden for each individual NMRA, streamline regulatory requirements for applicants, and thereby improve access to medicines.

11. To date, there are few comparative studies of national medicines regulatory systems, and limited documentation on the key opportunities and challenges in medicines regulatory harmonization. Further, as pharmaceutical sector trends and harmonization efforts differ across regions, region-specific analysis can provide critical information on characteristics and circumstances that are unique to a region, and which shape and have an impact on harmonization efforts.

12. This study aims to contribute to existing knowledge on these topics for the Southeast Asia region, with the following key objectives:

i. Provide an overview of pharmaceutical markets and key pharmaceutical policies in selected ASEAN countries, including trade aspects of pharmaceuticals, with a view towards understanding the potential scope for medicines regulatory harmonization

ii. Conduct a cross-country comparison of medicines regulatory systems of selected ASEAN countries, in particular to understand key opportunities and constraints in capacity and capabilities of National Medicines Regulatory Authorities

iii. Provide an account of harmonization efforts, opportunities, and challenges in the ASEAN region

iv. Identify potential next steps towards regional medicines regulatory harmonization

13. Within ASEAN, five countries have been purposively selected for this analysis. The five countries are: Indonesia, Malaysia, the Philippines, Thailand, and Vietnam. These countries were selected due to their substantial market sizes among ASEAN member states and strong domestic pharmaceutical manufacturing base. Findings from these countries are intended to be broadly indicative but not fully representative of the trends in ASEAN, as we recognize that ASEAN is a diverse region.

14. The study was commissioned by the World Bank Group, and is co-funded by the Umbrella Facility for Trade and Development and the Global Medicines Regulatory Harmonization (GMRH) initiative. The GMRH initiative focuses on medicines regulatory harmonization in the Africa region, with small grants to other regions such as this grant to the East Asia and Pacific region.

\section{Methodology}

15. The team first conducted a review of existing literature on medicines regulation and regulatory harmonization. This included published and unpublished reports, articles, and presentations on national, regional and international medicines regulatory 
harmonization initiatives, review of NMRAs, as well as pharmaceutical sector in analysis countries.

16. We then developed a questionnaire for purposes of collecting information from key stakeholders on information that was not already available in existing literature. The questionnaire developed by the team was adapted from the World Health Organization's (WHO) NMRA assessment tool, and includes the following main sections: key health sector issues; pharmaceutical sector analysis; review of NMRAs; towards medicines regulatory harmonization; international engagement; and capacity development needs. The questionnaire is included in Annex 1.

17. Using the questionnaire developed, semi-structured interviews were conducted with the NMRAs, governmental agencies, pharmaceutical associations and other key stakeholders of the pharmaceutical sector. A list of interviewees is in Annex 2.

18. The rest of the report is structured as follows. The background section provides an overview of the overall socioeconomic and health sector context in ASEAN. Part III on ASEAN pharmaceutical markets outlines the pharmaceutical sectors in the five analysis countries, including local and foreign market shares, product portfolio, and pharmaceutical policy trends. We then provide a conceptual framework for examining medicines regulation and regulatory harmonization efforts in Part IV. This is then followed by a comparative analysis of the NMRAs in Malaysia, Indonesia, the Philippines, Thailand, and Vietnam, focusing on selected capabilities and outcomes in each country that have a bearing on the countries' ability to participate in regulatory harmonization efforts. Part VI on harmonization initiatives in the region then explains the range of medicines regulatory harmonization initiatives in ASEAN, identifying key opportunities and constraints. The final section concludes, and suggests viable next steps for regulatory harmonization in ASEAN. 


\section{PART II - BACKGROUND}

\section{Southeast Asia region: Socioeconomic context}

19. The East Asia and Pacific (EAP) region ${ }^{4}$ is home to 2 billion people, accounting for close to 29 percent of the world's population, and ASEAN represents about 30 percent of this population. ASEAN is a diverse region, with wide variation across countries both in terms of population and economic status. Among ASEAN member states, Indonesia, also the fourth most populous country in the world, is the most populous with 257.6 million, followed by Philippines and Vietnam (Figure 2). Population growth rates in ASEAN countries have been high over the past few decades, and are expected to continue to rise, albeit at a reduced rate.

Figure 2: ASEAN population, 2015

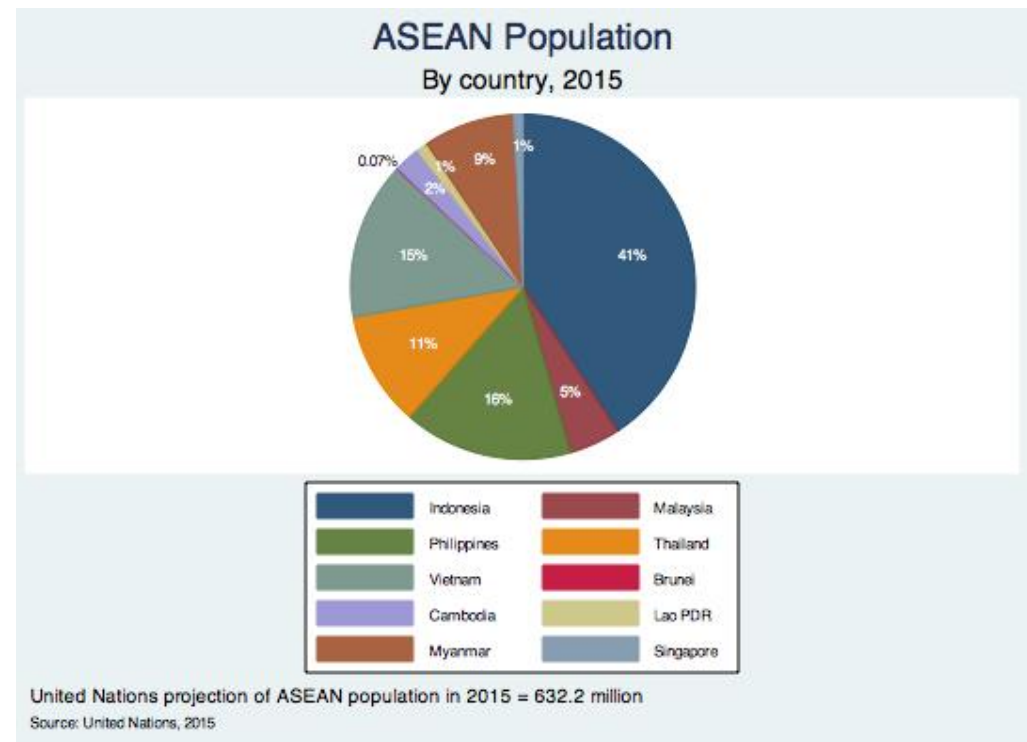

20. The EAP region has charted significant economic growth over the past 20 years, with the exception of the 1997 Asian Financial Crisis. Gross Domestic Product (GDP) per capita in the region increased more than twofold - from about USD 4,200 to USD 9,500 between 1995 and $2014^{5}$. In 2014, with a combined GDP of US\$ 2.6 trillion and a GDP per capita of US\$ 4,135, the ASEAN economy was the $7^{\text {th }}$ largest in the world and $3^{\text {rd }}$ largest in Asia. Combined, ASEAN represented the $3^{\text {rd }}$ largest market in 2014 in terms of population size, behind only China and India ${ }^{6}$. Among ASEAN member states, Brunei and Singapore are both high-income countries, followed by

\footnotetext{
${ }^{4}$ The World Bank Group country grouping includes 21 countries in the East Asia and Pacific region. All ASEAN member states are part of the EAP region. We thus present the ASEAN socioeconomic context in the broader context of EAP, for purposes of situating it within the World Bank Group's EAP grouping.

${ }^{5}$ World Bank. 2016. World Bank national accounts data, and OECD National Accounts data files. http://data.worldbank.org/indicator/NY.GDP.PCAP.CD [March 2016]

${ }^{6}$ ASEAN. 2015. ASEAN Economic Community at a Glance 2007-2014. Jakarta: ASEAN Secretariat
} 
Malaysia and Thailand which are in the upper-middle-income category. Indonesia, Lao PDR, Myanmar, Philippines, and Vietnam are lower-middle-income countries, while Cambodia is in the low-income country category ${ }^{7}$.

\section{Health outcomes and health sector context}

21. Population health outcomes vary widely across ASEAN countries. The average life expectancy in the ASEAN region is 73 , albeit with a 17 year gap between Singapore's life expectancy at birth of 83.7 years and Myanmar's life expectancy at birth of 66.5 years. This highlights the differences in the socioeconomic and health status of ASEAN member states. The ASEAN population is also relatively young, with over half of the population below the age of 30 in $2014^{8}$.

Figure 3: Burden of Disease in East Asia and Pacific by cause of DALYs, 1990-2013

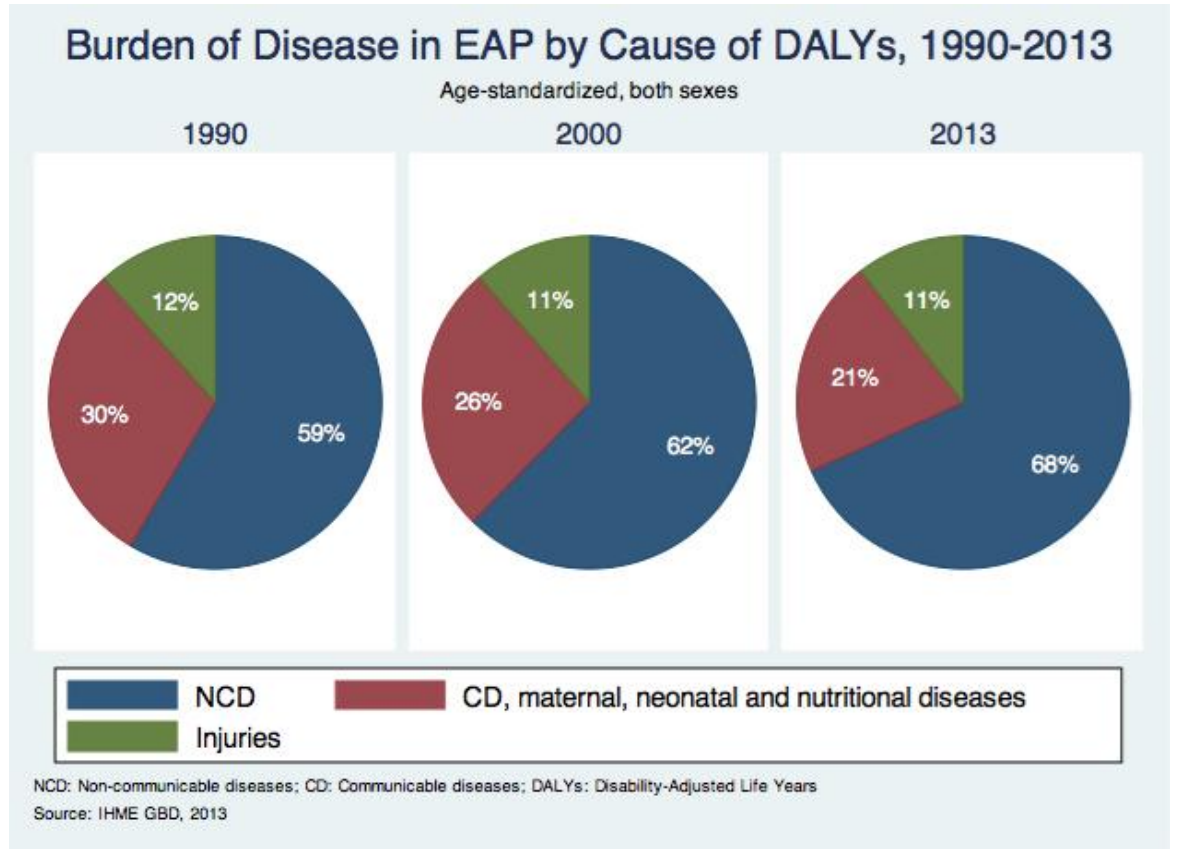

22. The EAP region is undergoing an epidemiological transition, with ASEAN countries experiencing the transition at a more rapid pace. In 1990, noncommunicable diseases (NCDs) accounted for less than 50 percent of Disabilityadjusted Life Years (DALYs) lost in four ASEAN member states - Cambodia, Indonesia, Lao PDR and Myanmar. By 2013, NCDs had risen sharply as a share of the total disease burden across ASEAN countries (Table 1) and were the main cause of morbidity and mortality, with cardiovascular diseases being one of the most pressing health issues in the region. The rising burden of NCDs, coupled with a relatively young, growing population means that the region is experiencing and will continue to face a tough battle

\footnotetext{
${ }^{7}$ Low-income economies are defined as those with a GNI per capita of $\$ 1,045$ or less in 2014; lower-middle-income economies are those with a GNI per capita of more than $\$ 1,045$ but less than $\$ 4,125$; upper-middle-income economies are those with a GNI per capita of more than $\$ 4,126$ but less than $\$ 12,735$; high-income economies are those with GNI per capita of $\$ 12,736$ or more. GNI per capita are calculated using the World Bank Atlas method.

${ }^{8}$ ASEAN, ASEAN Economic Community at a Glance 2007-2014.
} 
ahead to provide preventive and long term care - including access to medicines - to its population, placing a significant burden on the health system to ensure supply side readiness and resource availability. In addition, communicable diseases such as tuberculosis remain a significant threat to health in the region, further emphasizing the need for timely access to crucial, life-saving medicines in the region.

Table 1: Rising burden of non-communicable diseases in ASEAN, 1990 vs. 2013

\begin{tabular}{lccc} 
Country & $\begin{array}{c}\text { NCDs as share of } \\
\text { total burden of } \\
\text { disease, } 1990(\%)\end{array}$ & $\begin{array}{c}\text { NCDs as share of } \\
\text { total burden of } \\
\text { disease, 2013 (\%) }\end{array}$ & $\begin{array}{c}\% \text { increase between } \\
1990 \text { and 2013 }\end{array}$ \\
\hline Malaysia & 70.4 & 74.1 & 3.7 \\
Thailand & 64.4 & 70.3 & 6.1 \\
Philippines & 52.1 & 67.4 & 15.3 \\
Indonesia & 46.4 & 65.4 & 18.0 \\
Vietnam & 51.2 & 67.3 & 16.1 \\
ASEAN average & 56.3 & 68.9 & 12.6
\end{tabular}

Source: Institute of Health Metrics and Evaluation

\section{Expenditure on health and pharmaceuticals}

23. Among the countries in our analysis, total health expenditure ranged from 3 to 6 percent of GDP. On a per capita basis, however, total health expenditure varied from about US\$110 for Indonesia and Vietnam to US\$ 423 for Malaysia. This is still relatively low compared to the global average of US\$1038 in $2013^{9}$. Health care costs are borne differently across the countries. In Malaysia and Thailand, general government health expenditure comprise more than half of total health spending, whereas private health spending is higher than the government's share in Indonesia, the Philippines, and Vietnam. Key health expenditure indicators are summarized in Table 2. All five countries are working towards providing better access to healthcare through UHC programs, and are at present different levels of coverage in their UHC programs.

Table 2: Key macroeconomic and health expenditure information in selected countries, 2013

\begin{tabular}{|c|c|c|c|c|c|}
\hline Countries & Indonesia & Malaysia & Philippines & Thailand & Vietnam \\
\hline $\begin{array}{l}\text { Total GDP at market prices } \\
\text { (current US\$ millions) }\end{array}$ & 910,479 & 323,343 & 271,927 & 420,167 & 171,222 \\
\hline GDP per capita (current US\$) & 3,624 & 10,974 & 2,787 & 6,229 & 1,909 \\
\hline THE (\% of GDP) & 3 & 4 & 4 & 5 & 6 \\
\hline THE (current US\$ millions) & 26,644 & 12,583 & 11,964 & 17,714 & 10,192 \\
\hline THE per capita (current US\$) & 107 & 423 & 122 & 264 & 111 \\
\hline $\begin{array}{l}\text { General government health } \\
\text { expenditure (\% of THE) }\end{array}$ & 39 & 55 & 32 & 80 & 42 \\
\hline $\begin{array}{l}\text { Private health expenditure (\% } \\
\text { of THE) }\end{array}$ & 61 & 45 & 68 & 20 & 58 \\
\hline
\end{tabular}




\begin{tabular}{|c|c|c|c|c|c|}
\hline $\begin{array}{l}\text { External resources on health } \\
\text { (\% of THE) }\end{array}$ & 1 & 0 & 1 & 4 & 2 \\
\hline $\begin{array}{l}\text { Out-of-pocket expenditure (\% } \\
\text { of THE) }\end{array}$ & 45.8 & 36.1 & 56.7 & 11.3 & 49 \\
\hline $\begin{array}{l}\text { Population covered by UHC } \\
(\%)\end{array}$ & $\sim 60$ & $\sim 100$ & $\sim 80$ & $\sim 100$ & $\sim 70$ \\
\hline
\end{tabular}

Source: World Bank; WHO Global Health Expenditure Database NHA Indicators

24. Similarly, there is large variation in total expenditure on pharmaceuticals and by whom this expenditure is borne. Pharmaceutical expenditure per capita ranged from US\$ 42 in Indonesia to US\$ 171 in Thailand. The reasons for different levels of pharmaceutical expenditure could vary: high expenditure could represent more comprehensive medicines access programs, or conversely, inefficiencies in the system. Low spending on medicines might be due to efficient procurement and pricing, or conversely, signify insufficient access. With regard to sources of financing for pharmaceuticals, in Malaysia and Thailand, a major share of pharmaceutical spending is borne by the government, at 68 and 90 percent respectively. In all but high-income countries, most medicines are paid for by private sources, usually as OOP payments by individuals ${ }^{10}$; the estimate for Asia on average, in 2006, was 65 percent ${ }^{11}$. In OECD countries, $36 \%$ of OOP medical expenditure was due to pharmaceuticals ${ }^{12}$. As Table 2 shows, with the exception of Malaysia and Thailand, OOP expenditures accounted for about 50 percent of total health expenditure, a good portion of which could be spent at private retail pharmacies.

Table 3: Pharmaceutical expenditure in selected ASEAN countries, 2010

\begin{tabular}{lrrrrr}
\multicolumn{1}{c}{ Countries } & Indonesia & Malaysia & Philippines & Thailand & Vietnam \\
\hline $\begin{array}{l}\text { Pharmaceutical } \\
\text { expenditure (\% of THE) }\end{array}$ & 33.8 & 12.7 & 29.9 & 50.5 & 43.2 \\
$\begin{array}{l}\text { Pharmaceutical } \\
\text { expenditure per capita }\end{array}$ & 42 & 78 & 50 & 171 & 93 \\
$\begin{array}{l}\text { (US } \$ \text { PPP) } \\
\begin{array}{l}\text { Government share of } \\
\text { pharmaceutical } \\
\text { expenditure (\%) }\end{array}\end{array}$ & 15.2 & 68.2 & 12.1 & 90.4 & 23.4 \\
& & & & &
\end{tabular}

Source: OECD

\section{Access, affordability, and quality of medicines}

25. Ensuring reliable access to affordable and quality-assured medicines in the Southeast Asia region remains a challenge. Surveys on medicines pricing by Health

\footnotetext{
${ }^{10}$ WHO. 2011. The World Medicines Situation 3rd Edition: Medicines Expenditures. Geneva: $\mathrm{WHO}$

${ }^{11}$ WHO. 2014. "Pharmaceutical financing in Asia" in First Meeting on Access to Medicines Under Universal Health Coverage Coverage in the Asia-Pacfic Region Meeting Report. Philippines: WHO.

${ }^{12}$ OECD. 2015. "Out-of-pocket medical expenditure", in Health at a Glance 2015: OECD Indicators. Paris: OECD Publishing.
} 
Action International ( $\mathrm{HAl}$ ) using a validated standard methodology for measuring medicines prices, availability, and affordability developed with WHO reported findings for 4 of the 5 analysis countries, as shown in Table $4^{13}$. When comparing public facilities, consumers in Thailand, Philippines and Vietnam pay 1.7 to 6.4 times the international reference price (IRP) for generic medicines. Median public procurement prices range from 1.09 times of IRP for lowest priced generics in Malaysia, to 1.5 in Vietnam, suggesting that public procurement prices are relatively reasonable. Philippines, on the other hand, paid at least 5 times the IRP. In private facilities, consumers pay anywhere between 2 to 8 times the IRP for lowest priced generics. Unsurprisingly, the MPR of originator brands were higher in the region. Unfortunately, this meant that patients in Indonesia paid at least 32 times the IRP for branded medicines in private facilities. Countries choose to control medicines pricing in different ways - Malaysia for example, does not regulate medicine prices and leaves it to market forces ${ }^{14}$, Indonesia regulates prices by placing a price caps on about 200 generic medicines with prices updated every one to two years ${ }^{15}$ but leaves originator brands prices unregulated. Vietnam controls mark-up prices for wholesale pharmaceutical products ${ }^{16}$.

Table 4: Median price ratio of medicines in Indonesia, Malaysia, Philippines and Thailand ${ }^{17}$

\begin{tabular}{|l|c|c|r|r|r|r|r|r|}
\cline { 2 - 9 } \multicolumn{1}{c|}{} & \multicolumn{2}{|c|}{$\begin{array}{c}\text { Indonesia, 2010 } \\
\text { (N=50 medicines) }\end{array}$} & \multicolumn{2}{c|}{$\begin{array}{c}\text { Malaysia, 2004 } \\
\text { (N=47 medicines) }\end{array}$} & \multicolumn{2}{c|}{$\begin{array}{c}\text { Philippines, } \\
2005(\mathrm{~N}=34 \\
\text { medicines }\end{array}$} & \multicolumn{2}{c|}{$\begin{array}{c}\text { Thailand, 2006 } \\
\text { (N=43 } \\
\text { medicines) }\end{array}$} \\
\cline { 2 - 9 } & $\begin{array}{c}\text { Origina } \\
\text { tor } \\
\text { brand }\end{array}$ & $\begin{array}{c}\text { Lowest } \\
\text { price } \\
\text { generic }\end{array}$ & $\begin{array}{c}\text { Originat } \\
\text { or } \\
\text { brand }\end{array}$ & $\begin{array}{c}\text { Lowest } \\
\text { price } \\
\text { generic }\end{array}$ & $\begin{array}{c}\text { Origin } \\
\text { ator } \\
\text { brand }\end{array}$ & $\begin{array}{c}\text { Lowest } \\
\text { price } \\
\text { generic }\end{array}$ & $\begin{array}{c}\text { Origin } \\
\text { ator } \\
\text { brand }\end{array}$ & $\begin{array}{c}\text { Lowest } \\
\text { price } \\
\text { generic }\end{array}$ \\
\hline $\begin{array}{l}\text { Median MPR in } \\
\text { public sector } \\
\text { (Procurement } \\
\text { prices) }\end{array}$ & $\mathrm{NA}$ & 1.34 & 2.44 & 1.09 & 14.19 & 5.14 & 3.30 & 1.46 \\
\hline $\begin{array}{l}\text { Median MPR in } \\
\text { public sector } \\
\text { (Patient prices) }\end{array}$ & 18.40 & 1.76 & $\begin{array}{c}\text { FOC to } \\
\text { patients }\end{array}$ & $\begin{array}{c}\text { FOC to } \\
\text { patients }\end{array}$ & 15.31 & 6.40 & 4.36 & 2.55 \\
\hline $\begin{array}{l}\text { Median MPR in } \\
\text { private sector } \\
\text { (Patient prices) }\end{array}$ & 32.15 & 2.00 & 17.76 & 6.57 & 17.28 & 5.64 & 11.6 & 3.31 \\
\hline
\end{tabular}

MPR = Median Price Ratio. Median price ratio is defined as median local price divided by international reference price (converted to local currency using exchange rate on first day of data collection).

Source: Health Action International

\footnotetext{
${ }^{13}$ Health Action International (HAl) database. Prices are presented as median price ratio (MPR), a ratio of median local unit price divided by international unit reference price in local currency using the exchange rate on first day of data collection. For more detailed information on methodology, please refer to Cameron, A., M. Ewen, D. Ross-Degnan, D. Ball and R. Laing. 2008. "Medicine prices, availability, and affordability in 36 developing and middle-income countries: a secondary analysis". The Lancet. DOI:10.1016/S0140-6736(08)61762-61.

${ }^{14}$ Babar, Z. and M.I.M. Ibrahim. 2003. "Affordability of medicines in Malaysia - Consumer perceptions". Essential Drug Monitor No. 33. Geneva: WHO.

${ }^{15}$ Government of Indonesia. 2015. Minister of Health Decree No. HK.02.02/MENKES/525/2015

Tentang Harga Eceran Tertinggi Obat Generik.

${ }^{16}$ Nguyen A.T., R. Knight, A. Mant, Q.M. Cao and G. Brooks. 2010. "Medicine pricing policies: Lessons from Vietnam". Southern Med Review 3; 2:12-19

${ }^{17}$ Data from latest available year in the HAl database are presented. Data can be updated for more accurate representation of current prices, when available.
} 
26. In terms of availability of medicines, the mean availability of selected medicines in the Southeast Asia was 33 percent in public facilities and 45 percent in private facilities, the lowest when compared to other regions of the world ${ }^{18}$. Similar to medicines prices, availability of medicines differs across countries. Although comparable data are not available for all five countries in our analysis, figures from Indonesia and the Philippines indicate that the median availability of selected generic medicines in the public sector was 66 percent and 27 percent respectively ${ }^{19}$.

27. In addition to pricing and availability issues, the region also faces threats in substandard, spurious, falsely labelled, falsified and counterfeit (SSFFC) medicines. SSFFC anti-malarials have been reported in and across ASEAN member states such as Cambodia, Lao PDR, Myanmar and Thailand, undermining regional efforts and investments in combating malaria ${ }^{20}$. SSFFC medicines also plague more developed countries such as Malaysia and Singapore, with reports of counterfeit erectile dysfunction medicines sold in the market leading to life-threatening health complications for consumers ${ }^{21}$. The fluidity of SSFFC medicines in crossing country borders underlines the need for a medicines regulatory system that is equipped and prepared to deal with regional and worldwide threats. The implementation of national medicines policy which emphasizes rational use of medicine and encourages generic drug use, and the presence of robust, efficient national medicine regulatory systems are key to ensuring access to quality and affordable medicines.

\section{PART III - ASEAN PHARMACEUTICAL MARKETS}

\section{Growth rates and market shares}

28. The pharmaceutical sectors in our five analysis countries have experienced robust growth and are expected to continue to grow. On average, the pharmaceutical markets in the five countries are expanding quickly (estimate of 23.4 billion USD), with an average year-on-year growth rate of around $10 \%{ }^{22}$. Indonesia has the largest pharmaceutical market (6.5 billion USD), followed by Philippines (6.2 billion USD), Thailand (5 billion USD), Vietnam (3.5 billion USD) and Malaysia (2.2 billion USD). The fastest growing market is currently Vietnam, with an estimated year-on-year growth rate of $16 \%$.

29. While domestically-produced medicines have been increasing as a share of total consumption in terms of volume, they remain a small part of the overall

\footnotetext{
${ }^{18}$ Health Action International (HAI) database

${ }^{19}$ WHO. Global Health Observatory database: Median availability of selected generic medicines. http://apps.who.int/gho/data/node.main.488?lang=en [April 2016]

${ }^{20}$ Nayyar G., J.G. Breman, P.N. Newton and J. Herrington. "Poor-quality antimalarial drugs in Southeast Asia and sub-Saharan Africa". Lancet Infect Dis 2012; 12: 488-96

${ }^{21}$ WHPA Regional Workshop on Counterfeit Medical Products. 2011. Background Document on Counterfeit Medicines in Asia. http://www.whpa.org/background document counterfeit medicines in asia.pdf [March 2016] ${ }_{22}$ Pacific Bridge Medical. Target Asian Markets. http://www.pacificbridgemedical.com/targetasian-markets [March 2016]
} 
product mix in terms of value. Medicine consumption (value-wise) from domestically produced medicines is overall below 50\%, except in Indonesia (estimate of $70 \%$ domestic medicines) (Figure 4). Volume-wise, however, the domestic industry has a bigger share as most of the companies are producing mainly multisource generic products, largely unbranded, that are less expensive than innovator or branded products.

Figure 4: Medicines consumption from domestic medicines (value wise), 2015

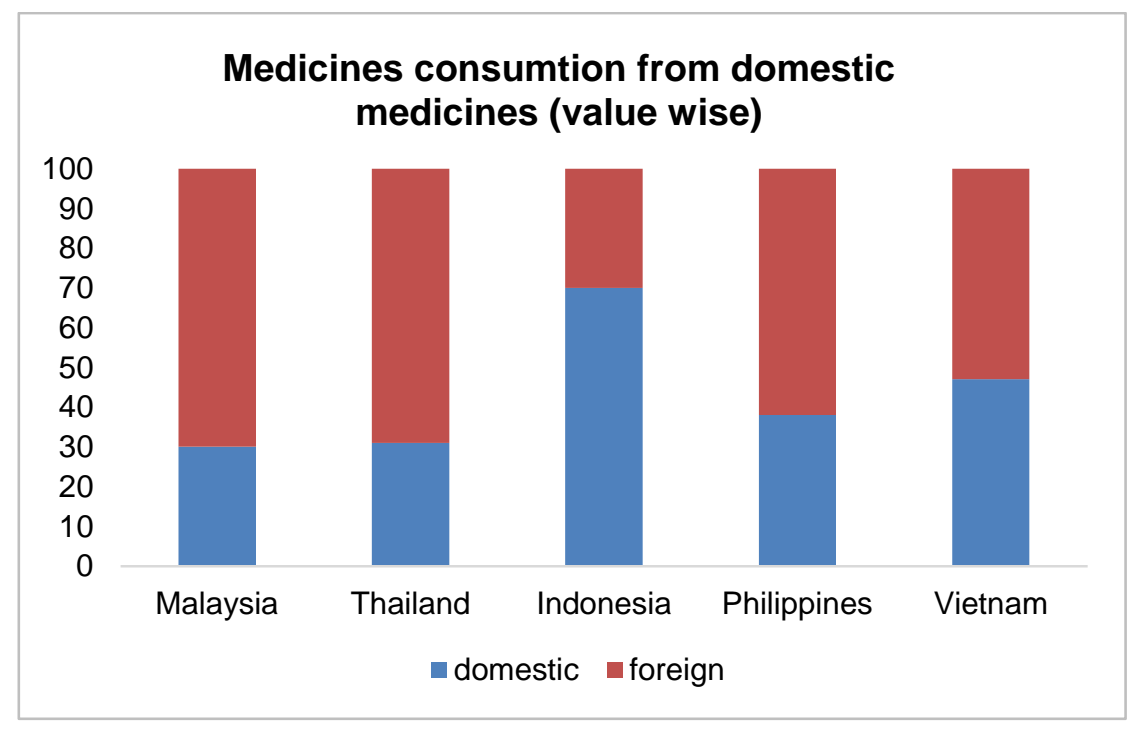

\section{Local pharmaceutical production}

30. Local manufacturers compete in a narrow therapeutic niche. There is little domestic research and development in innovator products, and no significant manufacture of biotech products or active pharmaceutical ingredients (APIs). APIs, which are the key input for manufacturing finished pharmaceutical products (FPP) and a substantial cost factor in production, are imported - with the highest values coming from China and from India. As a result, to date, the domestic pharmaceutical industry in most ASEAN countries comprises mainly generic and over-the-counter (OTC) products. Most local companies have similar product portfolios, and they compete with each other in the same market segments. The focus is on antibacterial medicines, analgesics, vitamins, cough and cold medicinal products, and diuretics. Diversification and moving to highervalue products is challenging due to lack of technical expertise, required human resources, and financing. High value innovative medicinal products, such as anticancer drugs, immunosuppressive drugs, or blood components, therefore, are mainly captured by multinational manufacturers.

\section{Trade in pharmaceutical products}

Trends in imports and exports

31. As a result of the limited therapeutic scope of domestic manufacturers, ASEAN countries still heavily rely on pharmaceutical imports, especially for innovator products. In most of the five countries, except for Indonesia, the inability of 
local pharmaceutical industry to sufficiently meet local demands for low-cost generic production and pharmaceutical innovation have allowed foreign companies to dominate the pharmaceutical markets.

32. At the same time, export rates of local manufacturers in the region are increasing, with other ASEAN countries as focal destinations. According to ASEAN data, both imports and exports of pharmaceutical products have increased significantly over the last decade, signaling increased consumption, production, and trade in this sector (Figure 5). Domestic manufacturers in the five countries export to other countries in the ASEAN region, as well as to the rest of Asia, Africa and partly to Europe and the US. Some manufacturers, especially in Indonesia, produce pharmaceuticals exclusively for exports. In Malaysia, export destinations that have shown significant growth in recent years were Myanmar, China, Nigeria and Germany. Pharmaceutical exports in Thailand are valued at over $\$ 300$ million $^{23}$ and are primarily shipped to other Southeast Asian nations like Myanmar (22\%), Vietnam (17\%), Cambodia (11\%), Singapore (8\%), Malaysia (7\%), Philippines (6\%) and Laos (4\%). Export of Vietnamese and Philippines manufacturers are generally very low, focusing on Laos, Myanmar, and Cambodia. Beyond the ASEAN region, there is also export to some African countries like Nigeria and Angola (mainly antimalarial products). Some manufacturers that meet $\mathrm{PIC} / \mathrm{S}$ standards also export to countries like Germany, Switzerland, Russia and the USA ${ }^{24}$.

Figure 5: ASEAN exports and imports of pharmaceutical products (1993-2013)

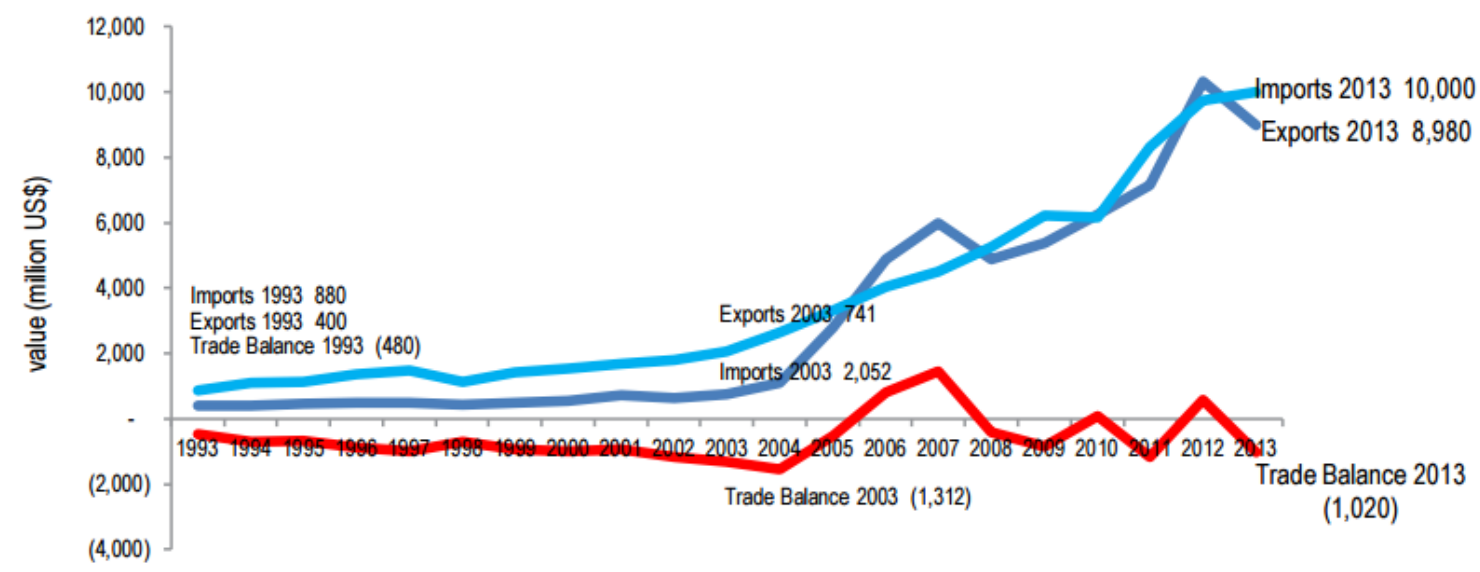

Source: ASEAN Community in Figures - Special Edition $2014^{25}$

33. These trends have several consequences for ASEAN pharmaceutical markets, which in turn have an impact on medicines regulatory functions. The large volume of generic products that flood the market - regardless of their source of origin (domestic or imported) - require regulatory attention. In addition, NMRAs have limited capability in assessing the efficacy and quality of medicines; this is especially challenging for innovative medicines. In some cases, regulators would rather let

${ }^{23}$ Pharma Phorum. Thailand Pharmaceutical Market Update 2014.

http://www.pharmaphorum.com/articles/thailand-pharmaceutical-market-update-2014 [March

2016]

${ }^{24}$ Interviews with local manufacturers associations.

${ }^{25}$ ASEAN. 2014. ASEAN Community in Figures - Special Edition 2014. Jakarta: ASEAN Secretariat. 
applications for innovator medicines pile up than risk letting unsafe medicines onto the market (see paragraph 48 for details). Combined, these pose a regulatory burden on the NMRA, often contributing to high workload and a backlog of applications. On the export side, local manufacturers may face similar regulatory hurdles when registering their medicines in the export destination.

34. Efforts to harmonize regulatory requirements for pharmaceutical products are situated within the broader architecture of the ASEAN Economic Community (AEC). Officially launched in 2015, the AEC aims to eventually create a single market and production base within ASEAN. This will allow for the free movement of goods, services, skilled labor, and investment among the 10 ASEAN member nations, and facilitate the freer flow of capital ${ }^{26}$. Harmonization of technical regulations and mutual recognition agreements are among the strategies that will be adopted by the AEC to reduce trade costs. There has already been some headway in this area of work, with the development of Mutual Recognition Arrangements (MRAs) on Bioequivalence studies and Good Manufacturing Practice in the pharmaceutical sector. Another sector that has developed MRAs is electrical equipment and electronics sector, while there is ongoing work on this front in the foodstuffs, automotive, and building and construction sectors.

Impact of regional trade developments on access to medicines and regulatory harmonization

35. While the trend - both globally and regionally - has been towards market integration, substantial barriers to trade and market access continue to exist. For the pharmaceutical sector, measures related to intellectual property (IP) rights in trade continue to pose significant non-tariff barriers. This includes IP requirements in both national legislation and trade agreements such as patents and restrictions on use of data and trade secrets. While it is beyond the scope of this study to examine the range of non-tariff measures that impact the access to medicines, some attention is given here to the Trans Pacific Partnership (TPP) ${ }^{27}$. This is due to the anticipation that the TPP will have an adverse impact on timely access to medicines.

36. Although evidence on the potential impact of the TPP on pharmaceutical products is currently quite thin, it is anticipated that the TPP will lengthen patent monopolies, delay market entry of generic products, and in turn lead to higher pharmaceutical prices. Initial analysis on clauses in the text of the TPP suggests that there are three main areas that will severely affect pharmaceutical products: ${ }^{28}$

i. Patentability criteria. While the criteria for being able to patent an invention differs across countries' patent laws, the laws usually require a product to be novel, to include a non-obvious inventive step, and to have industrial applicability. In addition to these requirements, the TPP allows for patenting of new uses of a known product, new methods of using a known product, or new processes of

\footnotetext{
${ }^{26}$ ASEAN. ASEAN Economic Community. http://www.asean.org/asean-economic-community/ [March 2016]

${ }^{27}$ The TPP is a trade agreement negotiated between the U.S. and eleven other Pacific Rim nations: Australia, Brunei Darussalam, Canada, Chile, Japan, Malaysia, Mexico, New Zealand, Peru, Singapore, and Vietnam.

${ }^{28}$ Information gathered from Knowledge Ecology International website: http://keionline.org/node/2413 [March 2016]
} 
using a known product. It is expected that this will substantially expand the scope and number of patents that are filed, and will lead to a phenomenon called "patent evergreening". Thought leaders in this area have suggested that evergreening yields no significant therapeutic advantage, and merely extends the monopoly of an existing product ${ }^{29}$.

ii. Patent term adjustments. The TPP includes an article that requires patent terms to be adjusted (extended) to compensate the patent owner for "unreasonable curtailment" of the effective patent term, as a result of the marketing approval process. To date, there has been little commentary on whether patent applicants are likely to invoke this clause to try to extend their patent term. However, the fear is that the increased volume of patents (due to the looser patentability criteria mentioned above) will cause a backlog in both patent approval and marketing approval, and thereby delay the entry of medicines onto the market.

iii. Data exclusivity. The pharmaceutical sector has generally allowed for clinical test data to be withheld during the lifespan of a patent, so as to prevent generic manufacturers from relying on this data for their own applications. Under the Agreement on Trade-Related Aspects of Intellectual Property Rights (TRIPS) administered by the World Trade Organization, however, the "Bolar exception" allows generic manufacturers to start producing test-batches of the product before the patent expires, in order to reduce the delay for generic product to enter the market after the patent expires. The TPP threatens to negate this TRIPS provision by reinstating data exclusivity for 5 years, or up to 8 years for biologic products. These clauses could potentially delay the registration of generic or biosimilar versions of a medicine.

37. In sum, the TPP could potentially impede access to medicines by imposing non-tariff measures via intellectual property rights. Supporters of the TPP suggest that the trade deal will in fact improve access to medicines by eliminating tariffs and continuing to recognize TRIPS provisions and exceptions for pharmaceutical products. Due to the secrecy of TPP negotiations and the limited information coming out of its process, there is currently insufficient analysis from which we can draw a definitive conclusion on how the TPP will eventually impact the pharmaceutical sector. More analysis will be needed on this topic.

\section{National pharmaceutical sector policies}

38. In addition to economic and trade agreements such as the TPP outlined above, national pharmaceutical sector policies also have a significant impact on the composition of the pharmaceutical market, industry development, and trade. In many instances, national pharmaceutical policies aim to support industrial policy objectives as well as achieve health policy goals. Whether explicitly or implicitly, this can result in either one objective superseding the other, and in some instances create a conflict between the two. For example, government policies to support domestic pharmaceutical sector development tend to introduce favorable conditions for local companies. This may result in an uneven playing field between multinational and

${ }^{29}$ Collier, Roger. "Drug Patents: The Evergreening Problem." Canadian Medical Association Journal 185.9 (2013): E385-E386. 
domestic manufacturers. In the long run, national pharmaceutical policies can substantially shape a country's pharmaceutical market.

39. Across the countries in this study, national pharmaceutical sector policies broadly support local manufacturers, often with explicit objectives of increasing the market share of domestically produced medicines, with a view towards selfsufficiency. The mechanisms used to achieve these objectives include broad policy pronouncements, specific projects to upgrade local pharmaceutical production capacity, funding for research and development, tax incentives, and targets for market share of local products. Table 5 summarizes some key initiatives which Indonesia, Malaysia, the Philippines, Thailand, and Vietnam have put in place to support local pharmaceutical production. 
Table 5: Examples of governmental initiatives to support local pharmaceutical production

\begin{tabular}{|c|c|c|c|c|c|}
\hline Country & Indonesia & Malaysia & Philippines & Thailand & Vietnam \\
\hline $\begin{array}{l}\text { Initiatives } \\
\text { towards local } \\
\text { pharmaceutical } \\
\text { development }\end{array}$ & $\begin{array}{l}\text { National Medicines } \\
\text { Policy 2006; } \\
\text { Ministerial Decree } \\
\text { 1010/2018 }\end{array}$ & $\begin{array}{l}\text { Projects under the } \\
\text { Performance } \\
\text { Management \& } \\
\text { Delivery Unit } \\
\text { (PEMANDU) of the } \\
\text { government; National } \\
\text { Medicines Policy } \\
2012\end{array}$ & $\begin{array}{l}\text { No recent } \\
\text { pharmaceutical } \\
\text { policies to support } \\
\text { local pharmaceutical } \\
\text { production known to } \\
\text { us. Generic Drugs } \\
\text { Act of } 1988 \text { (Republic } \\
\text { Act No. } 6675 \text { ). }\end{array}$ & $\begin{array}{l}\text { Thai national drug } \\
\text { system } \\
\text { development } \\
\text { strategy A.D.2012- } \\
\text { 2016; Investment } \\
\text { promotion act (BOI } \\
\text { annual report } \\
\text { 2014) }\end{array}$ & $\begin{array}{l}\text { National strategy on } \\
\text { development of the } \\
\text { Vietnam } \\
\text { pharmaceutical } \\
\text { industry up to } 2020 \text {, } \\
\text { with a vision toward } \\
2030\end{array}$ \\
\hline Objective & $\begin{array}{l}\text { Encourage local } \\
\text { pharmaceutical } \\
\text { production }\end{array}$ & $\begin{array}{l}\text { Transform Malaysia } \\
\text { into a high-income } \\
\text { nation by } 2020 ; \\
\text { Encourage local } \\
\text { pharmaceutical } \\
\text { manufacturing }\end{array}$ & $\begin{array}{l}\text { Promotes, requires, } \\
\text { and ensures the } \\
\text { production of an } \\
\text { adequate supply, } \\
\text { distribution, use, and } \\
\text { acceptance of } \\
\text { generic medicines. }\end{array}$ & $\begin{array}{l}\text { Encourage local } \\
\text { pharmaceutical } \\
\text { industry to move } \\
\text { up the value chain. }\end{array}$ & $\begin{array}{l}\text { Domestically } \\
\text { produce } 20 \% \text { of the } \\
\text { demand of raw } \\
\text { materials and } \\
\text { domestically cater } \\
\text { for } 80 \% \text { of total drug } \\
\text { consumption by } \\
2020\end{array}$ \\
\hline Details & $\begin{array}{l}\text { Provision of } \\
\text { incentives to local } \\
\text { pharmaceutical } \\
\text { companies, using } \\
\text { existing opportunities } \\
\text { under WTO } \\
\text { Agreements; } \\
\text { Promotion of local } \\
\text { pharmaceutical } \\
\text { development through } \\
\text { training and } \\
\text { technical guidance. }\end{array}$ & $\begin{array}{l}\text { Governmental } \\
\text { projects to support } \\
\text { upgrade the local } \\
\text { pharmaceutical } \\
\text { production capacity } \\
\text { and innovation; Local } \\
\text { pharmaceutical } \\
\text { manufacturers may } \\
\text { be eligible for } \\
\text { incentives as } \\
\text { determined by } \\
\text { government. }\end{array}$ & $\begin{array}{l}\text { Public procurement } \\
\text { preference on } \\
\text { generics medicines. } \\
\text { The President can } \\
\text { authorize the } \\
\text { importation of raw } \\
\text { materials tax and } \\
\text { duty-free. }\end{array}$ & $\begin{array}{l}\text { Introduction of } \\
\text { biotech parks and } \\
\text { big tax incentives. }\end{array}$ & $\begin{array}{l}\text { Governmental } \\
\text { support in terms of } \\
\text { policy and financial } \\
\text { resources; policies } \\
\text { are being issued to } \\
\text { promote research, } \\
\text { production, and } \\
\text { export of essential } \\
\text { medicines. }\end{array}$ \\
\hline
\end{tabular}


40. Vietnam, for example, plans to domestically produce 20 percent of the demand for raw materials and domestically cater for 80 percent of total drug consumption by $2020^{30}$. There is governmental support in terms of policy and financial resources, and policies have been issued to promote research, production, and export of essential medicines. While local manufacturers acknowledge the strategy as a good sign, there is also skepticism as to whether the objectives can be achieved in the short time span. There are also concerns about quality - feedback indicates that many consumers lack confidence in domestically manufactured medicines, and prefer foreign brands over local products. In Thailand, as another example, the government is now funding more research and development, encouraging the local pharmaceutical industry to move up the value chain. By introducing biotech parks and big tax incentives, the government is also promoting biotechnology ${ }^{31}$. According to the Thai Pharmaceutical Manufacturers Association, Thailand's aims to become a pharmaceutical hub in the ASEAN region. Among other requirements for such an endeavor, regulatory processes would need to be more transparent and efficient.

41. While national pharmaceutical sector policies are necessary to provide strategic direction on the overall trajectory of the sector, a key concern arises when policies are perceived to be erecting non-tariff measures. Non-tariff measures can broadly be defined to include quotas, import licensing requirements, and discriminatory government procurement rules ${ }^{32}$. Some initiatives and policies that have been laid out in the countries in our analysis can be - and have been - perceived to have a bias or unfair advantage towards local manufacturers. In Indonesia, for example, all registered medicines must have at least one part of the production manufactured locally according to $\mathrm{GMP}^{33}$. Thus, multinationals are required to set up manufacturing plants in the country, form partnerships with local companies to obtain a manufacturing license, or assign a local manufacturer to obtain registration approval on its behalf ${ }^{34}$. In addition, there are requirements for local production of imported products, if already offpatent, to start within 5 years of registration in the country and for transfer of technology from importer to local manufacturers to happen. At the same time, however, to encourage more foreign pharmaceutical investment, the country increased the maximum ownership allowed for multinational companies from 75 to 85 percent in $2014^{35}$. In Vietnam, the Law on Tendering which took effect from 1st July 2014 promotes the local pharmaceutical sector through a local purchase preference. When bidding for government tenders, if domestic medicines that fulfill the requirements by $\mathrm{MoH}$ are available, tenderers are not permitted to fulfil their supply using imported medicines. In addition, in instances where tenders are ranked equally, tenders where domestic production costs are higher than 25 percent will receive preferential treatment ${ }^{36,37}$. While from an economic and industrial policy perspective there may be rational reasons for

\footnotetext{
${ }^{30}$ National Development Strategy of Pharmaceuticals In Vietnam $2020-2030$.

${ }^{31}$ Thai National Drug System Development Strategy A.D. 2012-2016; Board of Investment Annual Report 2014: Investment Promotion Act.

${ }^{32}$ Cadot, O., M. Malouche, S. Sáez. 2012. "Streamlining Non-Tariff Measures: A Toolkit for Policy Makers". Directions in Development: Trade. Washington, DC: World Bank.

https://openknowledge.worldbank.org/handle/10986/6019 License: CC BY 3.0 IGO.

${ }^{33}$ Government of Indonesia. 2011. Regulation HK.03.1.23.10.11.08481 Year 2011.

${ }^{34}$ Government of Indonesia. 2008. Minister of Health Decree No. 1010 Year 2008.

${ }^{35}$ Government of Indonesia. 2014. Presidential Decree No.39 Year 2014.

${ }^{36}$ Government of Vietnam. 2013. Law No. 43/2013/QH13.

${ }^{37}$ Andaman Medical. Vietnam Pharmaceutical: A Brief Overview.

http://www.andamanmed.com/vietnam-pharmaceutical.html. [March 2016]
} 
promoting local production, the public health implications of policies which influence the development of the pharmaceutical sector need to be considered as well.

\section{Traditional medicines}

42. Traditional medicines are popular and comprise an important segment of local pharmaceutical production. In the Asian Pacific region, traditional medicines ${ }^{38}$ historically enjoy good reputation within the population and occupy a high market share. Given the inconsistent terminology and regulatory status of traditional medicines, it is difficult to precisely assess the size of the market. An estimate of $70-95 \%$ of the population in Africa, Asia, Latin America and the Middle East, use traditional medicine (TM) for primary healthcare. The global market for all traditional medicines (estimated at US\$ 83 billion annually in 2008) is growing, with the Asia-Pacific region the fastest growing markets ${ }^{39,40}$. But efforts to incorporate the knowledge of traditional medicines into modern healthcare and ensure its quality, safety and efficacy standards are not complete. In Thailand, for example, local pharmaceutical manufacturers are categorized in two main groups, 'modern' or traditional medicines producers. As reported by the Thai regulatory authority, despite the GMP requirement for both groups, not all actively producing traditional medicines manufacturers in Thailand comply with international GMP standards and therefore are not GMP certified. Regulation of traditional medicines is a complicated and challenging issue as it is highly dependent upon experience with use of these products. WHO, in cooperation with their Member States, has produced a series of technical documents in this field, including publications on GMP, along with other technical support, to assist with standardization and creation of high quality products $^{41}$.

\footnotetext{
${ }^{38}$ There are different definitions for traditional, complementary, alternative, non-conventional, herbal medicines. In our report, we use the terms interchangeably.

${ }^{39}$ WHO. 2011. The World Medicines Situation $3^{\text {rd }}$ Edition: Traditional Medicines: Global Situation, Issues and Challenges. Geneva: WHO.

${ }^{40}$ SciDevNet. Traditional Medicine for Modern Times: Facts and Figures. http://www.scidev.net/global/medicine/feature/traditional-medicine-modern-times-factsfigures.html [March 2016]

${ }^{41}$ WHO. The World Medicines Situation $3^{\text {rd }}$ Edition: Traditional Medicines: Global Situation, Issues and Challenges.
} 


\title{
PART IV - MEDICINES REGULATION
}

\author{
Why medicines regulation is important
}

43. Medicines are not ordinary articles of commerce, and consumers are not able to independently assess their quality, safety or efficacy. Medicines have implications for the consumers' health and safety if not used properly. They might be ineffective, of poor-quality or even toxic; for example if the dosing of the active ingredient is incorrect or if they contain harmful contaminations. Usually, patients-consumers are not able to independently assess the quality, safety or efficacy of medicines. This differentiates consumption of medicines from consumption of many other goods. As a consequence, patients may buy substandard, ineffective or even toxic medicines, some of them being deliberately falsified ('counterfeit' medicines ${ }^{42}$ ). This is a big issue in many rural areas of developing countries where access to quality-assured essential medicines is still problematic. Also, misuse of medicines such as antibiotics can have serious implications for individual and public health. Antibiotics that are not dosed correctly for eradication, can result in drug-resistance. Regulation needs to address the various steps from manufacturing to consumption of medicines.

44. The key objective of regulating medicines is to ensure safety and efficacy of medicines on the market, in order to ensure and promote public health. Medicines of uncertain quality, safety and efficacy can be worse than no treatment at all $^{43}$. Medicines regulations are the legal, administrative, and technical measures to ensure the safety, efficacy, and quality of medicines, as well as the relevance and accuracy of product information.

Figure 6: Key objectives of medicines regulation

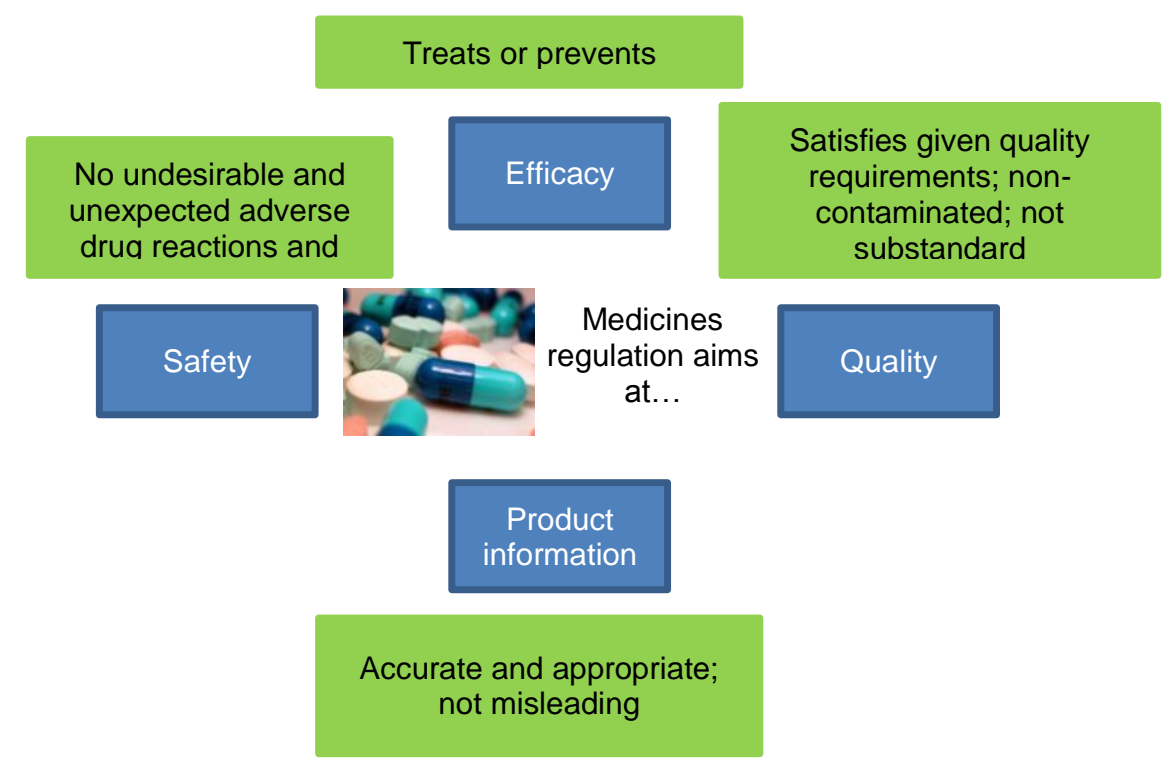

\footnotetext{
${ }^{42}$ WHO differentiates between substandard, spurious, falsely labelled, falsified and counterfeit (SSFFC) medical products; WHO. 2016. Substandard, spurious, falsely labelled, falsified and counterfeit medical products factsheet. http://www.who.int/mediacentre/factsheets/fs275/en/ ${ }^{43}$ Rago L. 2014. "Regulatory framework for access to safe, effective and quality medicines". Antiviral Therapy 19 Suppl 3:69-77. doi: 10.3851/IMP2902.
} 
45. The key role of medicines regulators is to act as gatekeepers and enablers. Medicines regulation is a complex process that includes several activities all aimed at protecting and promoting public health. Medicines regulators face two distinct objectives: first, an obligation to protect patients against ineffective or harmful medicines, and second, to protect patients against the consequences of untreated disease. The first objective results in a gatekeeper function. Regulators need to enforce stringent standards of assessment and - where necessary - need to deny marketing authorization for unsuitable products. By contrast, the second objective requires regulators to support and enable medicines research and development - ensuring that patients have access as early as possible to safe and effective medicines ${ }^{44}$.

46. Effective regulation of medicines thus requires that NMRAs have the capacity and capability to fulfill their regulatory obligations. The required activities and key capabilities of regulatory authorities generally include the functions listed in Table 6 below. For many countries, the main problem is the lack of an adequate qualified and skilled human resource base to carry out their regulatory functions. The scarcity of trained pharmaceutical professionals, a shortage of training institutions, and 'brain drain' all contribute to this problem.

Table 6: Medicines regulatory functions and capabilities

Regulatory function

License the manufacture, import, export, distribution, promotion and advertising of medicines

Issue marketing authorization for products

Inspect manufacturers, importers, wholesalers, and dispensers of medicines

Control and monitor the quality and safety

of medicines on the market, collect and analyze reports on adverse events

Control promotion and advertising of medicines

Provide independent information on medicine to professionals and the public

\section{Capability required}

Ensure that all activities and premises comply with Good Manufacturing Practices and other good practices

Before medicines are marketed, assess their safety, efficacy, and quality Control the manufacturing units and supply chain, including informal market and ecommerce to prevent illegal trade of medicines

Prevent harmful, substandard and counterfeit medicines from reaching the public

Prevent misleading information from reaching the public and health professionals Prevent irrational use of medicines

Source: Rago et al, 2014

47. In addition to technical capabilities, NMRAs also need a robust institutional setup that enables them to carry out their regulatory functions effectively. These institutional arrangements can vary across countries: in some countries, for example, all functions related to medicines regulation come under the jurisdiction of one single regulatory authority. In other countries, medicines regulatory functions are assigned to two or more agencies, at either the same or different levels of government. Nonetheless,

\footnotetext{
${ }^{44}$ Muellner M. et al. 2010. "Current issues in drug regulation" in Clinical Pharmacology: Current Topics and Case Studies. Vienna: Springer-Verlag.
} 
certain common criteria need to be fulfilled within an NMRA to enable effective medicines regulation. These criteria include ${ }^{45}$ :

- A clear mission

- Adequate medicines legislation and regulation

- Appropriate organizational structure and facilities

- Clearly defined roles and responsibilities

- Adequate and sustainable financial resources

- Appropriate tools, such as standards, guidelines and procedures;

- Cooperation and collaboration between NMRAs and other stakeholders;

- Accountability and transparency; and

- A good management system

Especially in low income countries, shortage of capacities in terms of personnel, technical infrastructure and financial resources result in less effective regulatory oversight - a problem that transcends national borders and has global implications ${ }^{46}$.

48. Using a comprehensive NMRA assessment tool, WHO works with countries worldwide in assessing their national regulatory systems to identify gaps, develop strategies for improvement and support countries in their commitment to build national regulatory capacity. According to $\mathrm{WHO}$, regulation of human medicinal products has four dimensions: administrative elements, regulatory functions, technical elements and level of regulation. This framework, as depicted in Figure 7 below, allows for comparison of medicines regulation across countries.

Figure 7: Framework with key component of medicines regulation

\section{Administrative elements}

- Policy

- Human Resources

- Finances

- Infrastructure

\section{Regulatory functions}

- Licensing of pharmaceutical premises, practices and key personnel

- Inspection of pharmaceutical manufacturers and distributors

- Assessment of pharmaceutical products and product

- Monitoring of medicines quality

- Control of medicines advertising and promotion

- Monitoring of adverse drug reaction
Technical elements

- Standards

- Specifications

- Guidelines

- Procedures

\section{Regulation level}

- Central

- State/province

- District

- Community

Source: WHO, Effective Drug Regulation, 2002

\footnotetext{
${ }^{45}$ WHO. 2003. Effective Medicines Regulation: Ensuring Safety, Efficacy and Quality. Geneva: WHO.

${ }^{46}$ lbid.
} 


\section{PART V - REVIEW OF SELECTED NATIONAL MEDICINES REGULATORY AUTHORITIES IN ASEAN}

49. A critical factor in effective medicines regulation is the capacity and capability of NMRAs to effectively conduct their regulatory tasks. Limited capacity and capability of regulators can lead to inadequate controls on the safety and efficacy of medicines that are allowed onto the market, and have an adverse impact on public health. Furthermore, delays and backlogs in the registration of essential medicines hinder timely access to quality-assured medicines. Pooling resources through cooperation and harmonization could therefore improve regulatory oversight by NMRAs. Effective harmonization, however, only takes place where there is trust across NMRAs in each other's capabilities and decisions, and where NMRAs can cooperate at similar levels of capacity. If there is a marked difference in capacity among the NMRAs, harmonization moves at different paces in different countries.

50. This section provides a comparative analysis of selected NMRA functions in the five ASEAN countries included in the study, using an adapted version of the WHO NMRA assessment tool mentioned above. We first look at the overall legal framework in which harmonization activities take place, and then focus on two key regulatory functions: marketing authorization and inspection for Good Manufacturing Practice (GMP) of pharmaceutical producers. The information presented is largely based on interviews with relevant stakeholders in the pharmaceutical sectors of these countries.

\section{Legal framework}

51. Legal basis for medicines regulation exists in all five countries. All five countries in the analysis have national medicines policies in place. The policies vest the responsibility for regulating medicines with the government. Important common elements in these policies include controlling the quality, safety and efficacy of medicines. The functions of the NMRAs in the region, as stipulated in their legislation, include but are not restricted to pre-marketing assessment, licensing and accreditation, post market surveillance. The regulators oversee regulation of medicinal products including vaccines and biological products, and also traditional medicines, cosmetics and foodstuff, in some instances. In Thailand and Philippines, the NMRAs also regulate medical devices.

52. However, medicines regulatory harmonization is not yet part of the legal frameworks of ASEAN member states. The ASEAN Charter, which came into effect in 2008, turned ASEAN into a legal entity and aimed to establish the institutional framework for further development of the ASEAN community. The ASEAN Economic Community (AEC) seeks to create ASEAN as a single market and production base and an economic region by 2020. One important stream of work that has been identified by ASEAN is the establishment of a free trade area, which necessitates the removal of technical barriers to trade to enable free flow of goods - including pharmaceuticals - in the region. Several ASEAN bodies are involved in the harmonization of technical requirements on health products, including the ASEAN Consultative Committee on Standards and Quality (ACCSQ) - and specifically the ACCSQ's Pharmaceutical Product Working Group (PPWG) - the Traditional Medicines and Health Supplements Product Working Group (TMHS PWG), and the ASEAN Traditional Medicines and Health Supplement Scientific 
Committee (ATSC). Details on the PPWG will be provided in Part VI. The overall direction is thus towards greater regional integration and regulatory harmonization. At present, however, there is no legally binding obligation across ASEAN for medicines regulatory harmonization. Each member state has its own legal framework for medicines regulation, separate from those of other ASEAN member states. Regulatory principles and frameworks established under the auspices of ASEAN require implementation through individual countries, in line with the national laws of ASEAN member states.

\section{Technical capabilities}

53. There have been substantial harmonization efforts on two key regulatory functions (as listed in Table 6 above): (i) Issuing marketing authorization for pharmaceutical products, and (ii) Inspecting manufacturers of pharmaceutical products. There has been some - but much less - harmonization on pharmacovigilance and quality assurance. Functions such as advertising, domestic inspections, and promoting rational use of medicines remain squarely under the purview of individual regulators. We thus focus on the key technical capabilities that NMRAs require in order to perform their regulatory functions of issuing marketing authorization and inspecting manufacturers. These can be indicative of the overall technical capabilities of each NMRA. Further analysis into all regulatory functions would be needed to obtain a complete picture of the NMRAs' capabilities, and is beyond the scope of this study.

54. Our analysis finds there have been significant successes but also impeding factors that influence effective marketing authorization and the inspection functions of NMRAs in the region. The regulators in the region have developed and implemented proper and clear technical guidelines for the registration of medicines. ASEAN has adopted the ASEAN Common Technical Document (CTD) for the submission of dossiers to apply for medicines registration. ASEAN CTD is based on the $\mathrm{ICH}$ model and regulators in all five countries require submissions of prescription medicines to follow this format. The ACTD and its registration process are currently paper-based, which implies that it involves a burdensome manual process, but there are plans for transitioning to an electronic submission system. The NMRAs have technical committees that assess applications for the registration of pharmaceutical products.

55. Across the NMRAs we surveyed, the most significant constraints are related to limited human resources and technical expertise. This includes inadequate experience in specialized areas such as new products and traditional medicines regulation. Regulators in the region report technical capacity gaps in evaluating dossiers of new chemical entities and biologicals products, as well as in assessing clinical trials and BA/BE testing. Due to a lack of in-house capacity, the NMRAs often use external experts for regulatory functions. In Thailand and the Philippines, for example, regulators largely rely on external evaluators, particularly for evaluating new products and bioequivalence. There is also consultation and close cooperation with academia for specialized evaluations. In Vietnam, the Drug Administration of Vietnam (DAV) is understaffed for evaluating dossiers. There is a high reliance on external experts who serve on an evaluation committee for product registration. However, feedback suggests that it continues to be difficult to efficiently and effectively evaluate registration applications based on sound scientific evidence, on a routine and regular basis, conducted by a permanent cadre of well-trained staff. 
56. On GMP inspections, the NMRAs in Malaysia and Indonesia are regarded to have relatively robust processes, followed by Thailand, Philippines and Vietnam. PIC/S membership (see Box 2) can be seen as an indicator of GMP inspection capabilities of regulators. Malaysia achieved PIC/S membership in 2002; Indonesia became a PIC/S member in 2012. As such, manufacturers in these countries need to comply with $\mathrm{PIC} / \mathrm{S}$ requirements to be GMP certified. This has helped to raise the bar of the quality of manufacturing in Malaysia and Indonesia, and is a step towards ensuring that manufacturers are producing and putting out quality-assured pharmaceuticals

onto the market. Thailand and Philippines are currently applying for PIC/S membership for the second time and expect evaluation within 2016. Thailand is improving in its capabilities for inspecting traditional medicines manufacturers, while the Philippines is working on improving existing personnel and database constraints. The DAV in Vietnam has not applied for PIC/S membership yet, but plans to do so in the near future.

57. Nonetheless, there are challenges in enforcing compliance with GMP standards. In all five countries, local manufacturers are inspected periodically on a riskbased approach to supervise the implementation of adequate GMP. To varying extents, the NMRAs also inspect factories outside their borders as part of the registration process. A key constraint across the countries, however, is with GMP inspection capabilities and capacity for biological products and Active Pharmaceutical Ingredients (APIs). Similarly, regulators have limited expertise and bandwidth for inspections on Good Clinical Practice. The DAV in Vietnam, for example, currently has only about 10 GMP inspectors, which is insufficient to carry out GMP inspections of all manufacturing sites, both in-country and abroad. Feedback suggests that a substantial increase in staff strength - with adequate training and expertise - would be needed in order to have sufficient capability and capacity for an adequate GMP inspection regime.

58. Table 7 below summarizes the findings on marketing authorization and GMP inspections. 
Table 7: Comparative review of 5 ASEAN NMRAs

\begin{tabular}{|c|c|c|c|c|c|}
\hline $\begin{array}{l}\text { Regulatory } \\
\text { capability } \\
\text { required } \\
\end{array}$ & Indonesia & Malaysia & Philippines & Thailand & Vietnam \\
\hline $\begin{array}{l}\text { Regulatory } \\
\text { agency }\end{array}$ & $\begin{array}{l}\text { National } \\
\text { Agency } \\
\text { of Drug \& } \\
\text { Food } \\
\text { Control }\end{array}$ & $\begin{array}{l}\text { National } \\
\text { Pharm } \\
\text { Control } \\
\text { Bureau }\end{array}$ & $\begin{array}{l}\text { Bureau } \\
\text { of Food \& } \\
\text { Drugs }\end{array}$ & Thai FDA & $\begin{array}{l}\text { Drug } \\
\text { Administration } \\
\text { Vietnam } \\
\text { (DAV) }\end{array}$ \\
\hline $\begin{array}{l}\text { Human } \\
\text { resources } \\
\text { (approximate } \\
\text { numbers) }\end{array}$ & $\begin{array}{l}4400 \\
\text { employees } \\
\text { in } 2015\end{array}$ & $\begin{array}{l}388 \\
\text { employees } \\
\text { in } 2014\end{array}$ & $\begin{array}{l}500 \\
\text { employees in } \\
2016 \text { with } \\
\text { approval to } \\
\text { hire } 250-300 \\
\text { more staff } \\
\text { mainly for the } \\
\text { field } \\
\text { inspection } \\
\text { operations }\end{array}$ & $\begin{array}{l}652 \\
\text { employees in } \\
2015\end{array}$ & $\begin{array}{l}\text { No concrete } \\
\text { number } \\
\text { available. } \\
\text { Largely } \\
\text { understaffed, } \\
\text { especially in } \\
\text { the field of } \\
\text { GMP } \\
\text { inspections }\end{array}$ \\
\hline \multicolumn{6}{|c|}{ Regulatory function: Issue marketing authorization for products } \\
\hline $\begin{array}{l}\text { Dossier } \\
\text { submission }\end{array}$ & \multicolumn{5}{|c|}{$\begin{array}{l}\text { ASEAN CTD format (based on ICH requirements except stability due to climatic } \\
\text { zone) }\end{array}$} \\
\hline \multicolumn{6}{|c|}{ Regulatory function: Inspecting manufacturers of pharmaceutical products } \\
\hline $\begin{array}{l}\text { GMP } \\
\text { inspections }\end{array}$ & \multicolumn{5}{|c|}{$\begin{array}{l}\text { Regulations allow inspections to be carried out in pharmaceutical manufacturing } \\
\text { facilities, according to GMP inspection plans based on risk-based approach. } \\
\text { Critical constraints are with staff strength and expertise in conducting } \\
\text { inspections. }\end{array}$} \\
\hline $\begin{array}{l}\mathrm{PIC} / \mathrm{S} \\
\text { membership }\end{array}$ & $\begin{array}{l}\mathrm{PIC} / \mathrm{s} \\
\text { Member } \\
\text { since } 2012\end{array}$ & $\begin{array}{l}\mathrm{PIC} / \mathrm{s} \\
\text { Member } \\
\text { since } 2002\end{array}$ & $\begin{array}{l}\text { 2nd } \\
\text { application, } \\
\text { next } \\
\text { evaluation } \\
\text { expected in } \\
\text { Q2, } 2016\end{array}$ & $\begin{array}{l}\text { 2nd } \\
\text { application, } \\
\text { next } \\
\text { evaluation } \\
\text { expected in } \\
\text { Q1, } 2016\end{array}$ & $\begin{array}{l}\text { No application } \\
\text { yet }\end{array}$ \\
\hline
\end{tabular}

59. Notably, several ASEAN regulators meet the standards of a stringent regulator for vaccines, despite substantial gaps in the institutions' overall capacity and capability. WHO has assessed vaccines management standards in Thailand, Indonesia and - just recently in June 2015 - Vietnam. The NMRAs of these three countries have been certified as stringent regulators for vaccines, which is considered to be a big achievement. All three countries have active local vaccines production, and meeting international vaccine management standards enables countries to export their vaccines. This highlights that the economic and trade imperatives continue to influence domestic production of medicinal products and vaccines in particular. Malaysia and Philippines do not actively produce vaccines.

\section{Institutional capacity}

60. In addition to technical capabilities, institutional capacity is a more general constraint for many regulators in the region. The key institutional capacity constraints 
identified by regulators range from the availability of inputs and resources such as funding and personnel, to adequate institutional structures. There is also a need to better allocate and utilize resources to avoid delays and backlogs, and in part, more efficient fee structuring can help to manage the flow of applications to each NMRA (see paragraph 79).

61. More fundamentally, the development of NMRAs as robust, sustainable institutions has been challenging. NMRAs often do not have the long term business and strategic plans for their institutions. Feedback from the Philippines, for example, points towards the need for more work to be done to support the regulator's institutional structure and capacity development for the long term. In the regulator's view, this would be preferable to - but not mutually exclusive with - technical capacity building on specific regulatory processes and functions. More broadly, having a clear medium to long term development plan, objectives and targets, and defined improvement processes to achieve these objectives would help each NMRA to progressively build institutional strength that will be sustainable into the future. An underlying challenge is the shortage of human resources. As mentioned above, Vietnam, for example, has insufficient capacity for inspections. In the Philippines, hiring rules result in up to 50 percent of personnel hired on short 6 month contracts. This system prevents the development of a pool of qualified and experienced staff as there is substantial brain drain to the pharmaceutical industry (private sector), and staff have low job loyalty due to the uncertainty that is inherent in the terms of contract. Developing NMRAs into robust and sustainable organizations will require substantial improvements in long term institutional planning, changes in staffing norms and procedures, and capacity building.

\section{Key capacity development needs for regulators and pharmaceutical industry}

62. The need for improvements in technical capabilities and institutional capacity are not limited to regulators. Pharmaceutical industry players would similarly benefit from capacity development. In fact, key areas of capacity development needs are similar across industry and regulators. Interviews with regulators and manufacturers in Vietnam, Philippines and Thailand revealed that many manufacturers would benefit from technical capacity building on GMP, in order to upgrade to PIC/S standards. In Thailand in particular, feedback suggests that there are substantial capacity development needs for traditional medicines manufacturers with regard to GMP compliance, and for GMP inspection capacity on the regulator's side. In all five countries, representatives from industry, associations, and regulators suggested that capacity development in the following areas would be beneficial: Good submission practices, including dossier preparation according to ACTD and e-submissions; good review practices, clinical trials and $B A / B E$ testing, reporting and assessment; R\&D and new technologies; and improved pharmacovigilance including introduction of a risk management plan (RMP). Figure 8 summarizes capacity development needs for regulators and industry in the region. 
Figure 8: Key capacity development needs for regulators and industry in the region

\begin{tabular}{|l|}
\hline \multicolumn{1}{|c|}{ Industry } \\
\hline - Good Submission \\
Practices \\
-Dossier preparation - for \\
ACTD and e-submission \\
-Technical support for \\
GMP upgrade to PIC/s \\
standards \\
-BA/BE requirements \\
\end{tabular}

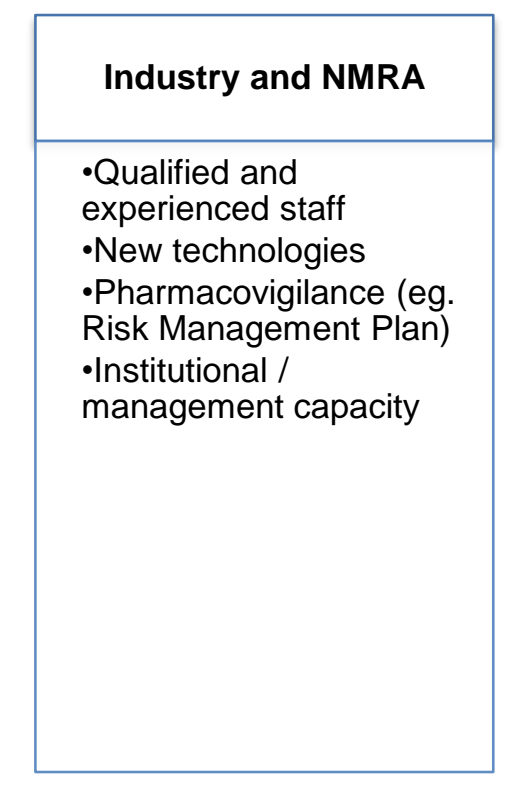

\begin{tabular}{|l|}
\hline \multicolumn{1}{|c|}{ NMRA } \\
\hline - Good Regulatory Practice \\
- priority setting to \\
overcome backlog in \\
applications \\
- GMP inspections \\
especially on biological \\
products, APIs, and \\
overseas inspections, \\
Good Clinical Practice \\
inspections \\
- Good Review Practices \\
- Review/assessment of \\
BE/BA reports, new \\
chemical entities, \\
biosimilars and biologicals \\
products \\
\hline
\end{tabular}

63. Capacity development especially in new technologies is needed for the pharmaceutical sector to move up the value chain. There is a move toward biopharmaceuticals compared to the traditional, synthetic chemistry-based small molecules. Global sales of biopharmaceutical products were US $\$ 154$ billion in 2012, with some analysts forecasting an increase to over US $\$ 200$ billion by $2018^{47}$. Many major pharmaceutical companies are moving towards biotechnology and biopharmaceutical development. In turn, this means that regulators worldwide need to be prepared with the knowledge and skills to regulate these new technology products. Box 2 below outlines the complexity of biopharmaceutical production. To date, the ASEAN pharmaceutical industry and regulators are largely inadequately equipped to join this new field of biopharmaceuticals; it is an increasingly important area for capacity development.

\footnotetext{
${ }^{47}$ BioPharmaceuticals Australia. Biopharmaceuticals. http://www.biopharmaus.com.au/biopharmaceuticals/ [March 2016]
} 
Box 2: Complexity of biopharmaceuticals requires skilled experts in industry and regulatory agencies

Biopharmaceuticals are proteins and other compounds produced by living organisms that have uses as therapeutics or in vivo diagnostics. Biopharmaceutical production is highly sophisticated - a molecule of aspirin, for example, consists of 21 atoms. A biopharmaceutical molecule however, might contain up to 25,000 atoms. To produce these therapeutic molecules, genetically modified living cells must be frozen for storage, thawed without damage, and made to thrive in the unusual environment of a reaction vessel. Carefully, without destroying their complex and fragile structures, the therapeutic molecules must then be separated from the cells and the media in which they were produced.

Highly skilled experts are needed for production and costs are high, with long process durations, low yields, expensive raw materials, and costly production facilities. As patent protection on more complex biopharmaceuticals expires, the 'biosimilar' industry with 'almost identical copies of original products' will further develop.

Many large international pharmaceutical companies are currently shifting their presence to biopharma. Biopharmaceutical production in Southeast Asia is still largely in its infancy, mainly due to lack of personnel and technical resources. Increasingly, however, there is a trend towards more investment in R\&D and new technologies including biosimilar production in the region.

Sources: McKinsey. 2014. Rapid Growth in Biopharma: Challenges and Opportunities.

\section{Regulatory outcomes}

Registration timelines

64. Technical expertise and institutional capacities strongly influence the registration process and timelines required. Medicines registration is a system that subjects all medicinal products to pre-marketing evaluation, marketing authorization, and post-marketing review to ensure that they conform to required standards of quality, safety, and efficacy established by the respective national authorities. The outcome of the medicines registration process is the issuance or the denial of a pharmaceutical product marketing authorization or license ${ }^{48}$.

65. Registering a pharmaceutical product can take up to four years in the countries included in this analysis. According to official NMRA estimates and publicly available data, registration timelines are similar to international timelines: they range from 150 to 254 days for new generics and up to 365 days for new chemical entities and biological products (Figure 9). To compare these data with other markets: the EU centralized procedure (which is compulsory for biotech products and new chemical entities) entails a single application, evaluation process and marketing authorization that is valid throughout the EU. There is a set timeline of 210 days for the evaluation process,

\footnotetext{
${ }^{48}$ WHO. 1998. How to Implement Computer-Assisted Drug Registration - A Practical Guide for Drug Regulatory Authorities. Regulatory Support Series No. 002, 1998
} 
followed by a decision-making process, and authorization approximately 2 months later ${ }^{49,50}$. In practice, however, the ASEAN experience has been that registration can take up to four years. This large gap between official and actual registration timelines could in part be because there may need to be several rounds of clarifications between the regulator and applicant, during which a "stop clock" system is used by one party but not the other. However, in some instances even the registration or re-approval of generic products could take a long time. In this case, the delay is more likely to be due to the backlog of applications that regulators have to cope with.

Figure 9: Official medicines registration timelines, 2015

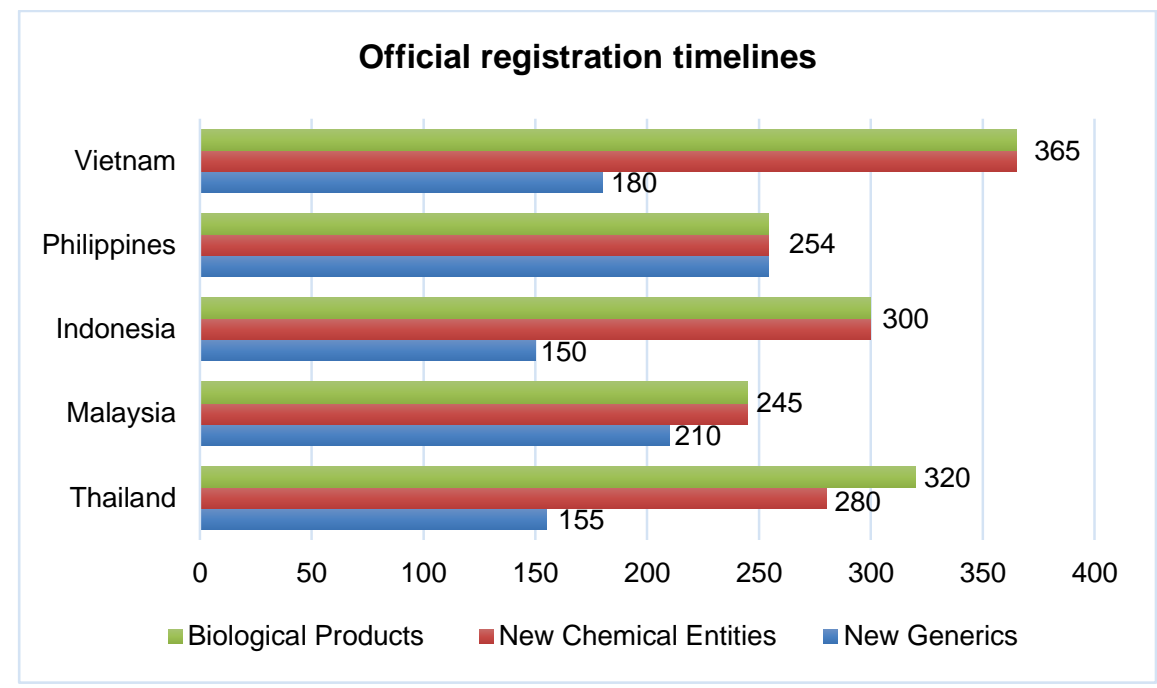

66. Recent developments among some ASEAN regulators have helped to reduce registration timelines. In 2015, Thailand introduced a facilitating Act for more transparency in licensing processes. After an application for medicines registration has been accepted, the Thai FDA cannot stop the clock any more to ask for additional information from manufacturers, whereas previously there were frequent clock stops and applications even for generics usually took 2 to 3 years. Under this system, the Thai FDA is obliged to register the product within a stipulated number of days of the application being accepted. This makes the registration process more transparent, as the clock cannot stop for a long time during the application review process, as it did before. Another positive achievement towards faster registration procedures is the Philippines FDA's use of the WHO-CRP (Collaborative Registration Procedure since 2015 (see Box 4 in Part VI for more details). This abridged procedure shows how a country can effectively use data that is openly available to regulators to make their work more efficient.

\footnotetext{
${ }^{49}$ European Commission. The Centralised Procedure. http://ec.europa.eu/health/authorisationprocedures-centralised en.htm [March 2016]

${ }^{50}$ Korakianiti, E. "Marketing Authorisation: The Evaluation Process" (presentation at $1^{\text {st }}$ EMEA Workshop for Micro, Small and Medium-Sized Enterprises). http://www.ema.europa.eu/docs/en GB/document library/Presentation/2009/10/WC500004235.p df [March 2016]
} 
Application backlog

67. It is also common among regulators in the region to experience a flood of submissions and suffer from severe backlog. Mainly due to insufficient number of staff and lack of expertise in specialized areas, as discussed above, some NMRAs cannot cope with all the applications and suffer from severe backlog. Malaysia received more than 48,000 applications in 2014, while the Philippines reports about 12,000 applications per year including renewals. In the Philippines, there are approximately 9000 applications that are queuing for evaluation, 50 percent of which are renewals which must be done once every three years - rather than registration of a new product.

68. There are several possible and related reasons for the large number of applications for marketing authorization and the backlog that results from it. First, several countries surveyed do not have sufficient controls on the number of products they are willing to put on the market. As an example - data suggest that there are more than 900 registered local paracetamol containing products in Vietnam, and more than 700 in Indonesia. This is a significantly higher number of registered products for the same molecule compared to the German market for example, where there are roughly 170 paracetamol containing products on the market ${ }^{51}$. Even within the region and among our countries of analysis, there are good examples of stricter controls on the number of identical products on the market: Thailand has 120, and Malaysia has just 24 (Figure 10). While in theory there may be good reasons for allowing broad product choice, in practical terms, a reasonable limit on the number of identical products registered would enable NMRAs to better control the market, and also reduce the number of applications they need to process. This improves regulatory control while simultaneously reducing regulatory burden.

Figure 10: Number of paracetamol containing products, 2016

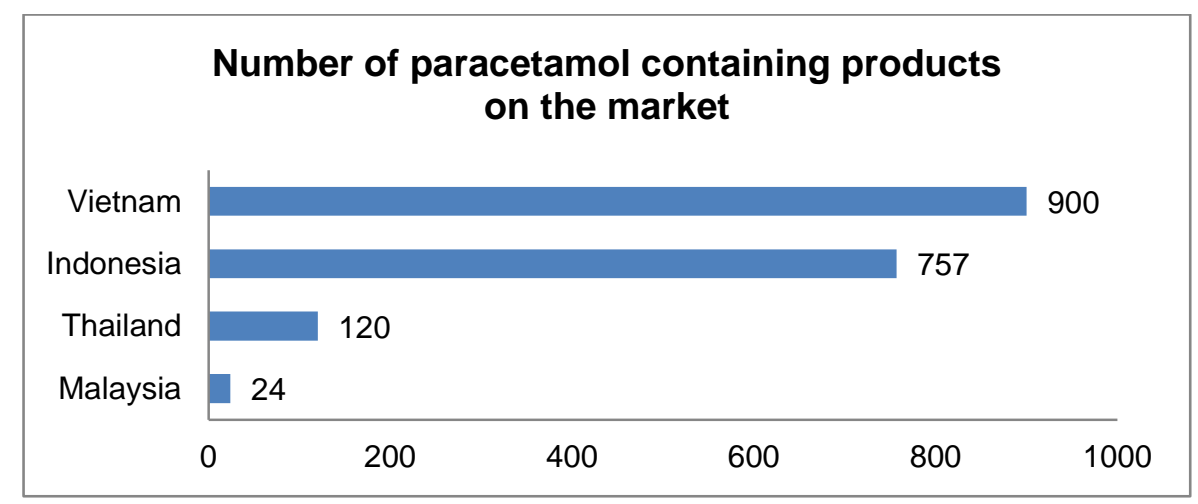

69. Second, low registration fees may contribute to the high volume of applications. NMRA fee structuring systems differ from regulator to regulator. They can be considered in two parts: contributions from government, and revenue generated from fees for services rendered. More advanced regulators have tended towards having more of their budget from fees, and a smaller share from government budget. In particular, the

${ }^{51}$ German data: www.aponet.del [March 2016], Vietnam data: anecdotal evidence, Indonesia data: http://cekbpom.pom.id [March 2016] and Malaysian data: http://quest3.bpfk.gov.my [March 2016]. 
fee for registering a new product contributes to the overall high cost of developing medicines. In the EU, for example, the basic fee for registering a medicinal product for human use via the centralized procedure is 278,800 EUR (approximately US $\$ 317,414$ ) for a single strength associated with one pharmaceutical form and one presentation. This centrally-authorized product may then be marketed in all EU member states. The US FDA's 2015 fee structure ranges from US $\$ 110,370$ for annual product registration, to US $\$ 2,335,200$ for a new application (with clinical data) ${ }^{52}$. Compared to this, the registration fees in Indonesia, Malaysia, Philippines, Thailand and Vietnam seem very low. In Thailand, the registration fee for new chemical entities as well as for generic products is only about US\$ 65 , and this registration provides life-long validity, with no need for re-evaluation on a periodic basis as in other countries. Registration fees for the five countries in our analysis are shown in Figure 11, where even Indonesia's fee of US $\$ 2000$ is low relative to the EU and US FDA prices. It is therefore not surprising that manufacturers in the region are not deterred by registration costs: anecdotal evidence suggests that there are duplicates of the same generic application that come in from the same applicant, with only differing proprietary names. Even manufacturers in the region indicate their willingness to pay more registration fees, provided that paying this higher price contributes to an improvement in efficiency in the registration processes. There is thus an opportunity to revise fee schedules in tandem with upskilling NMRAs, in order to improve overall regulatory outcomes.

Figure 11: Fees for medicines registration, 2015

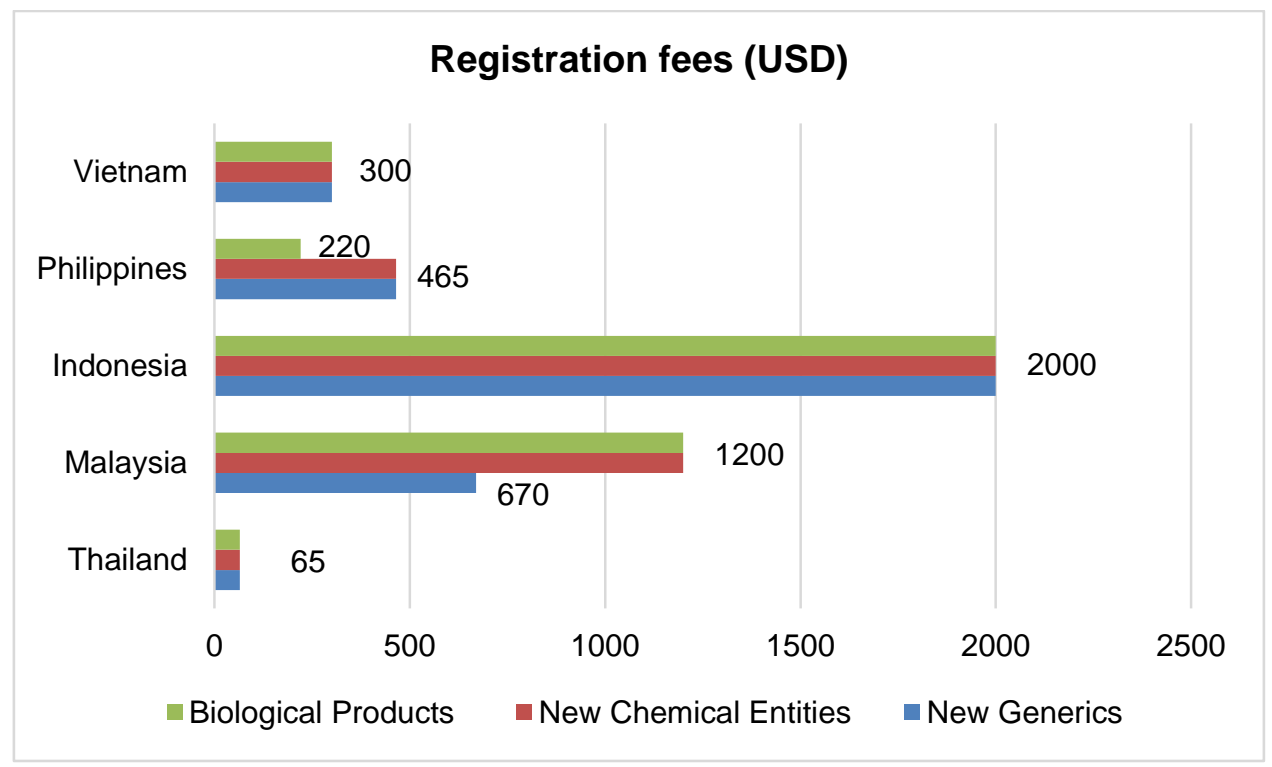

Access to innovative medicines

70. Ultimately, the most important regulatory outcome is improved access to medicines. ASEAN continues to face a challenge in this area, especially for innovative

\footnotetext{
${ }^{52}$ Regulatory Affairs Professional Society. 2014. FDA Announces all User Fees to be Paid by Pharma, Device Industries in 2015. http://www.raps.org/RegulatoryFocus/News/2014/08/01/19930/FDA-Announces-all-User-Fees-to-be-Paid-by-Pharma-DeviceIndustries-in-2015/ [March 2016]
} 
medicines: ASEAN countries obtain innovative medicines more than 3 years after global introduction. The time from drug discovery to marketing of new chemical entities or vaccines takes around 10-15 years, including the time for clinical trials. Patient access to innovative medicines in ASEAN, however, takes much longer. Vietnam is the country with the longest 'drug lag' across the five countries, averaging 5.6 years. Delays in the other four countries range from 3.2 years in Malaysia to 3.7 years in Philippines (see Figure 12). As a comparison, the relative 'drug lag' from US FDA approval to country approval in BRICS and $\mathrm{N}-11$ countries is approximately 1.5 years ${ }^{53}$.

71. This lag may be for several reasons. In some instances and for some products, manufacturers may not apply for registration in ASEAN markets until several years after the product is introduced in its country of origin. The underlying reasons for the decision not to register a product may differ across companies and products. One deterrent, however, could be additional regulatory requirements. Up till recently, for example, Vietnam required a local clinical trial to be conducted for new chemical entities that had been registered in their country of origin for less than 5 years. This meant that most manufacturers only attempted to register their product in Vietnam after the initial 5 year period, in order to avoid having to fulfil this requirement and incur more costs. Based on discussions with the DAV, the intention is to remove this stipulation. A more general constraint, however, relates to the overall capability and capacity of the NMRAs, as outlined above. When applications for these innovative medicines come in, NMRAs often face technical challenges in evaluating them, and take a long time to process the registrations. Improving regulatory processes - in terms of speed and quality - can help to reduce the time lag for registration of innovative medicines, and thereby improve access to these medicines for ASEAN populations.

Figure 12: Average lag in introduction of innovative medicines onto ASEAN markets

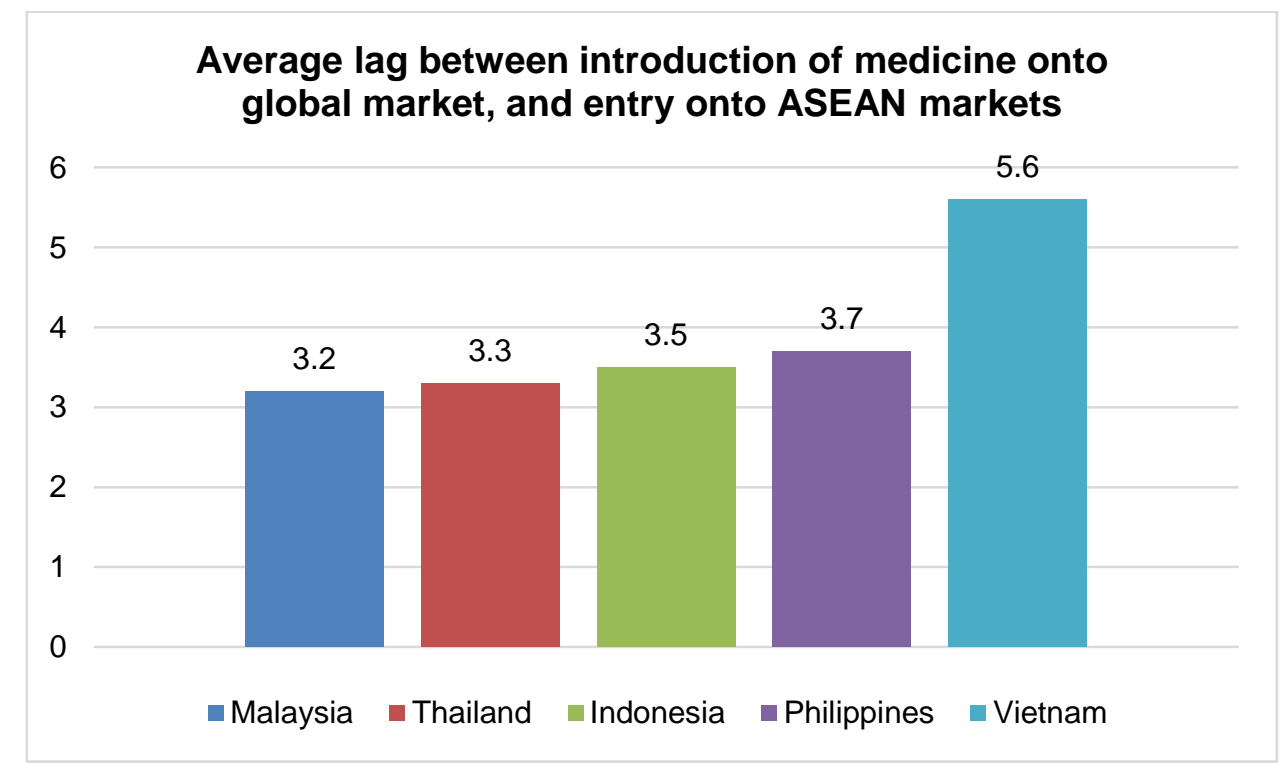

Source: Eurocham, Whitebook, 2016

\footnotetext{
${ }^{53}$ Wileman, H. and A. Mishra. 2010. "Drug Lag and Key Regulatory Barriers in the Emerging Markets”. Perspect Clin Res. Apr-Jun; 1(2): 51-56.
} 
72. Countries use special mechanisms to compensate for their slow regulatory processes and lack of innovative medicines on the market, especially in emergency situations. "Expanded access" or "compassionate use" is a treatment option that allows the use of an unregistered medicine. Under strict conditions, products in development or not registered in a specific country / region can be made available to groups of patients who have a disease with no satisfactory authorized therapies and who cannot enter clinical trials ${ }^{54}$. While several countries have included compassionate use in their national drug laws, it is important to note that compassionate use is granted as an exception and needs to be in line with adequate risk management. However, in response to slow national registration processes and lags in access to certain innovative medicines, some countries, such as the Philippines, now have a high number of compassionate use cases for unregistered medicines. If the national registration of a promising innovator medicine is not yet cleared, applications for compassionate use will be submitted, thereby circumventing the normal registration process. In Indonesia, a special access scheme also exists for medicines from donors, medicines for clinical trials and medicines to treat special conditions that have yet to be registered in the country. Similar to the Philippines, these medicines are allowed in under strict conditions, such as when the disease is serious and life-threatening, currently available medicines are not able to treat or control patients' conditions adequately or when the medicine's marketing authorization is halted for some reason ${ }^{55}$. While there may be reasons for special mechanisms to continue to be used in the long term - such as for rare diseases - the use of this channel as a workaround to the normal registration process is not a sustainable solution. Rather, the way forward is to improve the capacity of NMRAs to be more efficient in their registration process.

\footnotetext{
${ }^{54}$ EMA definition of compassionate use, see http://www.ema.europa.eu/

${ }^{55}$ Government of Indonesia. 2002. Keputusan Kepala BPOM No. HK.00.05.3.00914 Tentang Pemasukan Obat Jalur Khusus Year 2002.
} 


\title{
PART VI - FRAMEWORK FOR MEDICINES REGULATORY HARMONIZATION
}

\author{
The case for regulatory cooperation and collaboration
}

73. With the globalization of pharmaceutical production and trade and the growing complexity of medicinal products, it has become increasingly challenging for NMRAs to perform their regulatory tasks. Medicinal products are increasingly global commodities, with complex and internationally integrated manufacturing and distribution supply chains. As an example: a German finished pharmaceutical product may be produced using an active pharmaceutical ingredient made in China and excipients made in Europe, Japan or the US. These components may be shipped to India where the finished pharmaceutical product is manufactured and then imported into Germany for distribution. Regulators need to know these supply chains and provide regulatory oversight at all stages. Figure 13 below summarizes challenges that regulators worldwide are facing: besides ubiquitous financial and technical resource constraints, NMRAs need to be prepared to oversee increasingly complex medicinal products including research and development, supply chains, production, marketing, and trade.

Figure 13: Challenges for medicines regulators

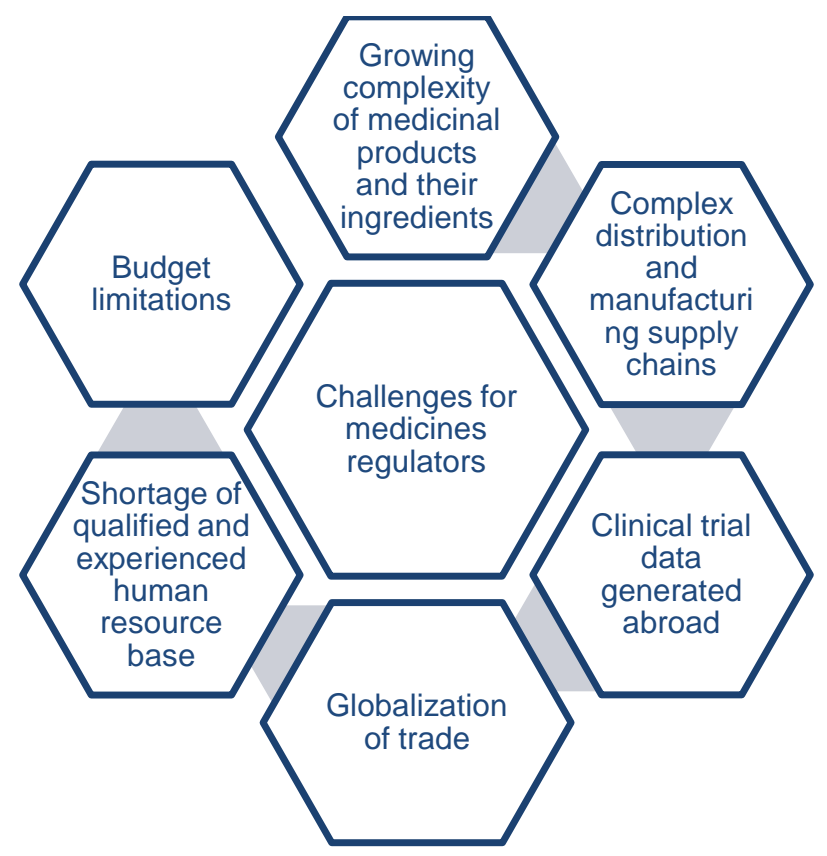

74. Nowadays, no regulator can work in isolation any longer ${ }^{56}$. Without effective regulatory cooperation and division of labor, regulatory authorities cannot cope with the new global challenges and fulfil their objective of protecting and promoting public health. Indeed, without regulatory cooperation, individual national regulation may even become

${ }^{56}$ WHO. 2014. WHO Drug Information Vol. 28 No. 1. 
a barrier to access. Many regulators worldwide are lacking technical and financial resources to rapidly yet rigorously review new medicines to determine their safety, efficacy, and quality. The standard challenges include bureaucracy, inefficiencies, lack of resources, and in some countries political backlash. As a result, many regulators experience severe backlog in applications as they cannot cope with their increasingly complex regulatory tasks. In some cases, regulators would rather let applications for innovator medicines pile up than risk letting unsafe medicines onto the market ${ }^{57}$. At the end of 2014, for example, over 18,500 drugs were queuing for approval in China. This backlog included bedaquiline, a critically important innovative medicine used to treat multidrug-resistant tuberculosis for people without other safe, effective treatment options. This underscores the importance of regulatory cooperation and harmonization especially in highly specialized areas where inefficiencies in lags in medicines approval processes are proving disastrous for public health.

75. There are strong arguments in favor of cooperation and collaboration on medicines regulation, both from the theoretical and practical perspectives. From the theoretical perspective, cooperation on medicines regulation enables regulators to "level up" to best practices and international standards. The science behind the production of pharmaceuticals and product quality assurance is clear - international standards exist for a range of processes and products across the spectrum. This includes GxP ${ }^{58}$ such as Good Clinical Practices, Good Manufacturing Practices, and Good Laboratory Practices. Collaboration provides regulators with access to information on these best practices and reduces the need for disparate national processes. Instead of reinventing the wheel, regulators can benefit from relying on robust international standards as a reference and basis for their decision making. This would ensure the quality and effectiveness of regulatory processes, which are based on sound scientific evidence and recognized standards. From the practical perspective, collaboration minimizes duplication of work across regulatory authorities, which in turn can save resources required by each NMRA. The optimal amount of resources and expertise required by each NMRA are often significantly higher than what is available in reality. These constraints are outlined in Part V.

76. Cooperation on medicines regulation is beneficial to a wide range of parties including manufacturers, governments, regulators, and consumers, as shown in Figure 14. From the industry's perspective, medicines cooperation and convergence benefits the pharmaceutical sector through less duplication of unnecessary processes, better utilization of resources, increased sharing of experience and knowledge, fewer clinical trials, and increased market access ${ }^{59}$. From the practical perspective of resource management and improving efficiency, harmonized standards and common submission requirements minimize the need for customized dossier submissions due to countryspecific requests. The possibility for the establishment of regional regulatory compliance centers, instead of national centers, also greatly increases efficiencies for manufacturers. Cooperation also enables the range of players involved in the medicines

\footnotetext{
${ }^{57}$ Treatment Action Group. 2015. Improving Regulatory Systems to Address Global TB Drug Access Failures. http://www.treatmentactiongroup.org/tagline/2015/fall/improving-regulatorysystems-address-global-tb-drug-access-failures [March 2016]

${ }^{58}$ Abbreviation for good (anything...) practice quality guidelines and regulations.

${ }^{59}$ Huckle, Paul. 2015. "Stepping into Regulatory Excellence through Convergence" (presentation at Centre of Regulatory Excellence (Singapore) Scientific Conference, October 5-6, 2015).
} 
regulation process to come to a common understanding on certain principles that should be adhered to. These include transparency, predictability, reliability, and good quality. Over time, a collaborative process also fosters mutual understanding and trust among those involved in the work.

Figure 14: Benefits of medicines regulatory harmonization

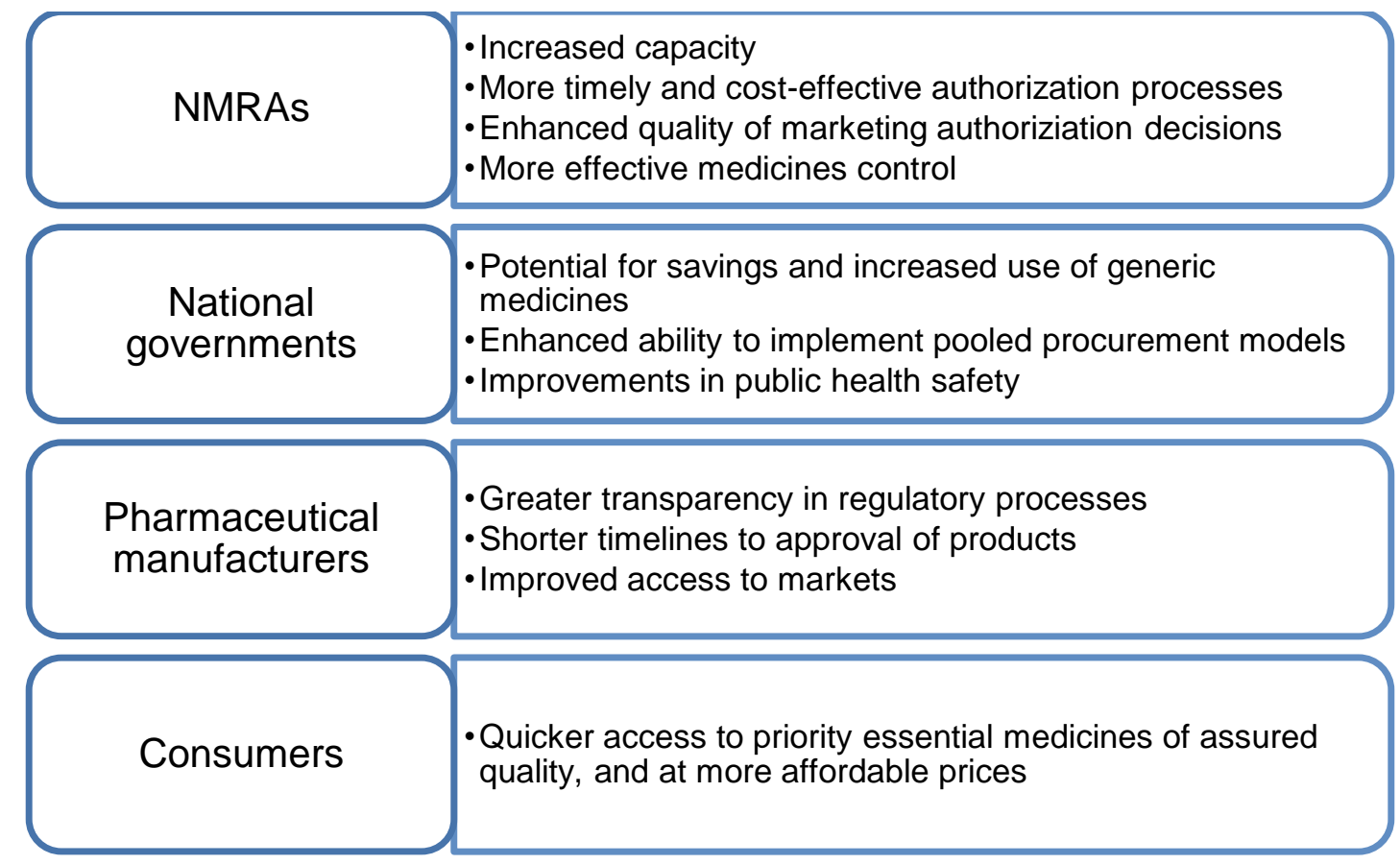

Source: Adapted from WHO presentation at Asia Pacific Regional Regulatory Partnership for Malaria Elimination meeting, March 31-April 1, 2016, Bangkok

\section{Frameworks for collaboration and harmonization efforts}

77. The terms medicines regulatory harmonization, cooperation and convergence can have different definitions depending on the context of its usage. In our report, we will use the terms interchangeably but highlight the technical differences below ${ }^{60}$ :

- In general, medicines regulatory cooperation represents efforts to leverage human, scientific, and financial resources as well as the knowledge and experience of other key regulatory authorities to avoid duplication of effort. Cooperation intends to increases synergies and efficiencies and allows limited resources to be focused on higher-risk areas of concern.

- Harmonization is defined as the process by which technical guidelines, formats, scientific requirements and standards are developed to be uniform across participating authorities. These harmonization efforts can focus on different processes of the regulatory system; examples for this harmonization mode are streamlined ASEAN technical guidelines and the ASEAN CTD format in the

\footnotetext{
${ }^{60}$ Lezotre, P. 2014. Convergence and Harmonization of Pharmaceutical Regulations. Academic Press (Elsevier).
} 
ASEAN region. The process of integrating national standards with international standards needs to be acceptable to all participants. Harmonization facilitates efficient global drug development and local registration. However, it does not mean unity in regulatory decision making among participating authorities.

- Regulatory convergence is defined as a process whereby the regulatory requirements across countries or regions become more similar or aligned over time as a result of the gradual adoption of internationally recognized technical guidance documents, standards and scientific principles, common or similar practices and procedures This approach does not require harmonization of regulations ${ }^{61}$.

78. Building on existing conceptual frameworks in published and grey literature ${ }^{62}$, medicines regulatory harmonization can be analyzed from several dimensions:

i. Scope. Some initiatives may be standalone activities, whereas others are part of broader work streams; some initiatives focus on technical areas and specific regulatory processes, while others include broader political agreements and dialogue.

ii. Institutional level, including international, regional, bilateral collaborations.

iii. Degree of harmonization, ranging from no harmonization (regulators working individually) to unified decision making.

Any initiative on medicines regulatory harmonization is likely to be characterized along one or more of these dimensions.

79. There are different approaches to collaboration across countries in the medicines regulation space. Any individual country can and may be a participant in a range of different activities and modes of collaboration, and it is important to note that the different modes of working are not mutually exclusive.

80. Elaborating on the dimensions outlined above, the scope of regulatory harmonization can range from technical and scientific work, to a model of integration which often involves political arrangements. An example of an initiative that focuses on technical work is the International Conference on Harmonization of Technical Requirements for Registration of Pharmaceuticals for Human Use (ICH). ICH focuses on producing technical guidelines and streamlined documentation and processes which individual regulators can rely on or adapt for their own purposes. In a multistep process, $\mathrm{ICH}$ develops - by consensus - guidelines for the evaluation of quality, safety and efficacy of drugs. These include, for example, Good Clinical Practice (GCP) ${ }^{63}$ and Good Manufacturing Practice (GMP) guidelines. Of great importance is also the unified format for the submission of registration documents, the $\mathrm{ICH}$ Common Technical Document

\footnotetext{
${ }^{61}$ U.S. Food and Drug Administration. Regulatory Harmonization and Convergence. http://www.fda.gov/BiologicsBloodVaccines/InternationalActivities/ucm271079.htm [March 2016] ${ }^{62}$ Lezotre, Convergence and Harmonization of Pharmaceutical Regulations; Lumpkin, M. 2015. "Exploring Opportunities and Challenges of Regulatory Convergence" (presentation at Centre of Regulatory Excellence (Singapore) Scientific Conference, October 5-6, 2015).

${ }^{63}$ Good Clinical Practice is a set of international quality standards to regulate clinical trials involving human beings. They include ethical aspects, quality documentation, conduct of trials, facilities, data management, and training. It involves parties such as clinical trial sponsors and investigators. GCP are ensured by quality assurance and GCP inspections. Internationally GCP standards are provided by $\mathrm{ICH}(\mathrm{ICH}-\mathrm{GCP})$.
} 
(CTD). On the other end of the spectrum is an integrated model such as in the European Union, where medicines regulation through the European Medicines Agency (EMA) follows political lines and the existence of a supranational, single market. It is important to note that the EMA does not completely negate the need for national regulators in EU countries - national procedures continue to exist in parallel as a viable channel for marketing authorization where necessary, and the role of national regulators in domestically-focused regulatory functions continues to be important. The different modes of gaining marketing authorization for sale of medicines in EU countries is outlined in Figure 15, and illustrates how an integrated model is not mutually exclusive with national processes.

Figure 15: Medicines registration procedures in the European Medicines Agency and the European Union

European Medicines Agency (EMA) EU - established to harmonize (but not replace) the work of national regulators in the EU. EMA should not only reduce costs for pharmaceutical industry to obtain separate approvals from each member state but also to reduce protectionist tendencies of sovereign states unwilling to approve new medicines that might compete with those already produced by domestic manufactures. There are several European marketing approval ways.

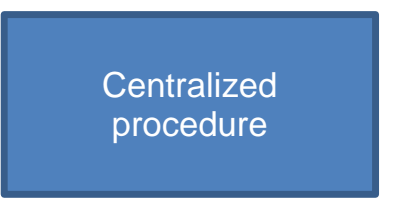

Application directly to the EMA. Single evaluation by European experts. MA valid throughout the EU. Compulsory for certain product types (e.g. biotech).

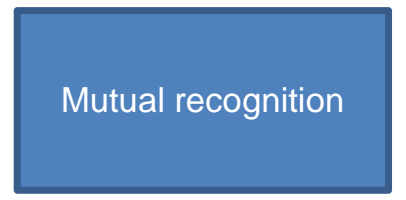

Recognition of an already existing national MA by one or more member states.

Decentralized procedure

Medicine that has not yet been authorized in the EU can be simultaneously authorized in several EU Member States.

Application to several EU NMRAs.

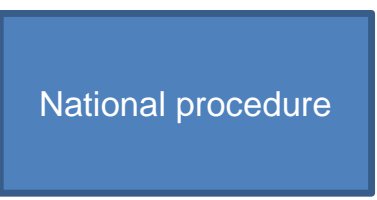

Authorization at national level by national competent authorities. MA only valid in this specific country.

81. In terms of institutional level, we see a range of initiatives led at the international level, but also regional collaboration which may respond better to specific characteristics and needs of geographically proximate regulators. Similarly, bilateral collaboration can be useful in providing knowledge transfer and training opportunities on specific capabilities. Examples of international and regional harmonization efforts are outlined in Box 3 below. 


\section{Box 3: Examples of international and regional harmonization efforts}

- ICH includes regulators and industry representatives from Europe, Japan, and the United States. $\mathrm{ICH}$ has produced guidelines on quality, safety, and efficacy and a common technical document. (http://www.ich.org/)

- WHO establishes medicinal, clinical, and technical standards and promotes regulatory capacity building, training, and work sharing for regulatory authorities. The Certificate of Pharmaceutical Product initiative and the WHO Prequalification of Medicines Programme, both intend to increase access to essential medicines in resource-limited countries and ensure that they meet acceptable standards of quality, safety, and efficacy. (http://www.who.int/)

- The International Conference of Drug Regulatory Authorities (ICDRA) provides member states with a forum for discussing further collaboration opportunities. (http://www.icdra.co.za/)

- PIC/S encourages mutual recognition of manufacturing site inspections. (http://www.picscheme.org/)

- The EU has harmonized the European-regulated market through EMA, which is a decentralized body of the EU, and its Heads of Medicines Agency, a network of the heads of agencies responsible for regulating human and veterinary medicines in the individual countries of the European Economic Area. (http://www.ema.europa.eu/ema/) (http://www.hma.eu/)

- Various regional harmonization programs, many of which participate in ICH's Global Cooperation Group (GCG), include initiatives in Africa, the Asia-Pacific area, Latin America, and the Middle East.

- In the East African Community under the African Medicines Regulatory Harmonization (AMRH) initiative, a harmonized medicines registration system is being set up, based on common documents, processes and shared information systems. (http://amrh.org/)

- The EMA - U.S. FDA Quality By Design (QBD) pilot plans to test a process of parallel review of specific drug development and manufacturing data components of manufacturers' marketing applications. (http://www.fda.gov/)

- Information sharing pilots of the International Generic Drug Regulators Programme (IGDRP) with the European Union's Decentralised and Centralised procedures. (www.igdrp.com)

Source: International Regulatory Harmonization Amid Globalization of Drug Development: Workshop Summary, 2013

82. The degree of harmonization can be thought of on a continuum, ranging from an instance in which there is no harmonization and regulators work in isolation, up to a stage of "unity" (Figure 16). To some extent, the attainment of these stages is a temporal development, where movement to the next stage can be expected to be a natural progression over time. A localized approach was much more common decades ago, when medicines regulation was much less complex and where regulatory authorities focused on their own domestic market. Towards the latter part of the $20^{\text {th }}$ century, harmonization initiatives began to emerge, focusing on efforts to streamline technical standards and regulatory guidance. Then the idea of alignment is introduced as a third step. This involves leveraging through standardized processes. On top of common standards and procedures, regulators rely on each other's work or some specific regulatory outcomes. The mode of alignment has been becoming more common in the 
last two decades, with Mutual Recognition Agreements as an example of an initiative that aims to achieve alignment. The fourth step, unity, is the highest level of cooperation and harmonization. It goes beyond technical standards towards united decision making in a larger geographic area. The centralized procedures in the EU are an example of unified decision making for the entirety of the EU.

83. A good example of the progression across these stages over time is the increasing trend of work-sharing today. International cooperation is moving more and more from strict harmonization of technical requirements towards a more reliance-based approach of alignment, emphasizing information and work-sharing, trust and synergies through multilateral cooperation and coalitions. On top of common standards and procedures, regulators in various regional and international contexts, increasingly rely on each other's regulatory work products.

Mutual reliance agreements between regulatory agencies can be the basis to share certain information in inspection reports and other non-public information that is critical to making decisions about the safety of foreign products. Mutual recognition agreements (MRAs) on work products such as good manufacturing practice (GMP) allow regulatory authorities to rely on GMP inspections performed by other regulators, the waiving of batch testing of products on entry into the country, and information sharing on inspection outcomes and quality defects ${ }^{64}$.

84. However, it is important to keep in mind that harmonization initiatives are established with different objectives. Not all regulatory harmonization initiatives aim for a stage of unity and full integration. As described above, there are significant differences in scope, institutional level, and degree of harmonization across various harmonization initiatives. Recognizing these differences, it is difficult to provide a comparative assessment of which mode of collaboration has, to date, been the most effective. Instead, assessing each initiative against its intended objective would provide fairer analysis on progress to date. Part VII below on harmonization initiatives in ASEAN aims to provide information on this.

${ }^{64}$ European Medicines Agency. International Affairs. www.ema.europa.eu [March 2016] 


\section{PART VII - MEDICINES REGULATORY HARMONIZATION INITIATIVES AND STATUS OF HARMONIZATION IN THE REGION}

86. In light of the framework on regulatory harmonization described above, we outline in this section the ASEAN experience in this field of work. The ASEAN experience to date shows the range of harmonization efforts that can take place within just one region, with substantial achievements in selected areas and countries. There have been harmonization efforts for different processes within the regulatory system and product cycle, and regulatory harmonization is at different stages of advancement, depending on the type of product or process involved.

\section{Achievements and milestones}

87. Since the start of coordinated efforts on medicines regulatory harmonization in 1999, the ASEAN region has made substantial progress in their efforts on medicines regulatory harmonization. These milestones are illustrated in relation to the lifecycle of a pharmaceutical product in Figure 17 below.

Figure 17: ASEAN harmonization milestones and pharmaceutical product cycle

\begin{tabular}{|l|c|c|c|}
\hline Basic research & $\begin{array}{c}\text { Product } \\
\text { development }\end{array}$ & $\begin{array}{c}\text { Production, } \\
\text { Quality } \\
\text { approval process } \\
\text { Management, } \\
\text { Distribution }\end{array}$ \\
\hline
\end{tabular}

Screening Clinical research Good laboratory GLP, GCP, GMP practices (GLP) for investigational products

\section{Application and approval processes}

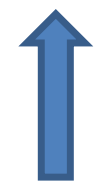

ASEAN

Streamlined technical

ASEAN

harmonization

milestones guidelines e.g. on

BA/BE, Process

Validation, Stability

\section{Commercial Manufacturing GMP, GDP}

Pharmacovigilance and Post market quality surveillance
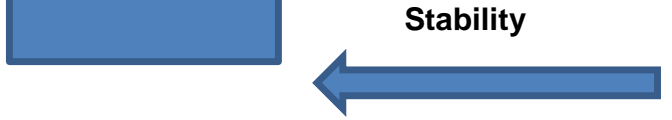

ASEAN Reference

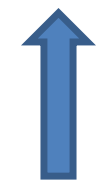

ASEAN

MRA on

GMP Inspections

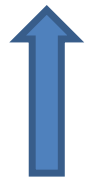

Shared Post

Marketing

Alert System

(PMAS)

\section{Substances (ARS) Project}


88. A typical pharmaceutical product goes through the phases of basic research, product development, regulatory approval process, production, quality management, distribution, and post-marketing surveillance. In product development phase, regulatory harmonization efforts have contributed towards the streamlining of standards and guidelines that serve to provide guidance for NMRAs and industry members in the region. These guidelines were adopted from established, international guidelines (such as from WHO and $\mathrm{ICH}$ ) for benchmarking and adapted to the ASEAN context. In the regulatory approval phase, harmonization efforts succeeded in developing and implementing the ASEAN Common Technical Dossier (ACTD) and ASEAN Common Technical Requirement (ACTR) that enabled, in principle, a common technical dossier to be submitted to all NMRAs in the ASEAN region. The ASEAN Reference Substances (ARS) Project (see Box 4) is a resource that enables regulators to conduct quality control tests on medicines submitted for regulatory approval. In the commercial manufacturing phase, the signing of the ASEAN Sectoral Mutual Recognition Agreement (MRA) on Good Manufacturing Practice (GMP) ${ }^{65}$ is a relatively recent achievement in 2010. Under the MRA on GMP, the GMP inspection reports or certificates issued by Listed Inspection Service ${ }^{66}$ or inspectorate groups would be recognized and accepted by the regulatory authorities of other ASEAN member states. This means that countries who wish to import medicines from manufacturers who have been issued GMP certificates from Listed Inspection Service no longer need to conduct GMP inspections on these manufacturers ${ }^{67,68}$, thereby reducing the workload on any individual NMRA in conducting GMP inspections. The MRA on GMP is an important accomplishment for the region as it is seen as an initial step towards obtaining PIC/S membership. In the final production phase of post-marketing, the region successfully initiated a platform in 2006 to share information on defective and unsafe health products, such as counterfeit, adulterated and recalled products in the ASEAN market, called the ASEAN Post Marketing Alert System. In this phase, the ARS project mentioned earlier also plays an important role in providing regulators with reference substances for post-marketing testing of products.

\footnotetext{
${ }^{65}$ MRA on GMP is restricted only to medicinal products in finished dosage forms (including prescription and non-prescription medicinal products for human use) but excludes biopharmaceuticals, radiopharmaceuticals, traditional medicines and investigational medicinal products intended for clinical trials.

${ }^{66}$ As members of PIC/S, NPCB Malaysia, HSA Singapore joined the list of inspectorate group in January 2000 , and was later joined by BPOM Indonesia after BPOM achieved PIC/S membership. More recently in March 2015, Thailand FDA joined the list after it was evaluated by a Panel of Experts under the ASEAN Sectoral MRA agreement.

${ }^{67}$ ASEAN. MRA on GMP FAQ. http://www. asean.org/?static post=asean-sectoral-mras [April 2016]

${ }^{68}$ ASEAN. ASEAN MRA On GMP Inspection Of Manufacturers For Medicinal Products Listed Inspection Service. http://www.asean.org/storage/images/2015/March1/asean sectoral MRA/LISTED\%20INSPECTI ON\%20SERVICE.pdf [April 2016]
} 
Box 4: The ASEAN Reference Substances (ARS) Project

The ASEAN Reference Substances (ARS) Project is a not-for-profit regional collaboration initiative by ASEAN regulatory laboratories aimed at improving the regional availability of chemical reference standards (CRS) and increasing technical capacity to produce and handle CRS. Similar to ACCSQ-PPWG initiatives in that it is also an ASEAN initiative, the ARS project's planning and adoption is overseen by the ASEAN Working Group on Technical Cooperation in Pharmaceuticals Program, as part of the work program of the ASEAN Health Ministers under the ASEAN Socio-Cultural Community pillar. The ARS Project was technically supported by WHO and financially supported by UNDP and Japan Pharmaceutical Manufacturers Association (JPMA), with Thailand as the coordinating center. Thailand also hosts the ASEAN CRS Center.

CRS are continuously needed by laboratories and/or NMRAs, quality control agencies and pharmaceutical manufacturers for quality control and quality assurance purposes, from the early stages of product development, to post-marketing inspection of medicines (as illustrated in Figure 17). Since CRS are usually costly, the ARS project enables NMRAs and laboratories to easily and affordably obtain standardized secondary pharmaceutical reference standards for their quality control and quality assurance needs. This is done through the joint efforts of ASEAN member laboratories to produce and validate the secondary CRS, after achieving consensus on which secondary CRS to be produced. Presently, there are 156 Reference Substances available which are offered at competitive prices. The ASEAN reference standards are validated in the national laboratories of the ASEAN member countries - Indonesia, Malaysia, Philippines, Singapore, Thailand and Vietnam - and are formally adopted after stringent qualitative and quantitative tests are carried out on the candidate substances.

In addition, the project has contributed to capacity development in the region through its knowledge sharing and joint training activities such as laboratory comparison measurements. The ARS project is an excellent example of a successful, ongoing regional collaborative initiative which is run in a fully consensus-driven manner. The ARS project is currently used as a benchmarking model in the East African region.

Source: Bureau of Drug and Narcotic. ASEAN/DMSc Reference Substances; Authors

89. In addition, there is country-specific work among selected regulators in the region, which utilize the concept of reliance on international standards to streamline domestic regulatory processes. Most notably, the Philippines and Singapore have made progress on harmonization through their collaboration with other NMRAs (e.g. US FDA, EMA) and WHO, as summarized in Box 5. 
Box 5: Country-Level Harmonization Initiatives

\section{Philippines}

In late 2015, the Food and Drug Authority (FDA) of the Philippines joined WHO Common Review Procedure (CRP) - the first country in ASEAN to do so. The WHO CRP is an abridged procedure for evaluation of products under the WHO prequalification scheme. The Philippines FDA can now access a database with product evaluation reports and based on the information provided - needs to decide whether to authorize the medicinal product or not within 90 days. The adoption of WHO CRP by Philippines FDA marked a shift in the FDA's focus from pre-market to post-market regulation, capitalizing on available data and adopting collaborative review procedures.

\section{Singapore}

Singapore's Health Sciences Authority (HSA) employs the concept of reliance in the regulation of medicines in Singapore. New medicines, generics and products submitted for major variations that have been evaluated and approved by at least one regulatory agency are allowed to undergo abridged evaluations whereas new medicines, generics and products submitted for major variations evaluated and approved by primary reference agencies (at least two reference agencies for new medicine applications and at least one reference agency for generics) undergo verification evaluations in HSA - significantly cutting down the processing timelines for the products and increasing medicines regulatory efficiency in Singapore. HSA reference agencies include European Medicines Agency (EMA), US FDA, Health Canada, Therapeutic Goods Administration (TGA) Australia and Medicines and Healthcare Products Regulatory Agency (MHRA) UK.

Source: Tan, D. 2010. "Innovative Regulatory Review Practices for Better Efficiencies - The Singapore Experience"; Health Sciences Authority. 2011. Guidance on Medicinal Product Registration in Singapore.

90. ASEAN's approach and progress on medicines regulatory harmonization illustrates how a single region can utilize a combination of approaches and modes of collaboration. These range from adopting guidelines from standalone technical initiatives (e.g. $\mathrm{ICH}$ ), to broader platforms that are part of a political configuration (ASEAN architecture), to country-specific work that utilizes the concept of reliance.

91. Despite the region's substantial efforts on regulatory harmonization, there are significant challenges in implementation. Some country-specific requirements, such as local labeling requirements, local BE requirements and local clinical trial requirements remain, challenging the practical implementation of the ACTD/ACTR across the region. The implementation of the ACTD was carried out in phases, with full ACTD implementation adopted by Malaysia in July 2003, Indonesia and Thailand in early 2009, Vietnam in late 2009 and Philippines in 2013. Implementation is also hampered by the shortage of resources and expertise in each member state - many of which were raised in Part $\mathrm{V}$ (NMRA review). An additional, specific concern related to harmonization is the shortage of dedicated funding for this purpose. While external funding exists to support medicines regulatory harmonization work, this funding is mainly used for training and capacity-building purposes. Feedback suggests that more sustained funding is required to support regulatory harmonization requirements - from institutional costs associated with recruiting and maintaining trained staff, to necessary but costly upgrades of systems and processes such as Quality Management Systems for NMRAs. Implementation is also further complicated by existing local laws and 
regulations on pharmaceuticals, such as price setting, import restrictions, and halal requirements. In the absence of an overarching ASEAN legislative framework, national legislation can end up being an obstacle to a country's ability to implement harmonized standards. Finally, the willingness and ability of countries to take on the harmonization agenda often depends on various health and pharmaceutical sector policies, the state of professional practice in pharmacy in the country, and the conditions of their local pharmaceutical manufacturing sector.

92. The implementation of harmonization initiatives in the region could be improved through greater oversight, clearer strategic framework with follow through and a scorecard that emphasizes tangible end-results. At present, the oversight for medicines regulatory harmonization in the ASEAN region is provided by the ASEAN secretariat. However, the mandate of the ASEAN secretariat, which includes coordination and effective implementation of ASEAN projects and activities, is very broad. With multiple working groups and products to oversee, the secretariat has limited resources to keep track of progress on every working group in detail. Furthermore, there are working groups in different ASEAN communities that focus on similar products ${ }^{69}$, including various working group on pharmaceuticals. Coordination and collaboration across these groups that capitalizes on each group's strength and expertise are currently unclear. ASEAN has recently established a monitoring division within the ASEAN secretariat to assist with the monitoring and implementation of ASEAN projects and activities for each ASEAN community, and hopes to provide more effective oversight for implementation via this division.

\section{Key players in the region}

93. A wide range of institutions participate in harmonization initiatives in ASEAN, including multilateral and regional organizations, via bilateral and national arrangements, development partners, and academic institutions. Each institution and its initiative has a different focus or mandate, sometimes with objectives and work scope overlapping with one another. The following paragraphs provide a short description of the aims, focus and main activities and milestones of some of the key players in the region.

Regional trade initiatives

94. The Pharmaceutical Product Working Group (PPWG) is a regional working group for pharmaceutical products that was established in 1999 by the ASEAN Consultative Committee on Standards and Quality (ACCSQ) under the ASEAN Economic Pillar, with oversight provided by the ASEAN secretariat, as mentioned above. The group was formed to address harmonization issues pertaining to pharmaceuticals in the region, with the aim to eliminate technical barrier to trade for pharmaceutical products for the ASEAN region, without compromising on quality, safety and efficacy. Members of the group include NMRAs of each ASEAN member states with industry representation through the Implementation Working Group (IWG). The PPWG works by

${ }^{69}$ Working groups focusing on pharmaceuticals include: (1) The ASEAN Working Group on Pharmaceutical Development (AWGPD) under the purview of the ASEAN Socio-Cultural Community, which aims at building the capacity of health officials and developing cooperation in pharmaceutical sector in ASEAN; (2) The ASEAN Pharmaceutical Product Working Group (ASEAN PPWG) under the purview of the ASEAN Economic Community. 
consensus, which has sometimes resulted in a rather lengthy decision making process if a consensus could not be achieved initially. The group is responsible for most of the medicines regulatory harmonization milestones achieved in the region, such as streamlined technical standards, adoption of ACTD/ACTR, MRAs and PMAS. However, the group's main shortcoming is the inability to enforce implementation of harmonization initiatives as under the fundamental principles of ASEAN, implementation is left to purview of individual countries.

95. Another regional trade bloc initiative active in the ASEAN region is the AsiaPacific Economic Cooperation (APEC) Regulatory Harmonization Steering Committee (RHSC). Formed under the purview of APEC Life Sciences Innovation Forum (LSIF) in 2008, RHSC focuses on promoting strategic and coordinated approach to regulatory harmonization or convergence of medical products, as well as capacity building efforts within the APEC region, such as training on Good Review Practices (for regulators) and Good Submission Practices (for industry), which were held in collaboration with the Asian Partnership Conference of Pharmaceutical Associations (APAC), led by JPMA. APEC RHSC is noted for its innovative Center of Excellence (CoE) operating model that promotes capacity building in regulatory sciences in a sustainable and non-duplicative manner. Recent activities include the workshop on multi-regional clinical trials that was conducted by the Duke-NUS Centre of Regulatory Excellence (CoRE) - one of the designated CoEs for the topic ${ }^{70}$.

\section{Technical partners}

96. The WHO is the key technical partner for NMRAs. WHO adopts a holistic approach to supporting regulators worldwide. This includes:

i. Developing evidence and knowledge of the situation and needs of regulatory systems worldwide,

ii. Providing direct country support through technical advice and capacity building activities. This support is based on Institutional Development Plans that are developed together with each NMRA.

iii. Developing and continuously improving tools to assist regulatory work, such as standards and guidelines, databases and other informational materials, and tools for exchange of regulatory information.

iv. Providing technical support to regional and sub-regional networks through technical advice, training, and helping to establish Centres of Excellence, and

v. Promoting WHO's regulatory systems strengthening work.

97. In ASEAN, a recent WHO project aimed to support the region's harmonization efforts. "Supporting the Implementation of ASEAN Harmonized Requirements for Drug Registration (SIAHR)" Project aimed to analyze country-specific requirements and identify gaps in the implementation of the ACTD/R by individual ASEAN medicines regulators. The project would then identify capacity strengthening needs and propose actions to ensure homogenous interpretation and implementation of the relevant ACTD/R guidelines. The SIAHR project concluded its first phase of study in 2015, with findings of the study available to the ASEAN PPWG and NMRAs. A second phase of the

\footnotetext{
${ }^{70}$ Centre of Regulatory Excellence. APEC RHSC Center of Excellence Workshop "Multiregional Clinical Trials". https://www.duke-nus.edu.sg/core/event/apec-rhsc-center-excellence-workshopmultiregional-clinical-trials [March 2016]
} 
project is currently being planned, focusing on piloting feasible and practical interventions for a truly harmonized ACTD/R.

Regulatory agencies groups

98. The International Generic Drug Regulators Program (IGDRP) was initially launched as a three year program in 2011 by a group of regulators aiming at generic drug regulatory convergence and cooperation. However, since 2014, it has become a permanent program with participating countries and organizations from Australia, Brazil, Canada, China, Chinese Taipei, the EU, Japan, Korea, Mexico, New Zealand, Russia, Singapore, South Africa, Switzerland, U.S. and WHO, and aims to facilitate the timely authorization and availability of safe, effective and quality generic medicines, with plans to expand to biosimilars at a later stage. Currently established working groups focus on "Active Substance Master Files/ Drug Master File (ASMF/DMF)", "Biowaivers" and "IT business needs".

\section{Capacity building initiatives}

99. Academic institutions working to address capacity, leadership and policy needs in the region include the Duke-NUS CoRE which was formed in 2014. CoRE plays the role of a neutral platform to enable networking and collaboration opportunities across regulatory agencies, industry and academia in the region. CoRE collaborates actively with other initiatives and partners, such as APEC RHSC and the Asian Development Bank Institute (ABD), providing capacity building opportunities in the region and also conducting research to advance regulatory sciences in the region. Local academic institutions have also worked actively to address the capacity needs of its own country and neighbors. Chulalongkorn University's Faculty of Pharmaceutical Sciences, for example, offers dossier preparation workshop and planning for assessment report writing courses and plans to become a Centre of Excellence for regulatory sciences. The university also provides training opportunities to regulators from Cambodia. In addition ad-hoc training is also provided by NMRAs of most countries, and PPWG. In Malaysia, for example, the National Pharmaceutical Control Bureau together with other pharmaceutical industry associations such as the Pharmaceutical Association of Malaysia (PhAMA), Malaysian Organisation of Pharmaceutical Industries (MOPI) and Malaysian Association of Pharmaceutical Suppliers (MAPS) provide training on GMP and product registration.

\section{Development partners and others}

100. Development partners and other organizations (e.g. bilaterals) working on the regulatory harmonization agenda in the ASEAN region include the Asian Development Bank (ADB), the World Bank Group and the U. S. Pharmacopeial Convention (USP). The ADB supports the agenda of malaria elimination in the region, which includes regulatory capacity building measures to improve the regulation of artemisinin-based combination therapy (ACT) medicines, through agencies such as CoRE and Asia Pacific Leaders Malaria Alliance (APLMA). The World Bank Group, along with other partners, manages the Global Medicines Regulatory Harmonization (GMRH) initiative and has provided support to the African Medicines Regulatory Harmonization (AMRH) initiative since 2009. This report is the World Bank Group's first involvement in medicines regulatory harmonization in the East Asia Pacific region. The USP, through its Promoting 
the Quality of Medicines (PQM) program funded by the United States Agency for International Development (USAID), provides technical assistance at both country and regional levels to ensure safety and quality of medicines. In the Southeast Asia region, PQM has provided technical support in the areas of quality control training, medicines quality control monitoring, and support on Quality Management Systems (QMS) and GMP to Thailand, Myanmar, Cambodia, Indonesia, the Philippines and Vietnam. In addition, the USP also provides chemical reference substances and training services through its country offices.

101. A critical challenge which comes as a result of the multitude of players and partners in the region is that of effective coordination among the various parties. Currently, there is no common platform to engage all the players involved in the medicines regulatory harmonization agenda - ranging from PPWG, industry members, technical partners, and academic institutions to development partners. While an engagement platform exists for NMRAs - and to some extend the industry - via PPWG, better alignment and coordination between national, regional and international key players is needed given the various on-going and planned initiatives in the region. For example, better coordination could happen through information sharing platforms such as an information dashboard that is well-maintained, where all organizations involved could have access to timely updates of each other's progress and achievements. Better alignment of efforts via a common platform will also prevent duplication of efforts. Immediate areas where better coordination efforts could benefit all parties include training and capacity building efforts, given the range of training activities offered in the region.

\section{Status and characteristics of medicines regulatory harmonization in ASEAN}

102. The current status of medicines regulatory harmonization in the ASEAN region could be described as between the stages of alignment and harmonization, according to the four step approach presented in paragraph 82. Harmonized technical standards and documents such as the ACTD exist, but implementation is not yet fully standardized across all ASEAN member states. The MRA on GMP inspections represents a step towards further alignment, but likewise, adoption by all countries will take several years, as NMRAs in across ASEAN countries work towards "levelling up" to GMP standards that all fellow ASEAN members will recognize and accept.

103. To understand the status of medicines regulatory harmonization in ASEAN, it is important to first understand the characteristics of harmonization in the region - that standards and recommendations are set regionally, but adoption and implementation is dependent on each member state's readiness, capability and capacity. Because of differences in resources, capabilities and readiness among NMRAs in the region, countries with more advanced regulatory agencies often take the lead in the implementation of the harmonization standards or agreements; other NMRAs adopt the standards or requirements later on when they become technically, institutionally and financially ready to do so. This notable characteristic of harmonization in the ASEAN region is also termed the ASEAN minus $X$ (ASEAN-X) approach. At the same time, regulatory harmonization could also happen on a bilateral level, as countries in the region are free to implement other harmonization efforts in collaboration with other 
partners within or outside the region. For this reason, regulatory harmonization efforts in the region is between the stages of alignment and harmonization, as standards and processes are being streamlined among NMRAs, and mutual recognition agreements of some - but not all - of the regulatory processes across NMRAs are achieved.

104. In general, ASEAN member states employ a step-wise approach in their harmonization strategy. Broadly, on a regional level, this is done by first targeting specific tasks or areas to be harmonized based on the criteria of Safety, Quality and Efficacy, followed by the formation of taskforces or committees to coordinate the drafting and revisions of guidelines, documents or agreements. A consensus or agreement is then obtained from leaders and stakeholders, followed by adoption and implementation (usually with implementation grace period) although the execution of the guidelines or agreements is often left to the oversight of individual countries. It is important to note that not all standards, guidelines, and regulatory processes are harmonized all at once, but instead could happen at a different pace according to the feasibility or priority of the task. At the national level, countries also employ a step-wise approach to harmonization, by initially taking up or implementing guidelines and agreements that are within their capabilities, capacity and legal mandate. Then, as resources, expertise and political support grows, countries may proceed with the adoption of more harmonized initiatives. Figure 18 provides a simplified diagram on the regulatory harmonization mechanism in ASEAN.

Figure 18: ASEAN medicines regulatory harmonization mechanisms

\section{ASEAN Medicines Regulatory Harmonization Mechanism}

\begin{tabular}{|c|c|c|}
\hline $\begin{array}{l}\text { Regional Stepwise } \\
\text { Approach } \\
\text { 1. Decide on tasks/areas to } \\
\text { be harmonized } \\
\text { 2. Form specific taskforce/ } \\
\text { committees } \\
\text { 3. Draft guidelines, } \\
\text { agreements and } \\
\text { documents } \\
\text { 4. Obtain consensus from } \\
\text { leaders and stakeholders } \\
\text { 5. Adoption and } \\
\text { implementation }\end{array}$ & $\begin{array}{l}\text { Regional } \\
\text { Harmoni- } \\
\text { zation }\end{array}$ & $\begin{array}{l}\text { National Stepwise } \\
\text { Approach } \\
\text { 1. Assess national } \\
\text { regulatory agency and } \\
\text { sector's capability and } \\
\text { capacity } \\
\text { 2. Implement harmonization } \\
\text { initiatives, based on } \\
\text { country readiness and } \\
\text { political will to take on } \\
\text { the task } \\
\text { 3. Implement more } \\
\text { harmonization initiatives } \\
\text { as resources and } \\
\text { capabilities grow }\end{array}$ \\
\hline
\end{tabular}




\section{Barriers to regulatory harmonization in the region}

105. Despite the milestones achieved, the pursuit of regional regulatory harmonization in the region is marked with challenges and full convergence is still some ways away. While some of the challenges are technical in nature and could be addressed with capacity building, improved planning and resource reprioritization, others are due to the fundamental principles of ASEAN and reflect political realities of the region.

106. One major challenge of the ASEAN regulatory harmonization is the nonstandard adoption of harmonized initiatives in the region; as a result, countries are at different levels of harmonization. The WHO SIAHR project described above aimed to address the non-standard implementation of the ACTD/R across countries. This is mostly due to the characteristics of harmonization in the region described earlier - where standards and recommendations are set regionally, but interpretation and responsibility for implementation continues to lie with individual member states. At the same time, existing local regulations and policies that prevent the practical implementation of free flow of pharmaceutical goods, such as in the case of Indonesia where restrictions are placed on imported pharmaceuticals, continue to challenge harmonization.

107. The fragmented approach to regulatory harmonization in the region is also partly due to the absence of stronger regulatory supervisory support for harmonization initiatives. While significant progress has been achieved in the region, support for a strong harmonization strategic framework with more effective monitoring and evaluation could help the working groups and other key players develop a better aligned, stronger and more inclusive agenda for the region, as mentioned above.

108. There are also several critical challenges on the technical front. Regulatory harmonization initiatives have raised the standards and requirements in regulatory and manufacturing sciences in the region, which brings the region closer to the ultimate aim of access to safe and quality medicines. However, this has also highlighted gaps in technical expertise of NMRAs and pharmaceutical industry across the countries in the region. Differences in technical expertise and understanding have led to a perceived lack of mutual trust in NMRAs' capacities and systems. Institutionally, NMRAs in the region are diverse, with NMRAs of some countries like Malaysia, Indonesia and Thailand being more technically equipped and ready to handle harmonization requirements. In most countries, domestic manufacturers, especially small manufacturers that specialize in traditional medicines, require more technical support than MNCs. Thus, the region is tasked with the challenge of elevating technical standards from very varied levels to the highest possible, throughout the region. Countries in the region are also faced with challenge of aligning understanding of the technical requirements for harmonization to reach the same scientific justification to support harmonization work. For example, anecdotal experience has shown that even among players in the region, there are differences in the interpretation of ASEAN guidelines, leading to confusion and set-backs in the harmonization agenda.

109. The region also faces challenges in building a stronger political engagement that is needed to push medicines regulatory harmonization agenda forward in a sustained manner. Engagement with key economic ministers in the region 
has been consistently on-going through ASEAN, but the region lacks engagement with key leaders on two levels - the first on a broader level to ensure the issue of free trade of pharmaceutical products and access to quality and affordable medicines is well recognized by leaders from other sectors, and the second, engagement on the highest level of governments for sustained political traction and continuity of vision. 


\title{
PART VIII - CONCLUSION AND RECOMMENDATIONS
}

\author{
Key findings
}

110. In the $\mathbf{1 7}$ years since coordinated efforts to harmonize medicines regulation in the ASEAN region started, the region has made significant progress to remove technical barriers to medicines regulation, largely driven by the ACCSQ PPWG initiative under ASEAN. Notable milestones in the ASEAN medicines regulatory harmonization landscape include the streamlining of technical guidelines that serves to improve standards and help with informed decision-making, the development of a common technical dossier for the region, the signing of an MRA on GMP inspections, and a platform for post-marketing information sharing.

111. While the PPWG continues to improve technical standards and recommend initiatives for regulatory harmonization in the region, the working group and the region is challenged by the staggered implementation of harmonization initiatives. This has resulted in the ASEAN-X approach, where countries move ahead in adopting standards, guidelines, and processes as and when they are ready to do so. The status of medicines regulatory harmonization in the ASEAN region is regarded as between the stages of harmonization and alignment. Streamlined technical processes are in place, but implementation across countries is not yet fully standardized and homogenous.

112. Differences in technical capabilities and institutional capacity across ASEAN member states are a critical underlying reason for the ASEAN-X approach. This is true for both regulators and industry players, both of whom could benefit from upskilling and capacity building. On the technical front, constraints include inadequate expertise of personnel in evaluating dossiers and insufficient experience in specialized areas such as evaluating new technology medicines and traditional medicines. Staff also lack expertise in implementing and inspecting international GMP and GCP requirements. From the institutional perspective, NMRAs would benefit from more holistic and long term institutional development, including fundamental aspects such as work planning, staffing - both in terms of staff strength and expertise - and overall management.

113. Providing adequate support to NMRAs in the region in a concerted manner would require better coordination across the range of institutions that are currently involved in this work. Organizations such as APEC RHSC, WHO, CoRE, ADB and local academic institutions all play an important role in working with NMRAs to help build their capabilities and capacity, and in strengthening the regional regulatory harmonization agenda. The range of activities and initiatives ongoing include providing technical assistance, networks and platforms for engagement, and disparate capacity building training events. Given the multiple initiatives, there is a need for better alignment and coordination of efforts from all parties involved.

\section{Next steps}

114. The following section presents potential key policy recommendations towards medicines regulatory system strengthening and regulatory harmonization. We present country-specific recommendations as identified through our analysis, followed by regional policy recommendations for ASEAN. 
Country-specific recommendations:

Improve institutional and technical capacity development of NMRAs and industry

115. With institutional improvements and an upskilling in technical capabilities, NMRAs would be much better equipped to engage in regulatory harmonization activities. NMRAs across our countries of analysis experience similar constraints; based on the key constraints identified in this analysis, we suggest three main areas in which NMRAs in all five countries could be supported:

- Development of a long term, fully costed business plan and strategic framework for each NMRA, while ensuring regulatory harmonization needs are addressed in the plan;

- Development of institutional and financial sustainability plans for NMRAs, such as through more efficient fee structuring, better resource allocation and utilization, and more effective and transparent governance;

- Technical and institutional capacity development of NMRAs, in addition to advocating for supportive national governance mechanisms to ensure functionality, accountability, and performance of NMRAs.

116. In addition, we provide country-specific recommendations for the five analysis countries, based on the dimensions of administrative elements, technical elements and regulatory function elements presented in the NMRA assessment framework in Figure 7.

- Indonesia: Better alignment of local regulations and policies with regional medicines regulatory harmonization efforts;

- Malaysia: Improve regulatory and industry capacity to cope with new technologies, including biosimilars (this is true for all five analysis countries);

- Philippines: Improve human resources hiring system for institutional sustainability; Upgrade fee structuring system for more efficient services;

- Thailand: Improve fee structuring system for more efficient services and transparency of timelines with the advent of the new NIPA entity (independent state entity; authorized to take over some of Thai FDA's tasks with the ability to create fees); Improve clinical trial regulation including BA/BE and GCP inspections;

- Vietnam: Upgrade the GMP inspectorate which is currently severely under capacity.

117. At the same time, the pharmaceutical industry in all five countries would also benefit from improvements in technical areas such as GMP and submission practices. This is especially necessary for domestic manufacturers who do not have the benefit of a global corporate network like multinational pharmaceutical companies do, but remain critical to the development of local production capacity. Development partners and governments could explore mechanisms to support upskilling of local manufacturers. These could include forums for discussion with NMRAs so as to build mutual trust, training on selected topics relevant to manufacturers, and platforms for information sharing e.g. through a repository of regulatory requirements, which would aid registration processes. 
Regional level recommendations:

Strengthen the idea of referencing and reliance

118. Institutional development and capacity building are improvements which need to take place over the long term, and progress can be relatively slow. One good way of helping to increase capacity and capabilities of regulators in the short to medium term is in promoting the use of referencing and reliance in regulatory processes and decision making. While each regulator will continue to need their own institutional capacity for core regulatory functions, referencing and reliance allows NMRAs the opportunity to "leapfrog" in selected areas. Instead of working in isolation and making all regulatory decisions solely based on in-house processes and information submitted to them, NMRAs can benefit significantly from regulatory decisions by other parties, and in particular Stringent Regulatory Authorities (SRAs).

119. Indeed, not every regulator needs to develop a full range of capabilities and staff strength for every regulatory function. A viable way forward would be for ASEAN regulators who have limited resources to focus on building their capability in regulatory functions that need to be done by themselves. These include post-marketing surveillance, registration of products by local manufacturers, inspection of dispensing outlets, and supply chain management. At the same time, NMRAs would benefit from building the expertise to review regulatory decisions by SRAs and use these are reference material for their own decision making. This reduces the need to thoroughly review registration application dossiers for identical medicines that have been registered in SRAs, thereby reducing the time it would take the regulator to process to registration. An even more expedited process would be the use of reliance, such as in Singapore's case. If a product is registered by an SRA and an agreement is in place, Singapore can apply an abridged registration process. Other countries in the region could benefit from adopt this procedure, or even go another step further and fully rely on SRA decisions, while closely monitoring the product after it is on the market, through post-marketing surveillance.

120. Nonetheless, it is critical to introduce the concepts of referencing and reliance in an institutionalized, systematic way. Two critical elements include: (i) that the principles of referencing and reliance, as well as the information from SRAs that is being utilized, is clearly understood by the personnel involved, and (ii) that referencing and reliance become an institutionalized process in the NMRA, with proper protocols in place, rather than to be used on an ad hoc basis with inadequate guidance for staff. Introducing these concepts without the necessary knowledge and checks in an NMRA's system could lead to a lapse in oversight. Ultimately, responsibility for registering a product must continue to lie with the national regulator.

Implementation support to regional platforms

121. As mentioned above, medicines regulatory harmonization in ASEAN has largely been driven by the ACCSQ PPWG. This working group has been instrumental in convening national regulators and other parties who are invited to participate in meetings, such as industry associations. To date, it is the most effective platform for medicines regulatory harmonization in the region, and its good work should continue. However, there are challenges in implementing PPWG's work and decisions - this is 
due to the fact that implementation is under the remit of each country, but more importantly, because the PPWG does not have a robust implementation support arm.

122. While country-level implementation is likely to continue through the ASEAN-X approach, better operational support at the regional level can help to support more effective implementation at the country level. Operational support could be provided through an organization or secretariat that is mandated and resourced to implement PPWG guidelines and decisions. This would require a robust work plan for the group, a budget, implementation support capacity and expertise, and monitoring and evaluation mechanisms. $\mathrm{ICH}$, for example, has a different setup with an $\mathrm{ICH}$ steering committee that oversees all harmonization activities of $\mathrm{ICH}$, determines $\mathrm{ICH}$ policies and procedures; decides on the adoption of $\mathrm{ICH}$ projects; and monitors and facilitates the progress.

123. In the context of the overall ASEAN architecture, a steering body would likely report to the ASEAN Secretariat, but would be much more focused on pharmaceutical products than the ASEAN Secretariat is. With a clear mandate for medicines regulatory harmonization and resources that are dedicated to supporting countries in implementing activities and processes agreed to in the PPWG, this body could potentially be very successful and influential in advancing the medicines regulatory harmonization agenda in ASEAN.

124. Organizations, or a partnership of organizations with multilateral arrangements, such as the World Bank and WHO, are strategically placed to provide such operational support to the region, for example in providing a platform to convene power, manage fiduciary arrangements, and develop institutional and financial sustainability plans. On a regional level, the focus could be on the coordination and development of business plans, interoperable information systems, and platform for convening whereas on a national level, the focus could be on technical assistance to countries with emphasis on both technical aspects of regulatory systems strengthening and institutional capacity building. The AMRH initiative involving WHO-World Bank is an example of such partnerships; in addition, the World Bank also provides technical asisstance to countries (such as the Democratic Republic of Congo) through lending projects with components dedicated to medicines regulation strengthening.

Increase coordination

125. Finally, better coordination would help to bring together the different initiatives in the medicines regulatory harmonization space in ASEAN. While ASEAN regulators already have a well-established platform for discourse among themselves, through the PPWG, coordination beyond ASEAN member states has been challenging. Based on feedback from key stakeholders, the following approaches could be feasible:

i. Establishing an information sharing platform where all organizations involved and interested in the medicines regulatory harmonization agenda in ASEAN can have access to timely updates of each other's progress and achievements. Better alignment of efforts via a common platform can help to minimize duplication of efforts. 
ii. Beyond ASEAN, Asia-wide regulatory workshops could promote the idea of more reliance and work sharing among regulators. Participation from more advanced regulators such as in Japan and Korea, as well as big Asian economies outside of ASEAN - most notably China and India.

iii. National level workshops which bring regulators together with a range of international partners, to set priorities and define a roadmap for each NMRA. This reduces the number of disparate and potentially overlapping proposals for training and capacity building for each NMRA, which often do not contribute adequately to a holistic plan for the institution.

iv. Related to (ii) above, coordination across training and capacity building outfits can provide more coherence to an overall curriculum for regulators. Existing training providers listed in Part VI could, collectively, cover the range of topics that regulators have an interest and need in learning more about. The approach that could work best for the region is to have various "hubs" through Centers of Excellence (CoE) - such as CoRE Singapore and other centers under APEC each focusing on a subset of topics, which, together, will provide a holistic approach towards capacity development for the region. 


\section{REFERENCES}

Andaman Medical. Vietnam Pharmaceutical: A Brief Overview. http://www.andamanmed.com/vietnam-pharmaceutical.html. [March 2016]

ASEAN. 2014. ASEAN Community in Figures - Special Edition 2014. Jakarta: ASEAN Secretariat.

ASEAN. 2015. ASEAN Economic Community at a Glance 2007-2014. Jakarta: ASEAN Secretariat

ASEAN. ASEAN Economic Community. http://www.asean.org/asean-economiccommunity/ [March 2016]

ASEAN. ASEAN MRA on GMP Inspection of Manufacturers for Medicinal Products Listed Inspection Service.

http://www.asean.org/storage/images/2015/March1/asean sectoral MRA/LISTED\% 20INSPECTION\%20SERVICE.pdf [April 2016]

ASEAN. MRA on GMP FAQ. http://www.asean.org/?static post=asean-sectoral$\underline{\text { mras }}$ [April 2016]

Babar, Z. and M.I.M. Ibrahim. 2003. "Affordability of medicines in Malaysia Consumer perceptions”. Essential Drug Monitor No. 33. Geneva: WHO.

Bigdeli, Maryam, David H. Peters, Anita K. Wagner eds, "Medicines in Health Systems: Advancing access, affordability and appropriate use", WHO, 2014

BioPharmaceuticals Australia. Biopharmaceuticals. http://www.biopharmaus.com.au/biopharmaceuticals/ [March 2016]

Cadot, O., M. Malouche, S. Sáez. 2012. "Streamlining Non-Tariff Measures: A Toolkit for Policy Makers". Directions in Development: Trade. Washington, DC: World Bank. https://openknowledge.worldbank.org/handle/10986/6019 License: CC BY 3.0 IGO.

Cameron, A., M. Ewen, D. Ross-Degnan, D. Ball and R. Laing. 2008. "Medicine prices, availability, and affordability in 36 developing and middle-income countries: a secondary analysis". The Lancet. DOI: 10.1016/S0140-6736(08)61762-61.

Centre of Regulatory Excellence. APEC RHSC Center of Excellence Workshop "Multiregional Clinical Trials". https://www.duke-nus.edu.sg/core/event/apec-rhsccenter-excellence-workshop-multiregional-clinical-trials [March 2016]

Collier, Roger. "Drug Patents: The Evergreening Problem." Canadian Medical Association Journal 185.9 (2013): E385-E386.

European Commission. The Centralised Procedure.

http://ec.europa.eu/health/authorisation-procedures-centralised en.htm [March 2016] 
European Medicines Agency. International Affairs. www.ema.europa.eu [March 2016]

Government of Indonesia. 2002. Keputusan Kepala BPOM No. HK.00.05.3.00914 Tentang Pemasukan Obat Jalur Khusus Year 2002.

Government of Indonesia. 2008. Minister of Health Decree No. 1010 Year 2008.

Government of Indonesia. 2011. Regulation HK.03.1.23.10.11.08481 Year 2011.

Government of Indonesia. 2014. Presidential Decree No.39 Year 2014.

Government of Indonesia. 2015. Minister of Health Decree No.

HK.02.02/MENKES/525/2015 Tentang Harga Eceran Tertinggi Obat Generik.

Government of Vietnam. 2013. Law No. 43/2013/QH13.

Huckle, Paul. 2015. "Stepping into Regulatory Excellence through Convergence" (presentation at Centre of Regulatory Excellence (Singapore) Scientific Conference, October 5-6, 2015).

Korakianiti, E. "Marketing Authorisation: The Evaluation Process" (presentation at $1^{\text {st }}$ EMEA Workshop for Micro, Small and Medium-Sized Enterprises).

http://www.ema.europa.eu/docs/en GB/document library/Presentation/2009/10/WC 500004235.pdf [March 2016]

Lezotre, P. 2014. Convergence and Harmonization of Pharmaceutical Regulations. Academic Press (Elsevier).

Lumpkin, M. 2015. "Exploring Opportunities and Challenges of Regulatory Convergence" (presentation at Centre of Regulatory Excellence (Singapore) Scientific Conference, October 5-6, 2015).

Muellner M. et al. 2010. "Current issues in drug regulation" in Clinical Pharmacology: Current Topics and Case Studies. Vienna: Springer-Verlag.

National Development Strategy of Pharmaceuticals In Vietnam 2020 - 2030.

Nayyar G., J.G. Breman, P.N. Newton and J. Herrington. "Poor-quality antimalarial drugs in Southeast Asia and sub-Saharan Africa". Lancet Infect Dis 2012; 12: 48896

Nguyen A.T., R. Knight, A. Mant, Q.M. Cao and G. Brooks. 2010. "Medicine pricing policies: Lessons from Vietnam". Southern Med Review 3; 2:12-19

OECD. 2015. "Out-of-pocket medical expenditure", in Health at a Glance 2015: OECD Indicators. Paris: OECD Publishing.

Pacific Bridge Medical. Target Asian Markets.

http://www.pacificbridgemedical.com/target-asian-markets [March 2016] 
Pharma Phorum. Thailand Pharmaceutical Market Update 2014. http://www.pharmaphorum.com/articles/thailand-pharmaceutical-market-update-2014 [March 2016]

Rago L. 2014. "Regulatory framework for access to safe, effective and quality medicines". Antiviral Therapy 19 Suppl 3:69-77. doi: 10.3851/IMP2902.

Regulatory Affairs Professional Society. 2014. FDA Announces all User Fees to be Paid by Pharma, Device Industries in 2015. http://www.raps.org/RegulatoryFocus/News/2014/08/01/19930/FDA-Announces-all-User-Fees-to-be-Paid-byPharma-Device-Industries-in-2015/ [March 2016]

SciDevNet. Traditional Medicine for Modern Times: Facts and Figures. http://www.scidev.net/global/medicine/feature/traditional-medicine-modern-timesfacts-figures.html [March 2016]

Thai National Drug System Development Strategy A.D. 2012-2016; Board of Investment Annual Report 2014: Investment Promotion Act.

Treatment Action Group. 2015. Improving Regulatory Systems to Address Global TB Drug Access Failures.

http://www.treatmentactiongroup.org/tagline/2015/fall/improving-regulatory-systemsaddress-global-tb-drug-access-failures [March 2016]

U.S. Food and Drug Administration. Regulatory Harmonization and Convergence. http://www.fda.gov/BiologicsBloodVaccines/InternationalActivities/ucm271079.htm [March 2016]

WHO. 1998. How to Implement Computer-Assisted Drug Registration - A Practical Guide for Drug Regulatory Authorities. Regulatory Support Series No. 002, 1998

WHO. 2003. Effective Medicines Regulation: Ensuring Safety, Efficacy and Quality. Geneva: WHO.

WHO. 2009. Statement on Access to Medicines, 13 March 2009.

http://www.who.int/mediacentre/news/statements/2009/access-medicines-

20090313/en/ [March 2016]

WHO. 2011. The World Medicines Situation 3rd Edition: Medicines Expenditures. Geneva: WHO

WHO. 2011. The World Medicines Situation $3^{\text {rd }}$ Edition: Traditional Medicines: Global Situation, Issues and Challenges. Geneva: WHO.

WHO. 2014. WHO Drug Information Vol. 28 No. 1.

WHO. 2014. "Pharmaceutical financing in Asia" in First Meeting on Access to Medicines Under Universal Health Coverage Coverage in the Asia-Pacfic Region Meeting Report. Philippines: WHO. 
WHO. 2015. WHO Global Health Observatory (GHO) Data: Per Capita Total Expenditure on Health at Average Exchange Rate (US\$).

http://www.who.int/gho/health financing/per capita expenditure/en/ [February 2016]

WHO. 2016. Substandard, spurious, falsely labelled, falsified and counterfeit (SSFFC) medical products factsheet.

http://www.who.int/mediacentre/factsheets/fs275/en/ [March 2016].

WHO. Global Health Observatory database: Median availability of selected generic medicines. http://apps.who.int/gho/data/node.main.488?lang=en [April 2016]

WHPA Regional Workshop on Counterfeit Medical Products. 2011. Background Document on Counterfeit Medicines in Asia.

http://www.whpa.org/background document counterfeit medicines in asia.pdf [March 2016]

Wileman, H. and A. Mishra. 2010. "Drug Lag and Key Regulatory Barriers in the Emerging Markets”. Perspect Clin Res. Apr-Jun; 1(2): 51-56.

World Bank. 2016. World Bank national accounts data, and OECD National Accounts data files. http://data.worldbank.org/indicator/NY.GDP.PCAP.CD [March 2016] 


\section{ANNEX}

\section{Country overview}

\section{Annex 1 - Interview Questionnaire}

\section{Key Health Sector Issues}

\begin{tabular}{|l|l|}
\hline & QUESTION \\
\hline 0.01 & Please provide information on the burden of disease and epidemiological transition, including aging and NCDs, in your country. \\
\hline 0.02 & Is there a national essential drug list for your country? Is there a national drug formulary for your country? \\
\hline 0.03 & $\begin{array}{l}\text { Please provide information on the expansion of universal health coverage in your country. Does your country have universal health } \\
\text { coverage? Is medicine covered under the scheme? Are there additional out-of-pocket expenses for medicines? }\end{array}$ \\
\hline 0.04 & $\begin{array}{l}\text { Is your country facing problems with regard to access to medicines? In terms of availability on the markets (rural areas / country side)? In } \\
\text { terms of quality of medicines on the markets? }\end{array}$ \\
\hline
\end{tabular}

\section{Pharmaceutical sector analysis}

\section{Key Trade Related Issues (to be addressed to private sector, associations, partly NMRAs)}

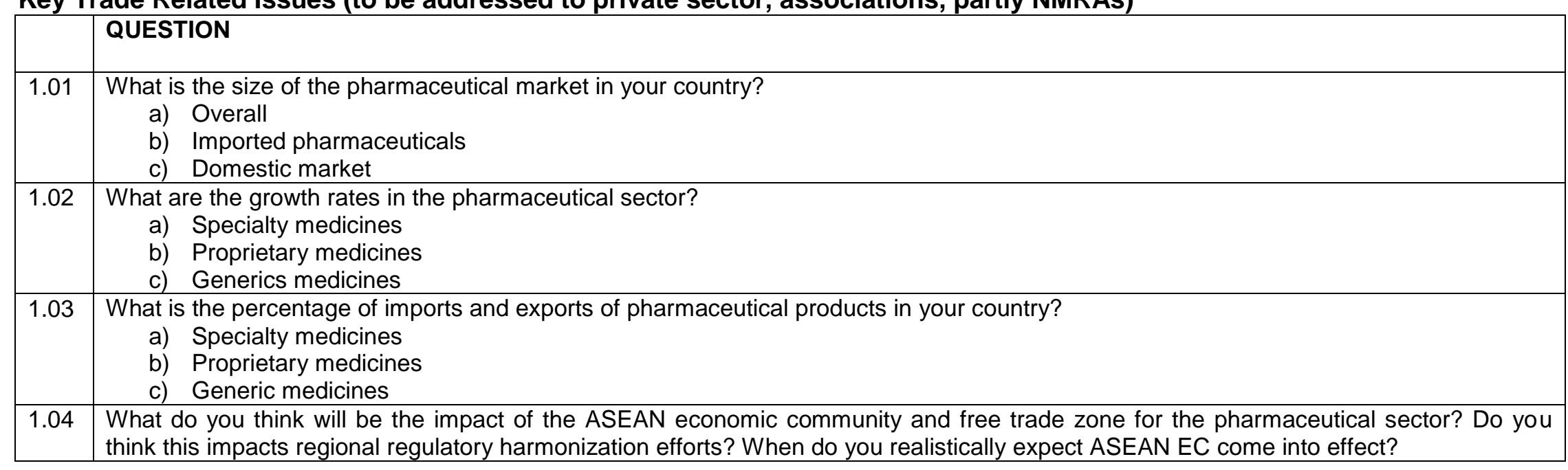




\begin{tabular}{|l|l|}
\hline 1.05 & $\begin{array}{l}\text { Does your country impose a tariff on pharmaceuticals (APIs, excipients and finished products)? Is this tariff waived, reduced or exempted } \\
\text { for essential medicines? }\end{array}$ \\
\hline 1.6 & What are the non-tariff barriers for pharmaceuticals in your country, especially for essential medicines? \\
\hline
\end{tabular}

\section{Key Players In The Pharmaceutical Sector (to be addressed to private sector, associations)}

\begin{tabular}{|l|l|}
\hline 1.7 & $\begin{array}{l}\text { QUESTION } \\
\text { also list main pharmaceutical manufacturers associations (for generic manufacturers, research based manufacturers). }\end{array}$ \\
\hline 1.8 & What is the product portfolio of local pharmaceutical manufacturers? Is there also local production of APIs? \\
\hline 1.9 & What is the market share of local pharmaceutical manufacturers vs imported products? \\
\hline 1.10 & Do local manufacturers export their products? Where to (mainly)? What are local manufacturers' future ambitions for export? \\
\hline
\end{tabular}

\section{Policy Environment For The Pharmaceutical Sector (to be addressed to private sector, associations, NMRAs, academia)}

\begin{tabular}{|l|l|}
\hline 1.11 & $\begin{array}{l}\text { Are there national industrial policies in place which encourage local pharmaceutical manufacturing? If yes, what are the impacts on local } \\
\text { pharmaceutical manufacturing?(E.g. tax and duty exemptions, local purchase preference). How does this affect the pharmaceutical sector } \\
\text { in your country? }\end{array}$ \\
\hline 1.12 & Are you aware of future reform plans that might affect the pharmaceutical sector in your country? \\
\hline
\end{tabular}

Capacity Development Needs for Pharmaceutical Sector (to be addressed to private sector, associations, NMRAs, academia)

\section{QUESTION}

1.13 Are there identified areas of need for capacity development for upgrade of quality standards of the pharmaceutical sector? Which areas? How do you plan to address this needs?

1.14 Which would be suitable modalities and partners for further regional regulatory harmonization initiatives and capacity strengthening? 


\section{Cross Cutting Issues (to be addressed to all interview partners)}

\section{Towards Further Medicines Regulatory Cooperation And Harmonization}

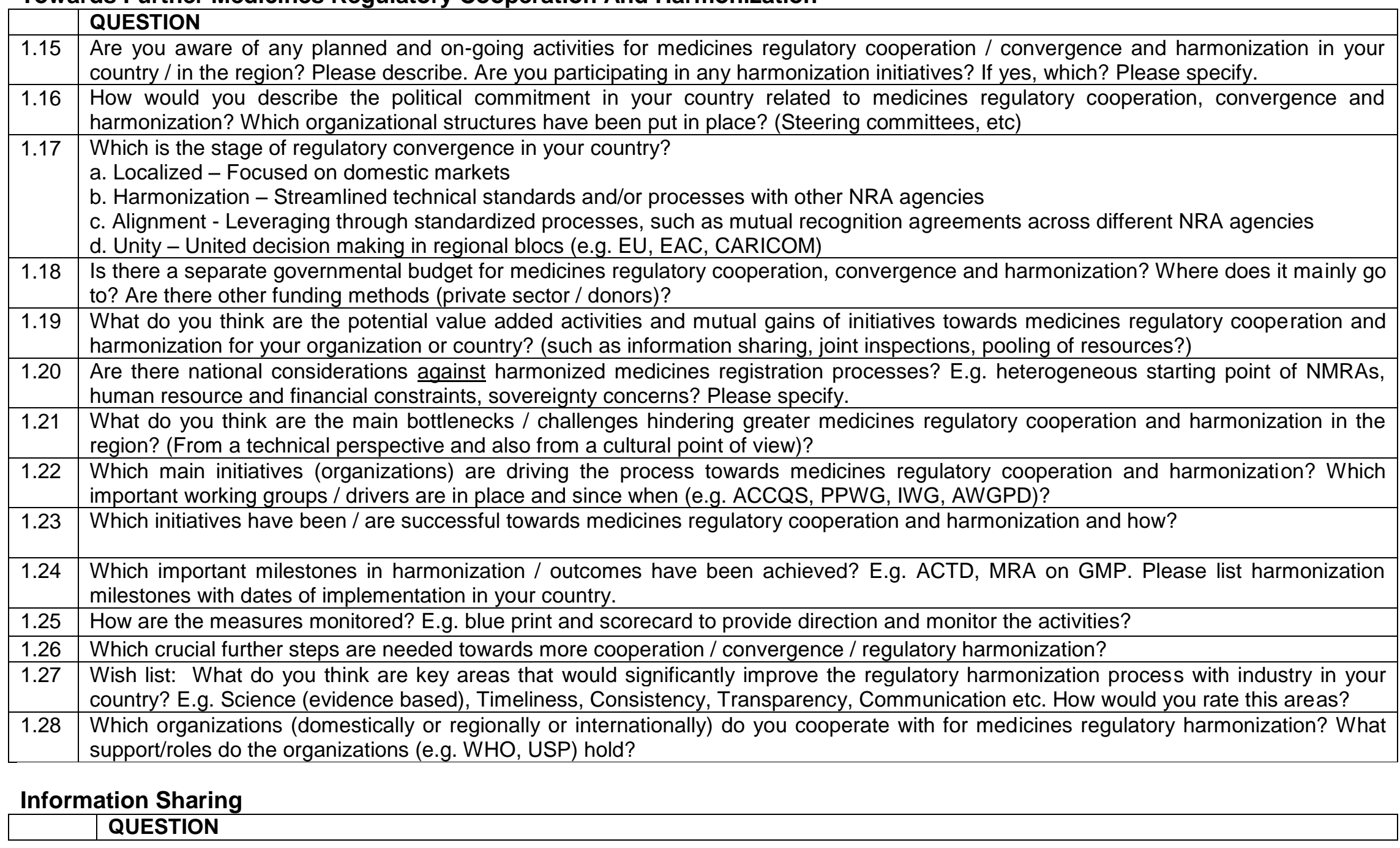


1.29 Will your institution / company be willing to share information and data with other countries? How is information currently been shared between NRAs in the region? E.g. recall information, information on counterfeit issues, etc. Please describe the framework and structures in place.

\section{Review Of NMRAs}

\section{Regulatory Framework (to be addressed to NMRAs, partly private sector, associations)}

\begin{tabular}{|c|c|}
\hline & QUESTION \\
\hline 1.30 & $\begin{array}{l}\text { What is included under the scope of the NRA in your country? Medicines, vaccines and blood products, medical devices, foodstuff, } \\
\text { cosmetics, complementary and alternative medicines, radiation control, etc.? }\end{array}$ \\
\hline 1.31 & $\begin{array}{l}\text { What is the regulatory function of NRA in your country? (licensing, inspection, product assessment and registration, QC, control of } \\
\text { promotion and information, price regulation) Do other agencies/organizations in your country carry out these functions either alone or in } \\
\text { collaboration with the NRA? }\end{array}$ \\
\hline 1.32 & Who is the NRA accountable to? What kind of legal entity is it? \\
\hline 1.33 & Has the NRA implemented a Quality Management System for all the regulatory processes, based on recognized standards (e.g. WHO)? \\
\hline 1.34 & $\begin{array}{l}\text { How is the NMRA institutionally funded? Do legal provisions enable the NRA to collect fees for regulatory services provided? Which } \\
\text { funding and fee framework is in place (\% retention of fees, \% funding)? }\end{array}$ \\
\hline 1.35 & $\begin{array}{l}\text { Is the infrastructure provided for performing the regulatory functions adequate? Is an adequate IT system available to keep and recover all } \\
\text { information relative to product licensing, registration, inspections, etc.? Is the NRA using a paper-based regulatory documentation system } \\
\text { or electronic document management systems (EDMS)? }\end{array}$ \\
\hline 1.36 & Is the NRA involved in a global network with relevant scientific associations and professional societies? \\
\hline 1.37 & $\begin{array}{l}\text { Does the NRA receive assistance from other non-government agencies, either domestic or international? If yes, please state type } \\
\text { assistance from (e.g. funding, technical assistance, administrative assistance) and specify amounts/projects if possible. }\end{array}$ \\
\hline \multicolumn{2}{|r|}{ Capacity Issues (to be addressed to NMRAs, private sector, associations, academia) } \\
\hline & QUESTION \\
\hline 1.38 & $\begin{array}{l}\text { Does the NRA have adequate (number and qualification) human resources to carry out all regulatory functions? Is there available a } \\
\text { sufficient pool of qualified regulatory human resource in the country to recruit new staff? How easy is it to recruit new (qualified) staff? }\end{array}$ \\
\hline 1.39 & What is the percentage of external staff? \\
\hline 1.40 & $\begin{array}{l}\text { Are training plans established? Are there regulatory training courses offered by academia? Has anyone from your organization attended } \\
\text { such courses? }\end{array}$ \\
\hline 1.41 & Are you participating in joint trainings with other NRAs in the region? Which ones? \\
\hline 1.42 & $\begin{array}{l}\text { Are there identified capacity constraints that limits the NRA ability from attending regional regulatory standards? Which are the main areas } \\
\text { of need for capacity development / upgrade? Please specify. }\end{array}$ \\
\hline 1.43 & further regional regulatory harmonization initiatives and capacity strengthening? \\
\hline
\end{tabular}


1.44 Is the NMRA in your country planning to become a PIC/S member? Where are you in your plans to become a PIC/s member? Which are the required steps and estimated timelines?

1.45 What do you think are the other country NMRAs' progress towards PIC/s membership?

Marketing Authorization (to be addressed to NMRAs, private sector, associations, partly academia)

\begin{tabular}{|c|c|}
\hline & QUESTION \\
\hline 1.46 & $\begin{array}{l}\text { Do legal provision require one to hold a Marketing Authorization (MA) before putting a pharmaceutical product on the market? Please } \\
\text { state which legal provision. }\end{array}$ \\
\hline 1.47 & $\begin{array}{l}\text { Does the NRA require registration submissions for pharmaceutical products to be in CTD format or ASEAN CTD format? If not, which } \\
\text { other format? }\end{array}$ \\
\hline 1.48 & $\begin{array}{l}\text { Are there any country-specific requirements, over and above what is required in the ASEAN Common Technical Dossier / Registration } \\
\text { process? Please specify. }\end{array}$ \\
\hline 1.49 & $\begin{array}{l}\text { Are you aware of / involved in the project "Supporting the Implementation of ASEAN Harmonized Requirements for Drug Registration } \\
\text { (SIAHR)" by WHO? Please specify. }\end{array}$ \\
\hline 1.50 & Is the registration submitted electronically or paper-based? \\
\hline 1.51 & $\begin{array}{l}\text { Are the same criteria used for the evaluation of MA applications regardless of the source (e.g. domestic, foreign, public/private sector) of } \\
\text { the products concerned? }\end{array}$ \\
\hline 1.52 & $\begin{array}{l}\text { Does the NRA recognize and/or use regulatory decisions, reports or information from other NRAs (in the region) or } \\
\text { international bodies for decision making? E.g. mutual recognition agreements on joint inspections. }\end{array}$ \\
\hline 1.53 & $\begin{array}{l}\text { Could you walk us through how a product registration is usually done in your country? Are there different pathways for different products } \\
\text { (i.e. new chemical entity, generics,)? Is there a preregistration requirements? }\end{array}$ \\
\hline 1.54 & How many MA applications do you receive in a year? Please specify by type of pharmaceuticals. \\
\hline 1.55 & $\begin{array}{l}\text { Which are the current approval timelines for novel and generic medicines in your NRA? (Average) Does the NRA conduct expedited } \\
\text { approvals for some products and if yes, what are they? }\end{array}$ \\
\hline 1.56 & Does the NRA adopt Adaptive Licensing? If not, will it be feasible? \\
\hline 1.57 & $\begin{array}{l}\text { For private sector: Have you tried submitting dossiers to other countries using your countries CTD as a benchmark? How many times } \\
\text { revisions were needed prior to successful acceptance by NRAs of other countries? }\end{array}$ \\
\hline 1.58 & $\begin{array}{l}\text { For private sector: Which are the current approval timelines for regulatory authority approval in further ASEAN countries? (Specify for } \\
\text { regional NRAs) }\end{array}$ \\
\hline 1.59 & /hich are the average costs for registration of a generic / multisource pharmaceutical product with the NRA? \\
\hline 1.60 & there a backlog in applications within the NRA? \\
\hline
\end{tabular}

\section{Regulatory Inspections (to be addressed to NMRAs, partly private sector, associations)}

1.61 Are inspectors permitted to inspect premises where pharmaceutical activities are performed? Do inspectors have adequate powers and authority to carry on their missions? 


\begin{tabular}{|l|l|}
\hline 1.62 & In which neighboring countries are your inspectors carrying out their inspections? \\
\hline 1.63 & Are local manufacturers inspected periodically to supervise the implementation of adequate GMP / GxP? \\
\hline 1.64 & $\begin{array}{l}\text { Does the legislation provide for adequate and proportional sanctions, penalties and prosecution upon } \\
\text { conviction based on violation of the applicable legislation? }\end{array}$ \\
\hline 1.65 & Are the same criteria used for the inspection of domestic, foreign, public and private facilities? \\
\hline 1.66 & Does the NRA have sufficient capacity to inspect and assess API sources? \\
\hline 1.67 & Does your country conduct joint regulatory inspections with neighboring countries' regulatory units? \\
\hline 1.68 & Are MRA for joint inspection implemented in your country? \\
\hline
\end{tabular}

\section{Import Control, Monitoring And Licensing (to be addressed to NMRAs)}

\begin{tabular}{|l|l|}
\hline 1.69 & QUESTION \\
& $\begin{array}{l}\text { Does your country allow medicines to be imported into the country? If yes, how are medicines imported into the country? Could you } \\
\text { describe the process? }\end{array}$ \\
\hline 1.70 & Do legal provisions exist requiring authorization to import medicines? \\
\hline 1.71 & Do legal provisions exist allowing the sampling of imported products for testing? Is there routine sampling, sampling plans? \\
\hline
\end{tabular}

Post-Marketing Surveillance And Controls (to be addressed to NMRAs, partly industry and associations)
\begin{tabular}{|l|l|}
\hline 1.72 & QUESTION \\
\hline 1.73 & Are recall procedures in place for non-compliant products? \\
\hline 1.74 & Does a national regulatory quality control laboratory (RQCL) exist in the country for testing? \\
\hline 1.75 & $\begin{array}{l}\text { Has the RQCL established a quality management system based on recognized standards as reference (WHO, PIC/S, } \\
\text { ISO, other)? }\end{array}$ \\
\hline 1.76 & $\begin{array}{l}\text { Is the RQCL is regularly audited by an external organization (e.g. certification, accreditation) and are the } \\
\text { results available. }\end{array}$ \\
\hline 1.77 & $\begin{array}{l}\text { Do you obtain your secondary reference material via the ASEAN Reference Substance center? Do you participate in trainings / } \\
\text { Proficiency Testing schemes by the ASEAN Reference Substance center? }\end{array}$ \\
\hline
\end{tabular}

\section{Clinical Evaluation (to be addressed to NMRAs, partly industry and associations, if time allows)}

\begin{tabular}{|l|l|}
\hline & QUESTION \\
\hline 1.78 & Do legal provisions exist requiring NRA authorization for conducting Clinical Trials? \\
\hline 1.79 & Do legal provisions exist requiring the agreement by an ethics committee/institutional review board of the Clinical Trial to be performed? \\
\hline 1.80 & Do legal provisions require sponsor, investigator to comply with Good Clinical Practices (GCP)? \\
\hline 1.81 & Do legal provisions require a company to conduct clinical trials on local population before a drug could be marketed? \\
\hline
\end{tabular}


Pharmacovigilance (to be addressed to NMRAs, partly industry and associations, partly academia, if time allows)

\begin{tabular}{|l|l|}
\hline & QUESTION \\
\hline 1.82 & Are there legal provisions in the Medicines Act that provide for pharmacovigilance activities as part of the NRA mandate? \\
\hline 1.83 & $\begin{array}{l}\text { Are there legal provisions for all stakeholders to report adverse reactions/event or any safety issues to the NRA? Who is leading this } \\
\text { activity? }\end{array}$ \\
\hline 1.84 & Does a national Adverse Drug Reactions database exist in the country? Is this database electronic or paper-based? \\
\hline 1.85 & Does a routine and crisis communication strategy exists? \\
\hline 1.86 & Do you work with other organizations (domestically or regionally) on pharmacovigilance? \\
\hline
\end{tabular}

\section{Counterfeit and Sub-Standard Medicines (to be addressed to NMRAs, partly academia and industry, associations)}

\begin{tabular}{|l|l|}
\hline 1.87 & $\begin{array}{l}\text { QUESTION } \\
\text { in this issue? How? }\end{array}$ \\
\hline 1.88 & Are policies and legislations in place to prevent counterfeit or sub-standard medicines? \\
\hline
\end{tabular}




\section{Annex 2 - List of Interview Partners by Country}

\section{Indonesia}

\begin{tabular}{|c|c|c|c|}
\hline No. & Name & Title/Position & Institution/Company \\
\hline 1 & \multicolumn{3}{|c|}{ National Agency for Drug and Food Control (NAFDC) of Republic Indonesia } \\
\hline 2 & Professor Sri Suryawati & $\begin{array}{l}\text { Professor and Head, } \\
\text { Division of Medicine Policy } \\
\text { and Management, } \\
\text { Department of } \\
\text { Pharmacology and } \\
\text { Therapeutics, Faculty of } \\
\text { Medicine }\end{array}$ & $\begin{array}{l}\text { Universitas Gadjah Mada, } \\
\text { Indonesia }\end{array}$ \\
\hline 3 & Mr. Parulian Simanjuntak & Executive Director & $\begin{array}{l}\text { International Pharmaceutical } \\
\text { Manufacturer Group (IPMG) }\end{array}$ \\
\hline 4 & Ms. Naomi Juliandary & Communications Officer & $\begin{array}{l}\text { International Pharmaceutical } \\
\text { Manufacturer Group (IPMG) }\end{array}$ \\
\hline 5 & Dra. Lucky S Slamet & Former Head & $\begin{array}{l}\text { National Agency for Drug } \\
\text { and Food Control (NAFDC), } \\
\text { of Republic Indonesia }\end{array}$ \\
\hline 6 & Mr. Christopher Raymond & $\begin{array}{l}\text { Chief of Party, Promoting } \\
\text { the Quality of Medicines } \\
\text { Program }\end{array}$ & $\begin{array}{l}\text { U.S. Pharmacopeial } \\
\text { Convention }\end{array}$ \\
\hline 7 & $\begin{array}{l}\text { Ms. Butet Benny } \\
\text { Manurung }\end{array}$ & GMP Specialist & $\begin{array}{l}\text { U.S. Pharmacopeial } \\
\text { Convention }\end{array}$ \\
\hline 8 & Ms. Yenny Franscisca & Quality Control Specialist & $\begin{array}{l}\text { U.S. Pharmacopeial } \\
\text { Convention }\end{array}$ \\
\hline 9 & Ms. Oce Y. Naomi Boymau & Senior Project Coordinator & $\begin{array}{l}\text { U.S. Pharmacopeial } \\
\text { Convention }\end{array}$ \\
\hline
\end{tabular}

\section{Malaysia}

\begin{tabular}{|l|l|l|l|}
\hline No. & Name & Title/Position & Institution/Company \\
\hline 1 & Mr. Jimmy Piong & Executive Council Member & $\begin{array}{l}\text { Malaysian Organization of } \\
\text { Pharmaceutical Industries } \\
\text { (MOPI) }\end{array}$ \\
\hline 2 & Mr. Ewe Kheng Huat & Executive Director & $\begin{array}{l}\text { Pharmaceutical Association } \\
\text { of Malaysia (PhAMA) }\end{array}$ \\
\hline 3 & Ms. Alice Chee & Regulatory Consultant & $\begin{array}{l}\text { Pharmaceutical Association } \\
\text { of Malaysia (PhAMA) }\end{array}$ \\
\hline 4 & Dr. Choe Tong Seng & Executive Director & $\begin{array}{l}\text { Malaysian Association of } \\
\text { Pharmaceutical Suppliers } \\
\text { (MAPS) }\end{array}$ \\
\hline 5 & Mr. Heng Thin Fook & Secretary & $\begin{array}{l}\text { Malaysian Association of } \\
\text { Pharmaceutical Suppliers } \\
\text { (MAPS) }\end{array}$ \\
\hline 6 & Mr. Lim Teng Chyuan & Council Member & Malaysian Association of \\
\hline
\end{tabular}




\begin{tabular}{|c|c|c|c|}
\hline & & & $\begin{array}{l}\text { Pharmaceutical Suppliers } \\
\text { (MAPS) }\end{array}$ \\
\hline 7 & Ms. Tammy Lim CM & Regulatory Director & $\begin{array}{l}\text { Malaysian Association of } \\
\text { Pharmaceutical Suppliers } \\
\text { (MAPS) }\end{array}$ \\
\hline 8 & Ms. Hezlen Mohd Sali & Regional Project Manager & $\begin{array}{l}\text { Malaysian-German } \\
\text { Triangular Cooperation }\end{array}$ \\
\hline 9 & Datuk Nancy Ho & President & $\begin{array}{l}\text { Malaysian Pharmaceutical } \\
\text { Society }\end{array}$ \\
\hline 10 & Mr. Leonard Ariff & Group Managing Director & CCM Malaysia Berhad \\
\hline 11 & Mr. Shaun Goh & $\begin{array}{l}\text { Business Development } \\
\text { Director }\end{array}$ & Ye' Zin Latt Co. Ltd \\
\hline 12 & $\begin{array}{l}\text { Associate Professor Asrul } \\
\text { Shafiee }\end{array}$ & $\begin{array}{l}\text { Head, Social and } \\
\text { Administrative Pharmacy } \\
\text { Affairs Department, School } \\
\text { of Pharmacy }\end{array}$ & Universiti Sains Malaysia \\
\hline 13 & Mr. Ravi CK Raman & Director, Sectoral Policy & $\begin{array}{l}\text { Ministry of International } \\
\text { Trade and Industry }\end{array}$ \\
\hline 14 & Ms. Thavamani Krishnan & $\begin{array}{l}\text { Principal Assistant } \\
\text { Director, Sectoral Policy }\end{array}$ & $\begin{array}{l}\text { Ministry of International } \\
\text { Trade and Industry }\end{array}$ \\
\hline 15 & $\begin{array}{l}\text { Mr. Ahmad Zaki Akbar Bin } \\
\text { Mohd. Raziff }\end{array}$ & $\begin{array}{l}\text { Assistant Director, Sectoral } \\
\text { Policy }\end{array}$ & $\begin{array}{l}\text { Ministry of International } \\
\text { Trade and Industry }\end{array}$ \\
\hline 16 & $\begin{array}{l}\text { Mdm. Rosilawati Binti } \\
\text { Ahmad }\end{array}$ & $\begin{array}{l}\text { Ketua Penolong Pengarah } \\
\text { Kanan, Head of Regulatory } \\
\text { Affairs Section }\end{array}$ & $\begin{array}{l}\text { National Pharmaceutical } \\
\text { Control Bureau Malaysia }\end{array}$ \\
\hline 17 & $\begin{array}{l}\text { Mr. Abdul Halim Mohamed } \\
\text { Shariff }\end{array}$ & $\begin{array}{l}\text { Senior Manager, Health } \\
\text { and Environmental } \\
\text { Products Section, Trade } \\
\text { and Services Promotion } \\
\text { Division }\end{array}$ & $\begin{array}{l}\text { Malaysia External Trade } \\
\text { Development Corporation }\end{array}$ \\
\hline 18 & Mdm. Noraisyah Nordin & $\begin{array}{l}\text { Senior Executive, Life } \\
\text { Sciences and Medical } \\
\text { Technology Division }\end{array}$ & $\begin{array}{l}\text { Malaysia Investment } \\
\text { Development Authority }\end{array}$ \\
\hline 19 & Mdm. Norhaliza Noordin & $\begin{array}{l}\text { Deputy Director, Life } \\
\text { Sciences and Medical } \\
\text { Technology Division }\end{array}$ & $\begin{array}{l}\text { Malaysia Investment } \\
\text { Development Authority }\end{array}$ \\
\hline
\end{tabular}

\section{Philippines}

\begin{tabular}{|l|l|l|l|}
\hline No. & Name & Title/Position & Institution/Company \\
\hline 1 & Ms. Diana Van Daele & $\begin{array}{l}\text { Programme Manager } \\
\text { Health }\end{array}$ & EU delegation to Philippines \\
\hline 2 & Mr. Raouf Abdel Qawwas & $\begin{array}{l}\text { Essential Medicines, } \\
\text { Pharm. Policies \& Drug } \\
\text { Regulation Specialist }\end{array}$ & $\begin{array}{l}\text { EPOS Health Management, } \\
\text { Technical Assistance for the } \\
\text { Philippine Health Sector } \\
\text { Reform }\end{array}$ \\
\hline 3 & $\begin{array}{l}\text { Ms. Maria Lourdes } \\
\text { Santiago }\end{array}$ & Director General & $\begin{array}{l}\text { Food and Drug } \\
\text { Administration, Philippines }\end{array}$ \\
\hline 4 & Ms. Melody M. Zamudio & $\begin{array}{l}\text { Officer-in-Charge, Center } \\
\text { for Drug Regulation and }\end{array}$ & $\begin{array}{l}\text { Food and Drug } \\
\text { Administration, Philippines }\end{array}$ \\
\hline
\end{tabular}




\begin{tabular}{|l|l|l|l|}
\hline 5 & Mr. Richard Binos & $\begin{array}{l}\text { Product Research and } \\
\text { Standards Development } \\
\text { Division }\end{array}$ & $\begin{array}{l}\text { Food and Drug } \\
\text { Administration, Philippines }\end{array}$ \\
\hline 6 & Dr. Klara Tisocki & $\begin{array}{l}\text { Coordinator Essential } \\
\text { Medicines and Health } \\
\text { Technologies }\end{array}$ & WHO WPRO Office Manila \\
\hline 7 & Mr. Teodoro Padilla & Executive Director & $\begin{array}{l}\text { Pharmaceutical \& } \\
\text { Healthcare Association of } \\
\text { the Philippines (PHAP) }\end{array}$ \\
\hline 8 & Mr. Eric Salenga & $\begin{array}{l}\text { National Professional } \\
\text { Officer EDM }\end{array}$ & $\begin{array}{l}\text { WHO Country Office } \\
\text { Philippines }\end{array}$ \\
\hline 9 & Dr. Kenneth Hartigan-Go & $\begin{array}{l}\text { Office for Health } \\
\text { Regulations }\end{array}$ & $\begin{array}{l}\text { Department of Health, } \\
\text { Philippines }\end{array}$ \\
\hline 10 & $\begin{array}{l}\text { Ms. Anna Melissa } \\
\text { Guerrero }\end{array}$ & $\begin{array}{l}\text { Pharmaceutical Division, } \\
\text { Office for Health } \\
\text { Regulations }\end{array}$ & $\begin{array}{l}\text { Department of Health, } \\
\text { Philippines }\end{array}$ \\
\hline
\end{tabular}

Thailand

\begin{tabular}{|l|l|l|l|}
\hline No. & Name & Title/Position & Institution/Company \\
\hline 1 & Dr.Yuppdee Javroongit & $\begin{array}{l}\text { Senior Expert on } \\
\text { Pharmaceuticals Standard, } \\
\text { Co-Chair of PPWG }\end{array}$ & $\begin{array}{l}\text { Food and Drug } \\
\text { Administration, Thailand }\end{array}$ \\
\hline 2 & $\begin{array}{l}\text { Ms. Charunee } \\
\text { Krisanaphan }\end{array}$ & $\begin{array}{l}\text { Senior Pharmacist } \\
\text { International Affairs and } \\
\text { Quality system group }\end{array}$ & $\begin{array}{l}\text { Bureau of Drug Control, } \\
\text { Food and Drug } \\
\text { Administration, Thailand }\end{array}$ \\
\hline 3 & $\begin{array}{l}\text { Ms. Worasuda } \\
\text { Yoongthong }\end{array}$ & International Affairs & $\begin{array}{l}\text { Thai Food and Drug } \\
\text { Administration FDA }\end{array}$ \\
\hline 4 & Mr. Patrick Deboyser & $\begin{array}{l}\text { Minister-Counsellor } \\
\text { (Health and Food safety) }\end{array}$ & $\begin{array}{l}\text { Delegation of the European } \\
\text { Union }\end{array}$ \\
\hline 5 & $\begin{array}{l}\text { Ms. Amporn } \\
\text { Charoensomsak }\end{array}$ & $\begin{array}{l}\text { Health System Partnership } \\
\text { Director }\end{array}$ & $\begin{array}{l}\text { Pharmaceutical Research } \\
\text { and Manufacturers } \\
\text { Association (PREMA) }\end{array}$ \\
\hline 6 & Dr. Chris Knight & $\begin{array}{l}\text { International Trade and } \\
\text { Commercial Counselor, } \\
\text { Advisor to PREMA Board }\end{array}$ & $\begin{array}{l}\text { Everett Knight (Asia Pacific), } \\
\text { Pte. Ltd. }\end{array}$ \\
\hline 7 & $\begin{array}{l}\text { Ms. Duangduen } \\
\text { Sahavechaphan }\end{array}$ & $\begin{array}{l}\text { Director of Strategic } \\
\text { Operation }\end{array}$ & $\begin{array}{l}\text { Pharmaceutical Research } \\
\text { and Manufacturers } \\
\text { Association (PREMA) }\end{array}$ \\
\hline 8 & Ms. Achara Eksaengsri & Deputy Managing Director & $\begin{array}{l}\text { The Government } \\
\text { Pharmaceutical Organization } \\
\text { (GPO) }\end{array}$ \\
\hline 9 & $\begin{array}{l}\text { Professor Rungpetch } \\
\text { Sakulbumrungsil } \\
\text { Rojsitthisak }\end{array}$ & $\begin{array}{l}\text { Dean Faculty of } \\
\text { Pharmaceutical Sciences }\end{array}$ & $\begin{array}{l}\text { Faculty of Pharm Sciences, } \\
\text { Chulalongkorn University }\end{array}$ \\
\hline 10 & Mr. Rachod Thakolsri & Managing Director & Biolab Co. Ltd. \\
\hline
\end{tabular}




\begin{tabular}{|l|l|l|l|}
\hline 11 & Mr. Noppadon Adjimatera & Regulatory Director & RB (Health, Hygiene, Home) \\
\hline 12 & Mr. Thun Pungcharoenkul & Executive Director & $\begin{array}{l}\text { Thai Pharmaceutical } \\
\text { Manufacturers Association }\end{array}$ \\
\hline
\end{tabular}

\section{Vietnam}

\begin{tabular}{|l|l|l|l|}
\hline No. & Name & Title/Position & Institution/Company \\
\hline 1 & Dr. Nguyen Van Tuu & Chairman & $\begin{array}{l}\text { Vietnam Pharmaceutical } \\
\text { Companies Association } \\
\text { (VPMA) }\end{array}$ \\
\hline 2 & Ms. Tran Thi Thu & $\begin{array}{l}\text { Cabinet of the Vietnam } \\
\text { Pharmaceutical } \\
\text { Companies Association } \\
\text { Companies Association } \\
\text { (VPMA) }\end{array}$ \\
\hline 3 & $\begin{array}{l}\text { Dr. Huong Nguyen Thi } \\
\text { Thanh }\end{array}$ & $\begin{array}{l}\text { Vice Chief Department of } \\
\text { Pharmaceutical } \\
\text { Management and Policy }\end{array}$ & $\begin{array}{l}\text { Department of } \\
\text { Pharmaceutical } \\
\text { Management and Policy, } \\
\text { Hanoi College of Pharm } \\
\text { Sciences }\end{array}$ \\
\hline 4 & Associate Professor Tran & Deputy Director & $\begin{array}{l}\text { National Institute of Drug } \\
\text { Quality Control (NIDQC) }\end{array}$ \\
\hline 5 & Ms. Cecile Degans & General Manager & IMS Health Vietnam \\
\hline 6 & Ms. Vu Thi Hiep & $\begin{array}{l}\text { Head of Legislation and } \\
\text { International Integration } \\
\text { Division }\end{array}$ & $\begin{array}{l}\text { Drug Administration of } \\
\text { Vietnam (DAV) }\end{array}$ \\
\hline 7 & Dr. Socorro Escalante & $\begin{array}{l}\text { Health Systems } \\
\text { Development Team }\end{array}$ & $\begin{array}{l}\text { World Health Organization, } \\
\text { Vietnam Country Office }\end{array}$ \\
\hline 8 & Dr. Nguyen Huy Quang & $\begin{array}{l}\text { General Director of Health } \\
\text { Legislation Department }\end{array}$ & Ministry of Health, Vietnam \\
\hline
\end{tabular}

